VISNYK

OF THE NATIONAL BANK OF UKRAINE

\section{No. 244 2018}

Published since March 1995

quarterly research journal

https://doi.org/10.26531/vnbu2018.244

\section{Editorial Board \\ Dmytro Sologub \\ (Chairman of the Editorial Board) \\ Deputy Governor, \\ National Bank of Ukraine}

\section{Tom Coupe}

Associate Professor,

University of Canterbury, PhD

\section{Oleg Korenok}

Associate Professor,

Virginia Commonwealth University,

PhD

\section{Oleksiy Kryvtsov}

Senior Research Director

in the International Economic

Analysis Department, Bank of Canada, PhD

\section{Oleksandr Petryk}

Professor, Banking University, Kyiv,

Doctor of Economics, Member of NBU Council

\section{Inna Spivak}

Head of International Economy Analysis Unit, Monetary Policy and Economic Analysis Department, National Bank of Ukraine, Doctor of Economics

\section{Andriy Tsapin}

Deputy Head of Research Unit,

Monetary Policy and Economic Analysis

Department, National Bank of Ukraine, PhD

\section{Sergiy Nikolaychuk \\ (Deputy Chairman of the Editorial Board) \\ Director of Monetary Policy \\ and Economic Analysis Department, \\ National Bank of Ukraine, PhD}

\section{Yuriy Gorodnichenko}

Professor, University of California,

Berkeley, PhD

\section{Viktor Koziuk}

Professor, Ternopil National Economic

University, Doctor of Economics,

Member of NBU Council

\section{Tymofiy Mylovanov}

Professor, University of Pittsburgh,

Honorary President of Kyiv School of Economics,

Deputy Chairman of NBU Council, PhD

\section{Marko Skreb}

Advisor on the Activities of Central Banks

\section{Oleksandr Talavera \\ Professor, Swansea University, PhD}

\section{Vitaliy Vavryshchuk}

Director of Financial Stability Department,

National Bank of Ukraine

\section{Vadym Volosovych \\ Associate Professor, \\ Erasmus University \\ Rotterdam, PhD}

Founder and publisher: National Bank of Ukraine

Editorial Board ensures compliance with ethical standards of publishing

For reprinting materials published herein the reference to the journal

"Visnyk of the National Bank of Ukraine" is compulsory

The Editorial Board can publish materials being under discussion, not sharing the author's opinion

The author bears responsibility for the accuracy of the materials

(C) National Bank of Ukraine 1995-2018

All rights reserved

Address: 9 Instytutska Street, Kyiv, 01601, Ukraine

E-mail: journal@bank.gov.ua
Design and layout: Zlatograf LTD.

Address: Ukraine, Kyiv, 01001,

Prorizna Street, 12, office 10.

Phone: +380 (44) 360-94-60. 


\section{PREFACE BY THE CHAIRMAN OF THE EDITORIAL BOARD}

\section{Dear readers,}

This edition of the Visnyk of the National Bank of Ukraine focuses on issues that are significant for central banks' monetary policy.

The first article, Price Stability and Inflation Targeting in Commodity Economies: Macroeconomics versus a Political Economy? by Viktor Koziuk, argues that natural resources abundance is not an obstacle for ensuring the price stability by the central bank. The mechanisms for securing price stability in resource-rich economies are determined by their resource rent distribution, and effectiveness of inflation targeting is extremely sensitive to the nature of their political regimes. Inflation targeting helps democracies achieve better financial stability parameters and a higher level of economic diversification. Among autocracies, the best price stability parameters are observed in countries that have a sovereign wealth fund.

The second article, How Does Fiscal Policy Affect GDP and Inflation in Ukraine? by Artem Vdovychenko, examines the impact of the main fiscal factors on GDP and inflation. Fiscal multipliers in Ukraine are shown to be higher in absolute values for budget expenditures than for taxes. Calculations show that unproductive expenditures, such as social welfare payments to the public, while having no impact on real GDP, have the effect of accelerating inflation.

The final article, The Redistributive Effects of Monetary Policy Across Generations by Olga Bondarenko, contains a thorough analysis of the main monetary transmission channels and their impact on income and wealth distribution across various generations of economic agents. The author determines that expansionary monetary shocks stimulate capital and debt accumulation to a larger extent for middleaged individuals, contributing to intergenerational inequality. Heterogeneity of labor income augments this effect, benefitting richer and more productive workers.

All three paper bring important practical conclusions for public and monetary policy decision makers and, thus, might be explored by the central banks. Indeed, we highlight the dependence of inflation targeting effectiveness in resource-rich economies on political regimes, the role fiscal policy plays in fueling inflation, and the redistributive effects of monetary policy on household income.

Researchers and scholars are invited to join the discussion started in this issue, and to submit their articles to the Visnyk of the National Bank of Ukraine for publication in the future.

Best regards,

Dmytro Sologub 


\title{
PRICE STABILITY AND \\ INFLATION TARGETING IN COMMODITY ECONOMIES: MACROECONOMICS VERSUS A POLITICAL ECONOMY?
}

\section{VIKTOR KOZIUK}

Ternopil National Economic University, National Bank of Ukraine

Email: viktorkoziuk@tneu.edu.ua; Viktor.Koziuk@bank.gov.ua

\begin{abstract}
In this study, the author argues that maintaining price stability in commodity economies is influenced by their resource rent distribution, and that economic stability is extremely sensitive to the nature of a political regime. The commodity factor alone is shown not to be an impediment to maintaining price stability and implementing inflation targeting. An empirical analysis based on data from 68 resource-rich countries provides evidence that the link between the timing of the implementation of inflation targeting and resource wealth variables is not skewed towards resource-poor countries. This study finds that among democracies, inflation targeters demonstrate the best price stability parameters, the most flexible exchange rates, more independent central banks, and more diversified economies, while among autocracies, the best parameters are seen in countries that have sovereign wealth funds
\end{abstract}

JEL Codes E58, E59, O23, Q33

Keywords price stability, commodity economies, inflation targeting, political regimes, central bank independence

\section{INTRODUCTION}

The ability of resource-rich countries to maintain price stability is very often viewed in the context of their overall macroeconomic vulnerability. This is related to a long tradition of viewing global commodity price fluctuations as something of a challenge. The financial integration of such countries further complicates the matter, adding the problem of macrofinancial stability to the issue of price shocks. Procyclical capital flows, and the private sector's tendency to accumulate the debt in times of favorable commodity market conditions, make the vulnerability profile of commodity economies more complex. These countries currently perceive the development of macroprudential instruments and counter-cyclical fiscal policy institutions as a benchmark of macroeconomic management. Similar innovations are being implemented amid a lack of fundamental differences in price stability maintenance capabilities between commodity exporters and other countries. The marginal case of Venezuela is rather an exception to the rule. At the same time, the fact that the inflation problem is receding into the background does not imply that resource wealth comes as a kind of antiinflation bonus. On the contrary, resource rent and its ability to distort the operation of economic policy institutions may prove to be a driver of the formation of a political regime under which maintaining price stability is either simplified as coalition bargaining costs minimization, or made more complex as political actors compete to capture rent. This implies that price stability in such countries can be viewed not only from a macroeconomic perspective but also from the standpoint of the political economy.

The worldwide spread of inflation targeting - specifically the growing number of inflation-targeting nations qualifying as commodity exporters - raises the question of how wellmatched conditions of resource wealth are to this method of maintaining price stability. On the one hand, the introduction of inflation targeting requires macroeconomic policy institutions to have matured to a certain level - one that naturally corresponds to the overall quality of the institutions. On the other hand, these countries' structural irregularities point to the possibility that maintaining price stability within them may run counter to meeting other objectives necessitated by the commodity factor. By way of example, the prevention of the Dutch disease requires a narrower exchange-rate fluctuation range, while the prudent averting of negative "balance sheet effects" may call for additional exchange-rate flexibility. Reserves hoarding requires liquidity sterilization, potentially resulting in the higher interest rates, in turn inviting pro-cyclical capital inflows. Along with this, commodity prices may fluctuate within a range that can turn a typical trade-offs that in nature is another class of macroeconomic objectives. 
Introducing inflation targeting in Ukraine has revived discussion about resource wealth's compatibility with price stability. This debate mainly appeals to our country's historical experience, and appears to be removed from the global context of the analysis of monetary regimes' performance. Simultaneously, estimates of the comparative efficiency of inflation targeting in terms of resource wealth also lack conclusiveness.

The paper puts forward the hypothesis that the natural resource factor, which is reflected in the export's structure, must not be perceived as (a better bias for) a price stability maintenance capability. The same goes for inflation targeters with a large share of non-commercial exports. The special nature of this monetary regime involves anchoring inflationary expectations and responding to anticipated inflation, ultimately incorporating a strong counter-cyclical component into macroeconomic policy. As a result, the basic monetary techniques for achieving price stability do not differ in countries that vary in their natural resource endowments, while the economic cyclicality induced by commodity price fluctuations is balanced out by central banks' actions.

This leads to the question of whether inflation targeters and non-targeters differ among themselves in terms of their price stability maintenance capabilities. This leads to a hypothesis that resource-endowed countries may or may not be successful in maintaining price stability, depending on how resource wealth determines the nature of their political regimes. This parameter is also an important driver of an economy's financial depth and complexity - structural characteristics that, in theory, should facilitate maintaining price stability through better adaptability to shocks. The same applies to the level of central bank independence, which is normally associated with price stability.

Political regimes also play an important role from the perspective of the introduction of counter-cyclical fiscal buffers. Where fiscal policy does not create reliable prerequisites for macroeconomic stability, central banks' capability to offset the pro-cyclicality of commodity prices is a result of institutional quality - to a much greater extent than the way in which institutional quality generates a counter-cyclical bias in fiscal policy. Put differently, price stability and its inflationtargeting-based maintenance is associated mainly with democratic political regimes that enable financial development, thereby positively impacting the accessibility of flexible-exchange-rate setting with a counter-cyclical objective.

This paper is structured as follows. The next section presents a review of the literature. Section 3 is concerned with a political-economy analysis of the link between resource rent and price stability. Section 4 contains an empirical assessment of the chronology of the introduction of inflation targeting. The next section discusses a grouping of resource-rich countries and gives a relevant analysis of identified patterns. The conclusions section summarizes the outcome of the research.

\section{PRICE STABILITY AND RESOURCE WEALTH: A LITERATURE OVERVIEW}

The baseline approach to the monetary problems of commodity economies is grounded in a theoretical analysis of links between global price shocks, foreign exchange inflows, and the choice of an optimal trajectory for inflation and exchange rate behavior. Against this background, this macroanalysis focuses on how domestic inflation impacts the real exchange rate and how the latter affects the deterioration of the economy's structure (as in cases of Dutch disease) (Corden, 1982; Corden and Neary, 1982). Within this framework, the issue of price stability is viewed in the context of the link between exchange rate behavior and the structural outcome when it appreciate. It is evident that price stability must play an important role in maintaining macroeconomic equilibrium in commodity economies. Otherwise, removing the conflict between the domestic inflation path and exchange rate would not have required large-scale counter-cyclical foreign exchange interventions. The key role of foreign exchange reserves in maintaining macrofinancial stability in resource-endowed countries manifests itself in their tendency towards setting fixed exchange rates, that empirically evident from Aliyev (2012), Aliyev (2013), and Aliyev (2014) suggests. Wills and van der Ploeg (2014) reach similar conclusions.

In subsequent research, the theoretical conceptualization of ways to achieve price stability underwent changes. A number of authors emphasize the political-economic factors involved in macroeconomic stability. In other words, a lack of stability is a result of political instability over the fight for rent (Auty, 2001a; Auty, 2001b). Coupled with fiscal policy, populism can add to problems related to controlling inflation. On the other hand, a politically stable autocracy makes possible an accumulation of fiscal buffers through the removal of coalition bargaining on budget parameters (Koziuk, 2016a; Koziuk 2016b).

In contrast to the political-economic approach, the macroeconomic perspective on the problem is less reliant on the role of rent-seeking in economic policy distortions. Price stability is to a greater extent viewed through the prism of central banks' reactions to the exchange rate and its role in open economies (Ball, 1998). However, the "fear-of-floating" debate recognizes the importance of export structure, alongside dollarization, strong spillover effects, etc. As a result, the tendency to maintain limited exchange rate fluctuations, and a strong response by interest rates to exchange rate developments, are seen as the mark of an optimal choice (Mohanty and Klau, 2004; Mishkin and Schmidt-Hebbel, 2007; Schmidt-Hebbel and Carrasco, 2016; Airaudo et al., 2016 , etc.).

However, because of several local waves of commodity price changes, the said problems are exacerbated as emerging markets grow more prone to fluctuations in global prices, as seen from the perspective of consumption structure. Put another way, the performance of inflation targeting in the light of commodity price volatility has come to be viewed in the context of optimal responses to supply shocks. In other words, resource wealth is indirectly identified with the special case of acute vulnerability to shocks in the prices of non-core inflation. While conventional monetary theory says that central banks can ignore transitive supply shocks, in emerging markets they cannot. A response to a supply shock - especially a shock to the supply of an agricultural commodity - may be optimal where core inflation is sensitive to movements in the most volatile components of the CPI. This is precisely the angle from which De Gregorio (2012) looks at inflation-targeting risks. Agenor and Pereira da Silva (2013), in turn, point out that, than exported commodities are also to consume domestically, terms-of-trade shocks are closer to supply-side shocks, and so the problem boils down to an optimal response to the gap between the most volatile prices 
and core inflation, rather than to the structure of exports. In effect, it means that resource wealth is not an impediment to maintaining price stability, including through inflation targeting. The only question is the extent to which the macroeconomic policy authorities are prepared to take the appropriate actions.

Viewed from another perspective, commodity economies have a set of distinguishing features that must be taken into account, as outlined in IMF (2012) and IMF (2015), for instance. First, commodity economies are extremely responsive to global-centric shocks. In these economies, most macroeconomic aggregates (such as consumption and investment) include an unambiguous pro-cyclical component. Second, the role of fiscal buffers in neutralizing the pro-cyclical effects of commodity price volatility has to be more distinct. Monetary policy may turn out to be more restricted in terms of the choice between price stability, exchange rate stability, and financial stability. Additionally, the higher the degree of commodity economies' integration into global finances, the more responsive they will be to capital flow shocks. Third, although commodity price volatility has little effect on the trend of potential GDP, its cyclical component's response to these fluctuations is twice as strong as that of other countries. This effect is more pronounced for energy exporters. In other words, the parameters in the NeoKeynesian inflation equation will change in such a way that the fluctuations in the monetary policy instrument variable in the reaction function may be more significant. Accordingly, importance is assigned to the components of the economy and economic policy that help reduce the significance of the impact of GDP's cyclical component on overall inflation. However, IMF (2012), Heenan et al. (2006) and Roger (2010) point out that inflation targeting is precisely the method that a number of commodity-rich economies try to use to decrease macroeconomic volatility.

Frankel et al. (2008) and Frankel (2010), in turn, find that inflation targeting in the resource-wealth case is not as counter-cyclical as expected. Maintaining price stability amid a positive commodity shock, they argue, requires a substantial strengthening of the exchange rate, just as a shock to commodity import prices requires comparable upward pressure on the exchange rate from higher interest rates. Furthermore, the authors point out that inflation targeting generates adverse pro-cyclical effects: monetary restrictions accompany a negative terms-of-trade shock, not vice versa. That being said, in the case of the simultaneous export and intermediate consumption of a country's core commodity, the domestic situation does not look so one-sided and is essentially reduced to the conventional problem of an optimal response to noncore inflation (Agenor and Pereira da Silva, 2013).

Aghion et al. (2009) show that the financial development level directly determines a flexible exchange rate's ability to offset terms-of-trade shocks. Insufficiently deep financial systems, when combined with sharp exchange rate fluctuations, have a negative effect on labor productivity growth This problem pertains to all countries with average and low incomes, but commodity-rich countries constitute a special case. In those countries, financial development can continuously remain depressed for institutional reasons (competition for rent capture, the insufficient protection of property rights, volatile and high inflation) and because the resource extraction sector can operate without the financial depth of the national financial system, thanks to a strong capacity to borrow from abroad in foreign currency (Kurronen, 2012; Koziuk, 2016a). That is to say, counter-cyclical response options under the price stability policy may be limited by the financial development factor. However, a structural change under which a transition to inflation targeting takes place produces better institutional quality. This improvement in quality is what unlocks financial development potential. It is not by chance that those resource-endowed nations that have the lowest hard-currency reserves tend to combine flexible exchange rates with high financial development indexes and are, for the most part, inflation targeters (Koziuk, 2016b). An empirical analysis of the response function for New Zealand, Australia, Canada, and the UK indirectly confirms this in the case of developed countries. The first two of them show a more pronounced response to exchange rate fluctuations, while the other two do not (Lubik and Schorfheide, 2007).

Nevertheless, exchange rate fluctuation responses remain a source of debate among the authors of such theoretical and empirical studies. If a weakening of the real exchange rate produces an increase in future inflation, a response to it is justified. But Aizenman et al. (2008) argue that, for a number of emerging markets, reverse causality appears to be true: higher inflation causes future exchange rate weakening. In another study, the same authors introduce resource wealth as a criterion to analyze central bank behavior in 16 emerging markets in 1989-2006 (Aizenman et al., 2011). The authors write that inflation targeters and non-targeters do not significantly differ in terms of growth rates, but that inflation is lower for the former; having a large share of commodity exports is associated with somewhat higher inflation, but at the same time, central banks show a stronger response to it; central banks also display a more pronounced response to exchange rates in commodity-exporting countries. Aizenman et al. (2011) explain this by saying that commodity exporters are more susceptible to termsof-trade shocks, while central banks' sensitivity to exchange rate movements relates not so much to attempts to indirectly ensure control over inflation, as to efforts to lower GDP volatility. Equally noteworthy is that the authors find a link between the share of commodities in exports and a stronger central bank response to inflation. This may mean that monetary authorities in resource-rich countries approach inflation as a challenge to macroeconomic stability, rather than considering themselves to be doomed to elevated inflation.

\section{COMMODITY ECONOMIES AND PRICE STABILITY: THE POLITICAL ECONOMY OF RENT AND ECONOMIC POLICY IMPLICATIONS}

The criticism that commodity countries cannot ensure low and stable inflation derives in fact mainly from their vulnerability to a wide range of commodity price fluctuations. Basic logic suggests that a strong positive shock to commodity prices will draw an exchange rate response that may hinder the development of non-extraction sectors. At the same time, a plunge in commodity prices will require a monetary policy easing that will quickly transform the devaluation into high inflation. By the same logic, the absence of an exchange rate response can also mean the existence of inflationary pressure. Commodity price growth, should it happen, activates the income effect, while a drop in commodity prices triggers attempts to revitalize aggregate demand, exerting pressure on the central bank to create economic stimuli. 
However, this approach is somewhat simplistic. It is immediately obvious that this reasoning leaves out institutions. A positive commodity price shock easily transforms into a boost to inflation if authorities or the central bank take no anti-inflation action. Increases in investment or rises in wages reflect to the same extent how the existing political regime approaches resource rent. Efforts to quickly convert rent into social welfare or redistribute it in favor of predatory elites is a key element of the mechanics of inflation acceleration during a commodity boom. The reason that the lack of counter-cyclical policy stems from a predatory attitude to rent is that understanding the temporal constraints of a positive price shock (even a rather persistent one) must rely on experience, which is common knowledge. Put differently, a price volatility cycle is not an issue of asymmetric information between macroeconomic policy authorities and other authorities. The same situation applies when commodity prices go into free fall. Adapting to new equilibrium conditions requires adjusting consumption and investment. It may also be necessary to adjust them simultaneously by cutting real wages and increasing investment. Those changes to the economy run into political and economic constraints that can be described as follows.

If under the existing political regime there is a certain status quo regarding rent access, the economy may perturb this status as it adjusts to the new equilibrium conditions. As a result, those experiencing a drop in welfare may forge an alternative alliance to help vested interests shift to other parties the burden of adjusting to the new equilibrium conditions. In either case, elevated inflation in a resource-rich country may signal a struggle over rent and indicate the unsustainability of the political regime, due to it lacking the resources to monopolize access to rent and transform price stability into a benefit with which to buy citizens' loyalty. In addition, if price stability is removed from the equation, the nature of rent access and the relevant sustainability of the political regime will affect the redistribution of the benefits/the burden of adjusting to the new equilibrium conditions. Given sufficient guarantees that such a redistribution has an acceptable form, political agents will not be interested in using pro-inflation policies to seize rent. By contrast, when those guarantees are scarce, pro-inflation policies may again be considered to be among the tools available for the redistribution of commodity price volatility losses/benefits.

Table C1 (in Appendix C) categorizes the potential monetary manifestations of commodity price fluctuations, grouped by political regime. It is assumed that the nature of rent distribution is not the only determiner of the modality of the democracy vs. autocracy comparison. In either case, competition for rent and how this competition affects institutional quality lead to different macroeconomic outcomes. For that reason, this comparison needs to be widened. There can be weak democracies, in which agents compete for rent access while social populism serves as one of the tools for such competition, and strong democracies, in which commodity rent is (at least to an extent) isolated from the current economic process and distributed according to a certain social optimum. Autocracies can be expropriatory, whereby rent access monopolization means control over other socio-economic and political processes amid intensified pressure on political and economic rivals, and prudent, in which rent monopolization is a method to avoid the wasting of rent, with its partial conversion into social welfare in exchange for loyalty.

From a strictly macroeconomic perspective, the link between commodity price fluctuations and domestic inflation reduces to the issue of there being an optimal response to a terms-of-trade shock. A positive shock will have expansionist effects, a negative one - restrictive effects. If price stability is in and of itself a policy objective, then in either case the response to various effects is a matter of available policy space or an acceptable trade-off between alternatives. The scale of commodity wealth and the corresponding scale of the economy's vulnerability to commodity price fluctuations will matter for the set of policy-mix instruments, rather than for inflation per se. This implies that, once price stability becomes a policy objective, the magnitude of commodity wealth begins to drive the search for an optimal combination of macroeconomic tools that would support such stability without causing additional macroeconomic fluctuations. That being said, even within this formulation, maintaining price stability may not be an exclusively technical issue, given the nature of the shocks, the varying impact of commodity prices on potential GDP, the sensitivity of inflation and the economy's cyclical position, the central bank's preferences, etc. In other words, the problem of commodity wealth may boil down to the typical dilemma of an inflation targeter: what should the response to a supply shock be?

Taking into account, however, that price shocks in resource-rich countries have the attributes of both supply shocks and demand shocks, the case becomes more complex (De Gregorio, 2012). For instance, an energy exporter and an agricultural products exporter with the same CPI structure may find themselves in different conditions in terms of consumer price behavior, especially if these exporters are countries with average or low incomes. Another problem is to identify the time at which not responding to a positive commodity shock ceases to be optimal strategy, as a result of a supply shock turning into a demand shock.

In this context, inflation targeting may bring in a number of positive aspects, as it involves the anchoring of inflation expectations, which should help decrease the sensitivity of the consumer price response to inflation drivers, activate countercyclical exchange rate behavior, restrain the central bank's politically motivated discretion, etc. Despite these positive aspects, criticism of inflation targeting (Frankel et al., 2008; Frankel, 2010) stems from the idea that stabilizing inflation and maintaining it within a target zone are actions opposite to offsetting a terms-of-trade shock. The important role of the exchange rate in shaping the trajectory of potential GDP is also seen as an impediment to inflation targeting, which is based on the principle of a floating exchange rate. However, the operation of this monetary regime on forward-looking principles does not make it identical to other monetary regimes, which adds stabilizing elements to the economy. On a grand scale, these should not ensue from the structure of exports even if the latter imposes additional constraints on optimal exchangerate behavior. Continual signaling to economic agents that, should they intensify the shifting of costs to the consumer, they will face demand-side constraints through interest rates, is critical to forming a common denominator between supply and demand shocks in a resource-rich country. In that interpretation, terms-of-trade shocks converge with the most volatile components of the CPI. The amplitude of the latter, which is determined by the scale of resource wealth, drives a more complex policy-mix toolkit precisely in order to avoid provoking the central bank into sporadically degrading the trade-off between variation in inflation and variation in GDP growth when a resource shock is persistent. It is in this context that the link between resource wealth and the monetary regime choice has to be considered. 


\section{RESOURCE WEALTH AND THE TIMING OF INFLATION TARGETING IMPLEMENTATION: AN EMPIRICAL PERSPECTIVE}

The importance of political and economic factors in ensuring price stability in a resource-rent economy and its vulnerability to terms-of-trade shocks raises the issue of substantiating the hypothesis about the role of a country's structural characteristics in its transition to inflation targeting. For instance, Ismailov et al. (2016) and Schmidt-Hebbel and Carrasco (2016) argue that, for the most part, safeguards against an accelerated transition to inflation targeting become relevant under the conditions of a substantial public debt (the risk of the preservation of fiscal dominance), high and volatile inflation (the risk of lack central bank credibility, potentially increasing disinflation costs), dollarization (the risk of exchange rate fluctuations having substantial impacts on the balance sheet, etc.), and the central bank's technical unpreparedness (the risk of the operational level of policy and macro-forecasting methodology). The export structure factor is not mentioned, making it all the more interesting whether this factor is a prerequisite for either a speedy transition to inflation targeting (given this factor's potential counter-cyclicality) or a delayed one (considering its potentially negative effect on the ability to maintain stable prices).

Graphical models reveal the nature of the link between resource wealth indicators (all three of the World Bank's World Development Indicators) and the chronology of nations' transition to inflation targeting (according to Central Banks News data) (see Figures 1-3).

As can be seen from Figures 1-3, there is no indication that inflation targeting is mainly introduced by countries that have no resource wealth. It is noteworthy, however, that it is possible to see certain ambiguous patterns in the link between resource wealth and the timing of the transition to inflation targeting.

First, all three figures show a rather clear-cut distinction between countries with high and low resource-wealth levels.

Second, the distribution between countries with greater resource wealth and those with lesser resource wealth is skewed towards the latter. The skew is most pronounced in Figure 3 (total resource rent as a percentage of GDP) and least pronounced in Figure 2, which features non-manufactured exports as an indicator. The pattern in Figure 2 is especially important, as it implies that the structure of exports is not a safeguard against an accelerated transition to inflation targeting. It is also important because this indicator demonstrates that this monetary regime is instituted by countries that rely on agricultural products for a significant share of exports. Given the composition of the CPI, the vulnerability to fluctuations in agricultural product prices in middle-income countries does not appear to be a significant flag against inflation targeting. That is, even if reaching a target is under serious threat as a result of agricultural product exporters viewing a drop in the crop harvest as the equivalent of a negative supply shock, it is not an impediment to transitioning to this monetary regime. It is safe to assume that the key is the way in which the central bank transforms the operational framework and conducts a systemic expectation-anchoring policy. Also important is the transformation of institutions in order to improve the allocation of resources.
Third, in the case of there being substantial resource wealth, a delayed transition to inflation targeting is more likely. This is best illustrated in Figure 3. In the other two cases, however, countries are relatively evenly spread out in time with regard to the link between resource wealth and the time this monetary regime is implemented. The difference in the nature of indicators used in plotting Figures 1-2 and 3 is intended precisely to demonstrate that inflation targeting will likely be the preferred monetary regime where, along with the extraction sector, there are other sectors that raise economic complexity. This may also mean that the presence of a more diversified economy, even one with a pronounced resource sector, will require greater price stability - which is only natural given the higher level of the intensity of economic transactions and, hence, the greater significance of the nominal anchor of price stability.

Fourth, the introduction of inflation targeting occurs later in time in countries outside the developed cohort, as developed countries have large resource endowments and were the first to introduce the regime (New Zealand, Canada, Australia, Norway). At the same time, Chile, Mexico, Brazil, Columbia, Peru, etc. exemplify that a rapid transition to this price stability regime is feasible in medium-income countries. On the one hand, the delayed transition to inflation targeting should be viewed in light of the fact that countries vary in how they mature towards the need to use instruments that ensure price stability in this monetary regime. For some, this may be the result of resource wealth being converted into the increased welfare of households, spurring financial development, which in turn fuels the growing role of capital flows in ensuring macroeconomic stability. Others may take the path of structural change, and minimize their dependence on extraction and other sectors.

\section{EMPIRICAL MEASURES OF THE LINK BETWEEN PRICE STABILITY AND THE STRUCTURAL CHARACTERISTICS OF RESOURCE- RICH COUNTRIES}

Some of the recent radical price turnarounds in world commodity markets allow for the empirical testing of how inflation conditions differ across inflation-targeting countries and countries that operate another monetary regimes. In addition, it is important to take into account the links between the price stability parameters and structural characteristics of the countries in the above two groups. The same applies to analyzing the problem of the dependence of the two groups' structural characteristics on the scale of their resource wealth.

To empirically test those links, a sample of 68 countries was compiled. The IMF has identified 52 countries as resource-rich (IMF, 2015). However, the IMF's criterion for identifying such countries is rather strict (under the criterion, commodities should make up 35\% of exports in 1962-2014, while net commodity exports should represent no less than $5 \%$ of gross foreign trade over the same period). In addition, this sample would not have resulted in a correct identification of the role that inflation targeting plays in ensuring price stability in resource-rich countries. For the purposes of this study, 16 countries with large commodity export volumes were added to the sample. These were the Dominican Republic, Tonga, Cape Verde, Fiji, Uganda, Iraq, Armenia, Ukraine, Mexico, South Africa, Australia, Canada, New Zea- 
Figure 1. Percentage of commodity exports and the year of inflation targeting implementation

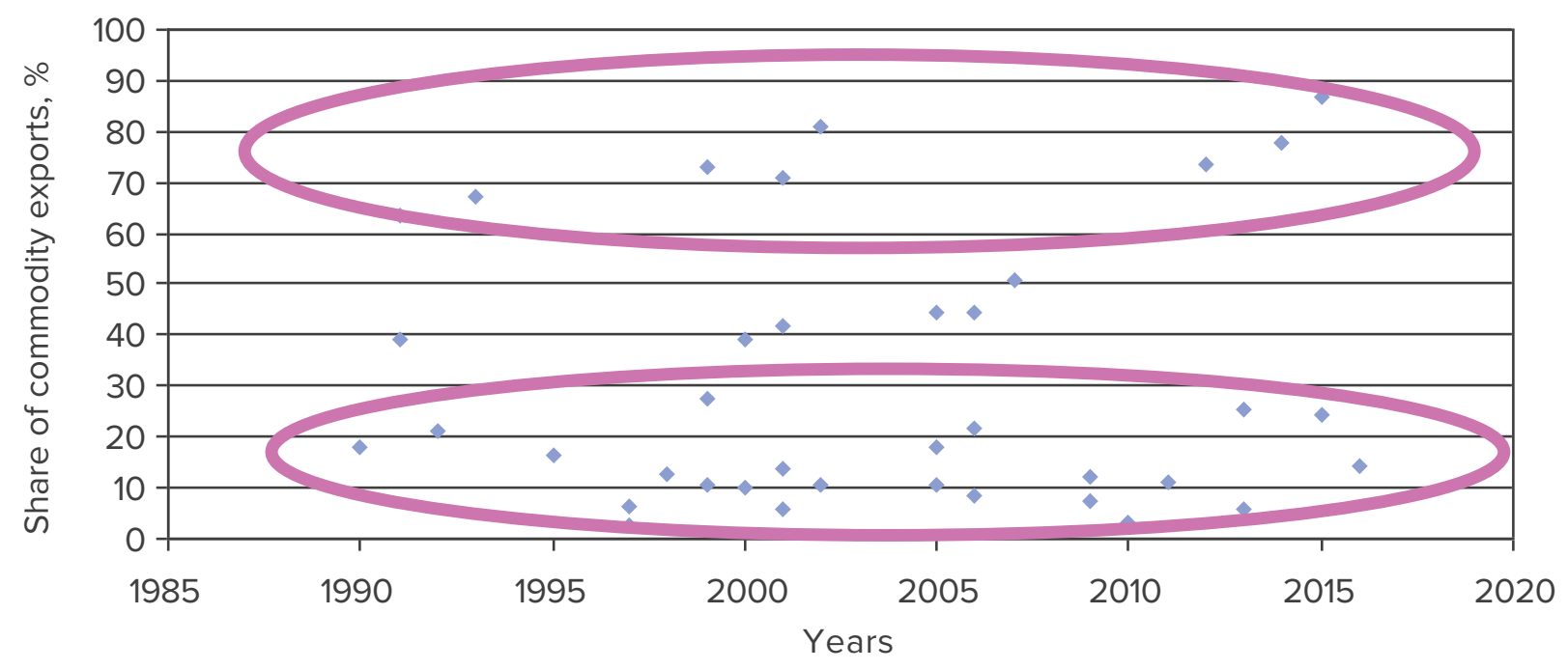

Figure 2. Percentage of nonindustrial exports and the year of inflation targeting implementation

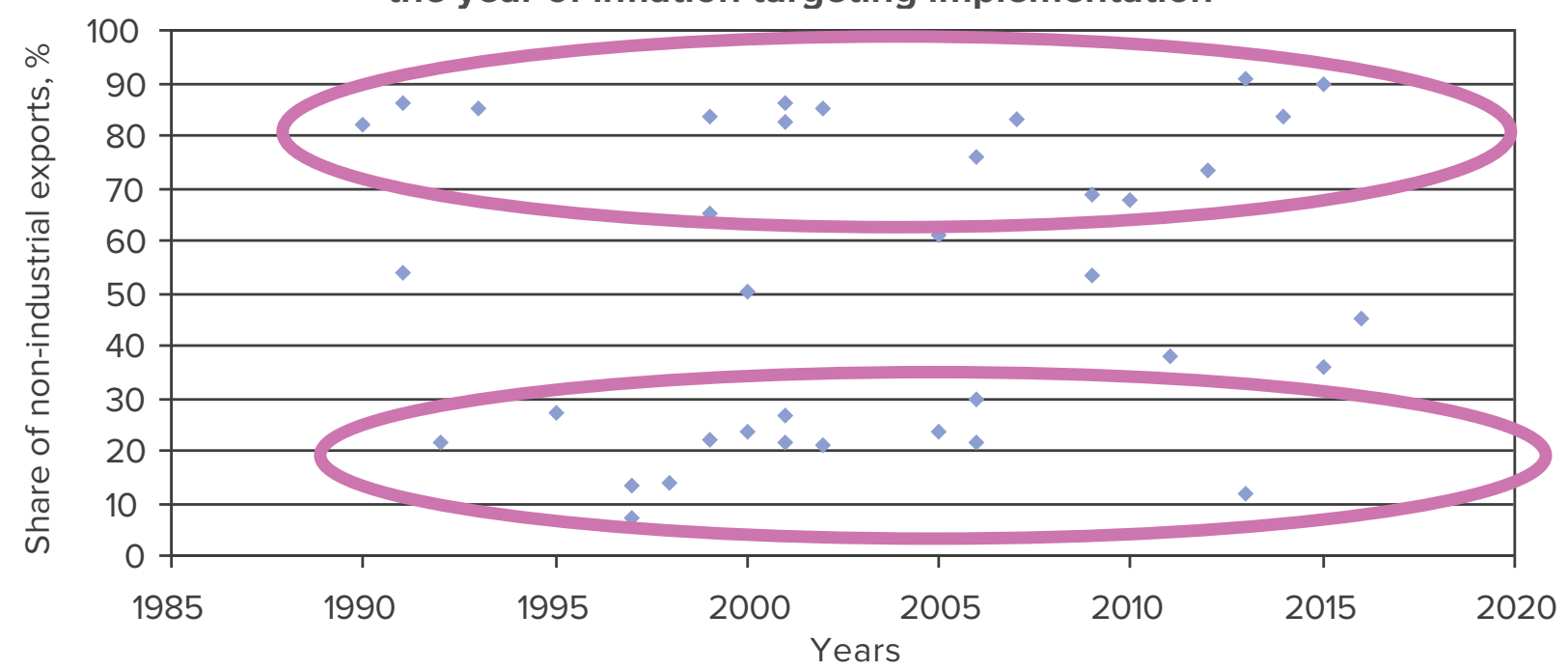

Figure 3. Resource rent and the year of inflation targeting implementation




land, Iceland, and Norway. The analysis covered the 19992017 period. Reinhart et al. (2017) argue that the 1999-2016 period chronologically captures the last full cycle of commodity prices. What makes this period stand out is that during it, resource-rich countries became less prone to the destabilizing effects of capital flows, thereby demonstrating the use of counter-cyclical policy instruments.

Price stability is analyzed using two indicators: average inflation and standard deviation of inflation for the selected period (IMF data). Non-manufactured exports was chosen as a resource wealth variable (World Bank's World Development Indicators) to account for the contribution of agricultural products to the structure of a country's foreign trade and, hence, to indirectly consider the issue of links between food prices, the significant share of food consumption in mediumand low-income countries, and the sensitivity of core inflation to shocks to the most volatile components of the CPI.

The following indicators describe the countries' structural characteristics:

- the financial depth index, which was developed by Svirydzenka (2016). This measure shows how an economy prone to terms-of-trade shocks can manage without proinflation stimuli from the central bank, as the financial sector absorbs some of the shocks. In addition, a lack of financial progress is viewed as a structural attribute of commodity economies that constrains their ability to maintain macroeconomic stability;

- the economic complexity index, which is calculated by MIT (https://atlas.media.mit.edu/en/rankings/country/eci). The average value of this index for 1999-2016 was used. It is assumed that the more the extraction sector dominates, the greater the extent to which it limits the development potential of alternative sectors, as the "resource curse" and "Dutch disease" approaches predict. By the same logic, the less diversified an economy is (the lower the index's value), the more inflationary are the consequences of a commodity price cycle;

- GMT - the central bank independence index. According to the literature, the level of central bank independence has an impact on maintaining price stability. But it is more important that the status of monetary authorities actually determines the country's choice of the institutional design of its macroeconomic policy. This design must determine how the costs and benefits of adapting to external shocks, which in turn determine the specific monetary measure of the resource rent, should be distributed. While resource-rich countries gravitate to low levels of monetary authority independence (Koziuk, 2016), this index could prove to be an important watershed divide between the groups of countries;

- the Democracy Index. This is an indicator of the political regime. It determines the nature of resource rent distribution and the quality of economic policy institutions. The link between them is not always traceable. Strong autocracies may institute fiscal buffers, as they draw no populist opposition over rent wasting, while weak democracies may find themselves incapable of implementing effective macroeconomic policy, both due to continual competition for rent and because of populism. Along with this, the way rent is spent may be dictated by competition for electoral advantage, leading to an outcome in which rent reinforces competitive populism. Predicting the nature of the link between this variable and price stability is going to be complicated.
Appendix A contains a graphical representation of established links. As shown, the split of the sample into inflation-targeting countries and countries with other monetary regimes is significant. In nearly every case, we see differences in the links' density or elasticity coefficient, and sometimes the links have opposite directions. Under otherwise equal conditions, the two groups differ in how the structural characteristics interact with inflation. The same applies to the link between the measure of resource wealth and the other measures used. A more concrete analysis identifies a number of other points.

First, both average inflation and variation in inflation are strongly related to the financial depth index in both groups of countries. This indicates that the development of financial markets and the availability of financing play an important role in reducing the need for monetary activism when responding to shocks. This could also mean that the inflow of foreign currency (resulting from either a positive trade shock or an inflow of capital in response to the growth in commodity prices) is more pro-inflationary where financial markets have lesser depth. However, inflation targeters manifest a better relationship between price stability parameters and financial depth (Figures A1-A4). At the same time, they display a more pronounced reverse relationship. This could be viewed as a consequence of their being at the higher level of economic development and the heterogeneity of countries under the financial development criterion, whereby financial depth is already important in the general institutional structure of the economy, but stops short of being able to offset pro-inflationary shocks.

Second, the nature of the link between price stability parameters and the economic complexity index is also evidence of the often-mentioned pro-inflation risks posed by responses to shocks in a poorly differentiated economy (Figures A5-A8). While the link's direction is the same here as in the case of financial depth, the link's density is much lower. In other words, the lack of differentiation of the economy is not an inflationary factor in itself, as the lack of financial depth can reduce the economy's ability to adapt to shocks, resulting in a deterioration of price stability. As with the previous case, inflation-targeting countries demonstrate a better elasticity coefficient in the link between the chosen parameters. Put differently, apart from their higher level of economic complexity, not having such a level is unlikely strongly pro-inflationary factor.

Third, the link between central bank status and price stability parameters is multidirectional in the context of the two groups of countries. For inflation targeters, a weak relationship is also theoretically predictable. For the other group, the relationship is direct (Figures A9-A12). This is because the members of the first group operate in a more conventional institutional format and deal with a traditional set of political and economic problems. Simultaneously, those in the other group show a different manifestation of institutional inflation buffers, which may or may not be associated with central bank independence. All in all, countries with stronger central bank independence may be substantially more vulnerable to political and economic pressure, while countries with weaker central bank independence may have other macroeconomic stability institutions, such as sovereign wealth funds.

Fourth, the resource wealth variable does not convincingly correlate with price stability parameters in either of the groups of countries. However, some differences are visible. 
Table 1. Mean values of variables by country group

\begin{tabular}{|c|c|c|c|c|c|c|c|c|}
\hline & $\begin{array}{l}\text { Democracy } \\
\text { Index }\end{array}$ & $\begin{array}{c}\text { Mean } \\
\text { inflation for } \\
\text { 1999-2017, } \\
\%\end{array}$ & $\begin{array}{c}\text { Standard } \\
\text { deviation of } \\
\text { inflation for } \\
1999-2017\end{array}$ & $\begin{array}{c}\text { Nonindustrial } \\
\text { exports, \% }\end{array}$ & $\begin{array}{l}\text { Exchange } \\
\text { rate } \\
\text { regime } \\
\text { variable* }\end{array}$ & $\begin{array}{l}\text { GMT } \\
\text { index }\end{array}$ & $\begin{array}{l}\text { Financial } \\
\text { depth } \\
\text { index }\end{array}$ & $\begin{array}{l}\text { Economic } \\
\text { complexity } \\
\text { index }\end{array}$ \\
\hline All 68 countries & 5.02 & 8.89 & 10.10 & 68.86 & 1.52 & 0.55 & 0.28 & -0.67 \\
\hline $\begin{array}{l}\text { Democracies, } \\
40 \text { countries }\end{array}$ & 6.51 & 8.90 & 11.06 & 62.30 & 2.15 & 0.59 & 0.33 & -0.41 \\
\hline $\begin{array}{l}\text { Democracies, } \\
\text { apart from } \\
\text { Venezuela, } \\
39 \text { countries }\end{array}$ & 6.54 & 6.39 & 4.72 & 62.69 & 2.15 & 0.59 & 0.33 & -0.41 \\
\hline $\begin{array}{l}\text { Autocracies, } \\
28 \text { countries }\end{array}$ & 2.90 & 8.88 & 8.73 & 76.80 & 0.61 & 0.48 & 0.21 & -1.03 \\
\hline $\begin{array}{l}\text { Democracies } \\
\text { with no or } \\
\text { little inflation- } \\
\text { targeting (IT) } \\
\text { experience (up } \\
\text { to } 7 \text { years), } \\
25 \text { countries }\end{array}$ & 5.90 & 11.29 & 16.19 & 65.20 & 1.44 & 0.58 & 0.22 & -0.63 \\
\hline $\begin{array}{l}\text { Democracies } \\
\text { with extensive IT } \\
\text { experience, } \\
15 \text { countries }\end{array}$ & 7.52 & 4.91 & 2.51 & 60.15 & 3.33 & 0.62 & 0.51 & -0.04 \\
\hline $\begin{array}{l}\text { Democracies } \\
\text { with extensive } \\
\text { IT experience } \\
\text { that are not } \\
\text { developed } \\
\text { countries, } \\
10 \text { countries }\end{array}$ & 6.60 & 5.99 & 3.01 & 58.63 & 3.10 & 0.61 & 0.40 & -0.15 \\
\hline $\begin{array}{l}\text { Autocracies } \\
\text { with sovereign } \\
\text { wealth funds, } \\
14 \text { countries }\end{array}$ & 3.00 & 4.54 & 4.07 & 80.10 & 0.57 & 0.50 & 0.30 & -0.73 \\
\hline $\begin{array}{l}\text { Autocracies with } \\
\text { no sovereign } \\
\text { wealth funds, } \\
14 \text { countries }\end{array}$ & 2.80 & 13.21 & 13.38 & 73.5 & 0.64 & 0.45 & 0.12 & -1.33 \\
\hline $\begin{array}{l}\text { All countries } \\
\text { with sovereign } \\
\text { wealth funds, } \\
17 \text { countries }\end{array}$ & 3.93 & 4.40 & 3.74 & 78.95 & 0.94 & 0.52 & 0.34 & -0.61 \\
\hline
\end{tabular}

Note 1. IT - inflation targeting.

Note 2. Kazakhstan and Russia, which have quantitative inflation targets but are classified as autocracies under the Democracy Index, were not combined into a separate group.

Note 3. *A variable that quantifies the exchange rate regime. This variable has a $0-4$ range. The 0 value is assigned to countries that have the following exchange rate regimes under the classifier: no separate legal tender, currency board, conventional peg, stabilized arrangements. A value of 1 is assigned to a crawling peg, crawl-like arrangements, pegged exchange rate within horizontal bands, a value of 2 to other managed arrangement, a value of 3 to floating, and a value of 4 to free floating.

Note 4. Only three countries that are classified as democracies under the Democracy Index have sovereign wealth funds (Norway, Chile, Trinidad and Tobago), and so they were not combined into a separate group. 
For countries with central banks engaged in inflation targeting, the resource wealth variable's average value hardly ever correlates with non-manufactured exports, which are, however, reversely correlated with the variation in inflation. Along with this, other countries show a more clear-cut reverse relationship between the resource wealth variable and inflation, but a direct relationship between the resource wealth variable and the variation in inflation (Figures B1-B4). These differences are probably best explained by differences in fiscal policy restrictions.

As the data above show, when coupled with the set of characteristics of the countries under analysis, export structure does not stand out in terms of its contribution to central banks' ability to ensure stable prices. Despite certain differences in the nature of the links between price stability parameters and structural change in favor of inflation targeters, the overall structure of exports must not be viewed as an insurmountable barrier on the way to price stability in resource-rich countries.

The obvious heterogeneity of commodity economies follows from the analysis conducted above. They differ in terms of monetary regime. In addition, as mentioned before, the political regime factor and the resource wealth level are viewed as an important determiners for potential policy-mix options and their institutional format in these political and economic conditions. To pinpoint the results of the earlier analysis, 68 of the sample countries were grouped under the general criterion of political regime (democracy vs. autocracy) and under subordinate criteria that identify macroeconomic policy regimes. The subordinate criteria were whether the countries were inflation targeters and whether the structure of their macroeconomic regimes included sovereign wealth funds (the results of the above analysis were based on a simple grouping on the principle of targeter vs. non-targeter). Indirectly, this approach enables the empirical verification of monetary effects in the context of the theoretical division of political regimes in commodity economies, as shown in Table C1 (see in Appendix C). The findings are presented in Table 1.

The grouping results presented in Table 1 allow the data shown in Appendix A to be refined, but confirm the theoretical assumptions outlined in Table C1 (see in Appendix C). Several key generalizations can be made. Democracies and autocracies differ in terms of inflation conditions, structural characteristics, and macroeconomic policy regimes. In the democracy group (40 countries), price stability parameters appear marginally worse than those in the autocracy group (28 countries). Removing Venezuela from the 40-country sample, however, changes the picture. The 39-country democracy group returns better results than the 28-country autocracy group. At the same time, compared to the autocracies, the group of countries with democratic regimes demonstrates the following pattern: they have smaller resource wealth, but prefer more flexible exchange rates, more independent central banks and have higher levels of financial development and more diversified economies (which fully matches the results of prior research (Koziuk, 2016a; Koziuk, 2016b). This outcome may be unambiguously interpreted as supporting the idea that a lower level of resource wealth decreases the likelihood of rent access monopolization, which in turn is generally a certain stimulus for the development of institutions that guarantee economic diversification and provide a boost to the financial system. Along with this, price stability is helped by a more independent central bank, while adjustment to shocks occurs via the exchange rate channel (at least in part, taking into ac- count the greater flexibility of exchange rate regimes). At the same time, this does not mean that the political regime as a determinant of financial depth and economic diversification is the only factor that matters for price stability. The macroeconomic policy regime is fundamentally important, as evidenced by the analytical groupings. Simultaneously, the qualitative characteristics of each of the political regimes are no less important in explaining which macroeconomic policy regime a country will prefer. And this is the fundamental reason for the differences seen among resource-rich countries.

First, countries with democratic regimes (barring Venezuela) are inferior to autocracies with sovereign wealth funds in terms of price stability and financial depth, but have higher levels of central bank independence, more flexible exchange rates, and more diversified economies. This is evidence of the fundamental importance of fiscal policy in maintaining price stability in countries with substantial resource wealth. But this does not rule out that the monetary policy regime is less significant.

Second, democratic countries that are differentiated under the criterion of the implementation/length of their inflation targeting regime differ in the same way as do autocracies with and without sovereign wealth funds. The 15-country group of democracies with long-term expertise in inflation targeting shows better results in the price stability domain compared to the 25-country group of democracies that either have little experience in targeting inflation or use an alternative monetary regime. The same applies to the group of countries that target inflation but are not classified as developed (10 countries). They are inferior to the aforementioned group of 15 countries, but substantially superior to the 25-country group by every measure. In other words, the monetary policy regime matters. Under any conditions, long-term inflation targeting in resource-rich countries unambiguously correlates with a more independent central bank, more flexible exchange rates, a deeper financial system, a more diversified economy, and a higher level of democracy. As for autocracies, breaking them down in terms of whether or not they have a sovereign wealth fund is rather illustrative. The 14-country group that has such a fund is, by every indicator, far ahead of the 14-country group that does not and, by the financial depth index, even ahead of the group of democracies with little or no inflation targeting experience. This has a straightforward interpretation. Countries that institute fiscal buffers attempt to counter the destructive cycles of commodity prices though converting resource wealth into social welfare (at least in part). They have also managed to achieve a certain reduction in pressure in terms of rent wasting, and are not explicitly expropriatory autocracies. This is evidenced by substantial differences in their financial depth and economic diversification.

Third, both the competitive populism inherent in weak democracies and the expropriatory voluntarism typical of primitive autocracies have similarly negative impacts on price stability and depress economic diversification and financial development. While weak democracies typically have more central bank independence greater exchange rate flexibility than primitive autocracies, the two groups are equally vulnerable to pro-inflationary political and economic risks, most likely regardless of their level of resource wealth. Rather, resource wealth acts to amplify such risks. The former group demonstrates lower average inflation rates for the selected period, but a higher variation in inflation. This may indicate the existence of a political business cycle factor, and its greater significance in democracies as opposed 
to autocracies. At the same time, a weak democracy is most likely less damaging to economic and financial development than an expropriatory autocracy, as seen from differences in the financial depth and economic complexity indexes.

Fourth, under the inflation criterion, inflation-targeting democracies are not too far behind the more advanced autocracies with sovereign wealth funds, which are able to sacrifice rights and freedoms (specifically, the three democracies with sovereign wealth funds (Norway, Chile, Trinidad and Tobago) improve the inflation outcome of the countries with sovereign wealth funds as a whole, compared to the autocracies alone, which have fiscal buffers at their disposal). Rights and freedoms are fundamentally important for economic diversification and financial development, even when they fall short of guaranteeing complete immunity to pro-inflation populism.

From the standpoint of this paper's focus, the data in Table $1 \mathrm{C}$ (see in Appendix $\mathrm{C}$ ) reinforce the notion that resource wealth is not an impediment to ensuring price stability, and that inflation targeting may be an effective instrumental manifestation of this.

\section{CONCLUSIONS}

From a theoretical perspective, commodity economies are viewed as being especially vulnerable to terms-of-trade shocks, which are subsequently added to by capital flow shocks. The conventional approach is to mainly analyze the maintenance of price stability in those economies from the perspective of acceptable exchange rate fluctuations, or in terms of a combination of inflexible exchange rates with the accumulation of reserves and/or with the establishment of sovereign wealth funds. The implementation of inflation targeting in many countries has altered the notion of this monetary regime's potential to be used to meet the pro-cyclical challenges that arise from commodity price volatility. For the most advanced inflation targeters, resource wealth and the terms-of-trade shocks that are associated with it are becoming the subject of a growing body of research into the optimal response to supply shocks, thus depriving the resource factor of its status as a special case that complicates the issue of ensuring price stability. However, it is possible that this factor may substantially complicate macroeconomic management. By contrast, in the context of Ukraine's transition to inflation targeting, it is the resource structure of exports that is viewed as a challenge to the central bank's ability to meet inflation targets.

The basic theoretical objection outlined in this paper is that maintaining price stability depends heavily on the distribution of resource rent within a political regime. In and of itself, the resource factor does not pose a challenge to price stability, but rather serves as the driver of a political struggle to capture rent. As a result, price stability is either perturbed as politics shifts towards populism (weak democracies), or maintained as a certain optimal choice (strong democracies), or ensured as reward for citizens' loyalty (prudent autocracies that limit rent wasting), or disrupted as a consequence of a predatory elite's actions (expropriatory autocracies).
The experience of other countries, as analyzed in this paper, shows that the availability of ample natural resources is not an impediment to ensuring price stability, including through conducting an inflation-targeting policy.

A comparison of the chronologies of countries' transitions to inflation targeting and the indicators of their resource wealth does not in general indicate that countries that adhere to this monetary regime have uniquely low levels of commodity dependence. In much the same way, there is no clear evidence that the subsequent transition to inflation targeting requires resource wealth.

Inflation targeters and non-targeters differ in terms of the nature of the link between price stability parameters and structural indicators. Along with this, the role of export structure does not stand out as a defining one, when compared to financial depth, economic complexity, and central bank independence. At the same time, inflation targeters have a much better trade-off between links, according to the majority of the analyzed variables.

The country grouping confirms that commodity economies are heterogeneous, so for the purposes of this study, political regime was chosen as the basic separation criterion (democracy vs. autocracy), while the presence/length of inflation-targeting experience (for democracies) and the existence of sovereign wealth funds (for autocracies) were selected as the functional criterion. Inter-group comparisons unambiguously indicate that the monetary regime for the former and the fiscal regime for the latter are the fundamental determinants of price stability. At the same time, democracies show higher levels of central bank independence, more flexible exchange rates, more diversified economies, and more developed financial systems. The exchange rate regime is an important aspect of the choice between available options. In the first case, its flexibility is linked to its shock-absorbing role and correlates with a deeper financial system. In the other case, counter-cyclical fiscal buffers eliminate the pressure that the terms of trade exert on the exchange rate regime. As a result, it may be less flexible.

The above generalizations imply that resource wealth per se does not represent a challenge to price stability or a factor that impedes the implementation of inflation targeting. The main factor at play here is the presence of a political regime within which price stability is not compromised during the struggle for rent. Because of this, the instrumental maintenance of such stability can be effectively implemented through a monetary regime of inflation targeting and/or a fiscal regime of countercyclical buffers.

Projecting this paper's conclusions onto the domestic situation exposes the critical importance of developing relevant institutions for ensuring price stability in Ukraine, given that it is a commodity-oriented economy. These institutions include, first and foremost, an independent central bank that is oriented towards meeting the objectives of price and financial stability. They also include fiscal regulations and medium-term budget planning to minimize the impact of the government's discretionary decisions on macroeconomic development. 


\section{REFERENCES}

- Aghion Ph., Bacchetta Ph., Ranciere R., Rogoff K. (2009). Exchange Rate Volatility and Productivity Growth: The Role of Financial Development. NBER Working Paper, No. 12117. Available at: http://www.nber.org/papers/w12117

- Airaudo M., Buffie E., Zanna L.-F. (2016). Inflation Targeting and Exchange Rate Management in Less Developed Countries. IMF Working Paper, No. 16/55, pp. 1-32.

- Aizenman J., Hutchison M., Noy I. (2008). Inflation Targeting and Real Exchange Rates in Emerging Markets. NBER Working Paper, No. 14561.

- Aizenman J., Hutchison M., Noy I. (2011). Inflation Targeting and Real Exchange Rates in Emerging Markets. World Development, Vol. 39, No. 5, pp. 712-724. https://doi.org/10.1016/j.worlddev.2010.11.005

- Agenor P.-R., Pereira da Silva L. (2013). Inflation Targeting and Financial Stability: A Perspective from Developing World. Banco Central do Brasil Working Papers, Sept., No. 324, pp. 1-113.

- Aliyev I. (2013). Procyclicality in Resource-Rich Countries. Ministry of Finance of the Czech Republic Working Paper, No. 1/2013, pp. 1-24.

- Aliyev R. (2012). Monetary Policy in Resource-Rich Developing Economies. CERGE-EI Working Papers, No. 466, pp. 1-49.

- Aliyev R. (2014). Determinants of the Choice of Exchange Rate Regime in Resource-Rich Countries. CERGE-EI Working Papers, No. 527, pp. 1-36.

- Auty R. (2001a). The Political Economy of Resourcedriven Growth. European Economic Review. Vol. 45, No. 4-6, pp. 839-846.

- Auty R. (2001b). Resource Abundance and Economic Development. Oxford: Oxford University Press.

- Ball L. (1998). Policy Rules for Open Economies. NBER Working Paper, No. 6760.

- Corden M. (1982). Exchange Rate Policy and Resource Boom. Economic Record, Vol. 58, No. 1 pp. 18-31.

Corden M., Neary P. (1982). Booming Sector and De-Industrialization in a Small Open Economy. Economic Journal, Vol. 92, No. 368, pp. 825-848. https://doi.org/10.2307/2232670

- Frankel J. (2010). How Can Commodity Producers Make Fiscal and Monetary Policy Less Procyclicall? Paper Presented on High Level Seminar on Natural Resources, Finance and Development, Algiers, Nov. 4-5, pp. 1-34.

- Frankel J., Smit B., Sturzenegger F. (2008). Fiscal and Monetary Policy in Commodity Based Economy. Economics of Transition, Vol. 16, No. 4, pp. 679-713.

- De Gregorio J. (2012). Commodity Prices, Monetary Policy and Inflation. Paper Presented for the Conference on Policy Responses to Commodity Price Movements, organized by IMF and Central Bank of Turkey, pp. 1-36.
- Heenan G., Peter M., Roger Sc. (2006). Implementing Inflation Targeting: Institutional Arrangements, Target Design, and Communications. IMF Working Paper, No. WP/06/278.

- IMF (2012). Commodity Price Swings and Commodity Exporters. World Economic Outlook. October 2012, Chapter 4, pp. 125-169.

- IMF (2015). Where Are Commodity Exporters Headed? Output Growth in the Aftermath of the Commodity Boom. World Economic Outlook. October 2015, Chapter 2, pp. 65103.

- Ismailov Sh., Kakinaka M., Miyamoto H. (2016). Choice of Inflation Targeting: Some International Evidence. North American Journal of Economics and Finance, Vol. 36, pp. 350-369. https://doi.org/10.1016/j.najef.2016.03.001

- Lubik A., Schorheide F. (2007). Do Central Banks Respond to Exchange Rate Movements? A Structural Investigation. Journal of Monetary Economics. Vol. 54, No. 4, pp. 1069-1087.

- Mishkin F., Scmidt-Hebbel K. (2007). Does Inflation Targeting Make a Difference. NBER Working Paper, No. 12876.

- Mohanty M., Klau M. (2004). Monetary Policy Rules in Emerging Market Economies: Issues and Evidence. BIS Working Paper, No. 149.

- Reinhart C., Reinhart V., Trebesch Ch. (2017). Capital Flow Cycles: A Long, Global View. Paper Presented at IMF Research Conference, pp. 1-83.

- Roger Sc. (2010). Inflation Targeting Turns 20. Finance and Development, Vol. 47, No. 1, pp. 46-49.

- Schmidt-Hebbel K., Carrasco M. (2016). The Past and Future of Inflation Targeting. Available at: www.bcb.gov. br/pec/depep/Seminars/2016_XVIIISenAnualMetasInBCB/ SMETASXVIII-\%20Klaus\%Schmidt.pdf

- Svirydzenka K. (2016). Introducing a New Broad-based Index of Financial Development. IMF Working Paper, No. $16 / 5$, pp. $1-42$.

- Wills S., van der Ploeg R. (2014). Why Do So Many Oil Exporters Peg Their Currency? Foreign Reserves As A De-facto Sovereign Wealth Fund. Paper Presented at the joint RES-SPR Conference on "Macroeconomic Challenges Facing Low-Income Countries”. IMF, Wash. DC. - Jan. 30-31, 2014.

- Kurronen S. (2012). Financial Sector in ResourceDependent Economies. BOFIT Discussion Papers, No. 6, pp. 1-35.

- Koziuk V. (2016a). Independence of Central Banks in Commodity Economies. Visnyk of the National Bank of Ukraine, No. 235 pp. 6-25.

Koziuk V. (2016b). Financial Development, Forex Reserves and Political Regimes in Resource Rich Economies. Economic Theory (in Ukrainian language). No 3, pp. 82-102. 


\section{APPENDIX A}

Figure A1. Inflation and financial depth in inflation-targeting countries

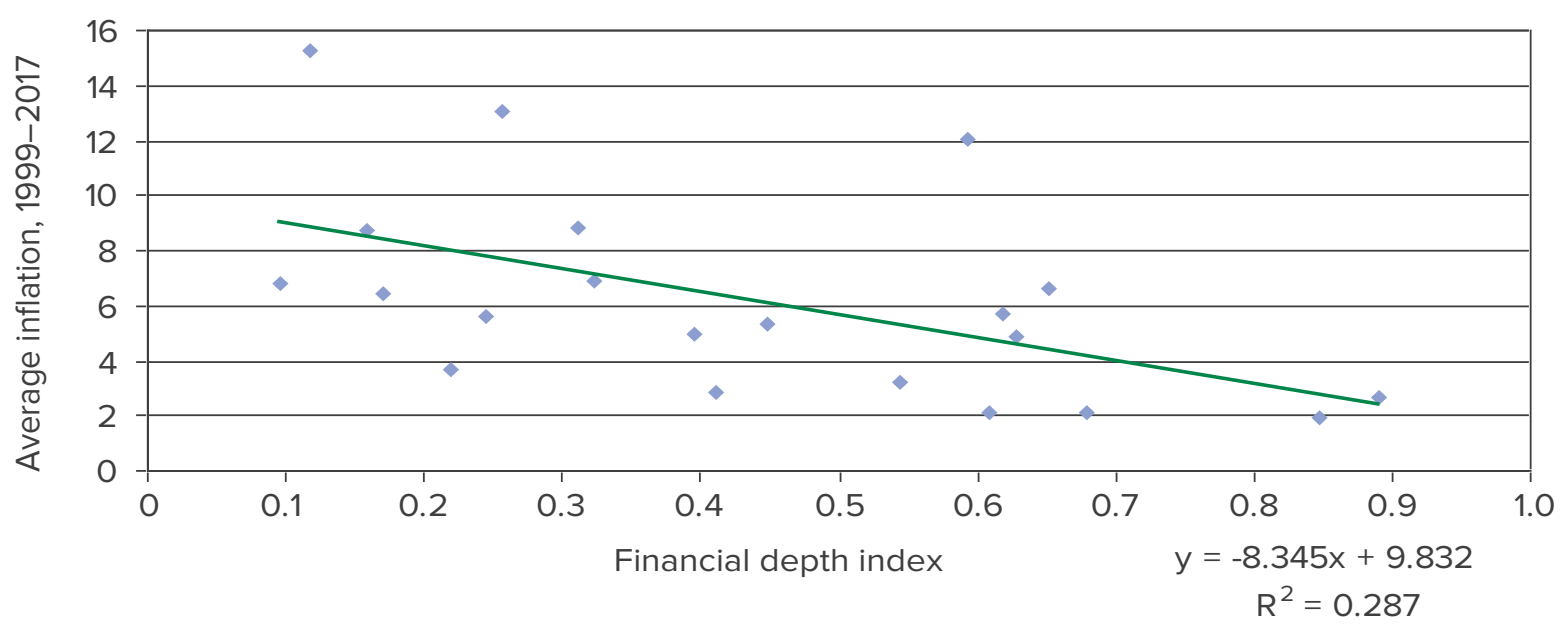

Figure A2. Inflation and financial depth in countries that do not target inflation

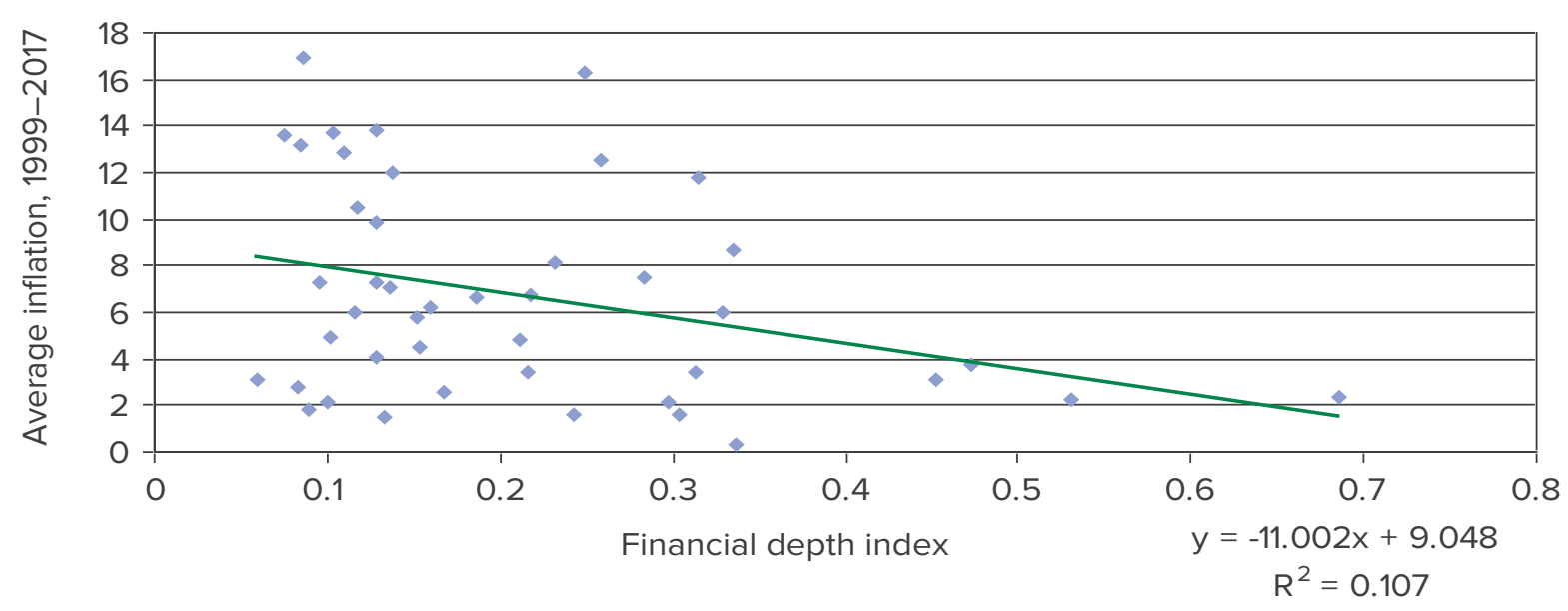


Figure A3. Financial depth and variation in inflation in countries that target inflation

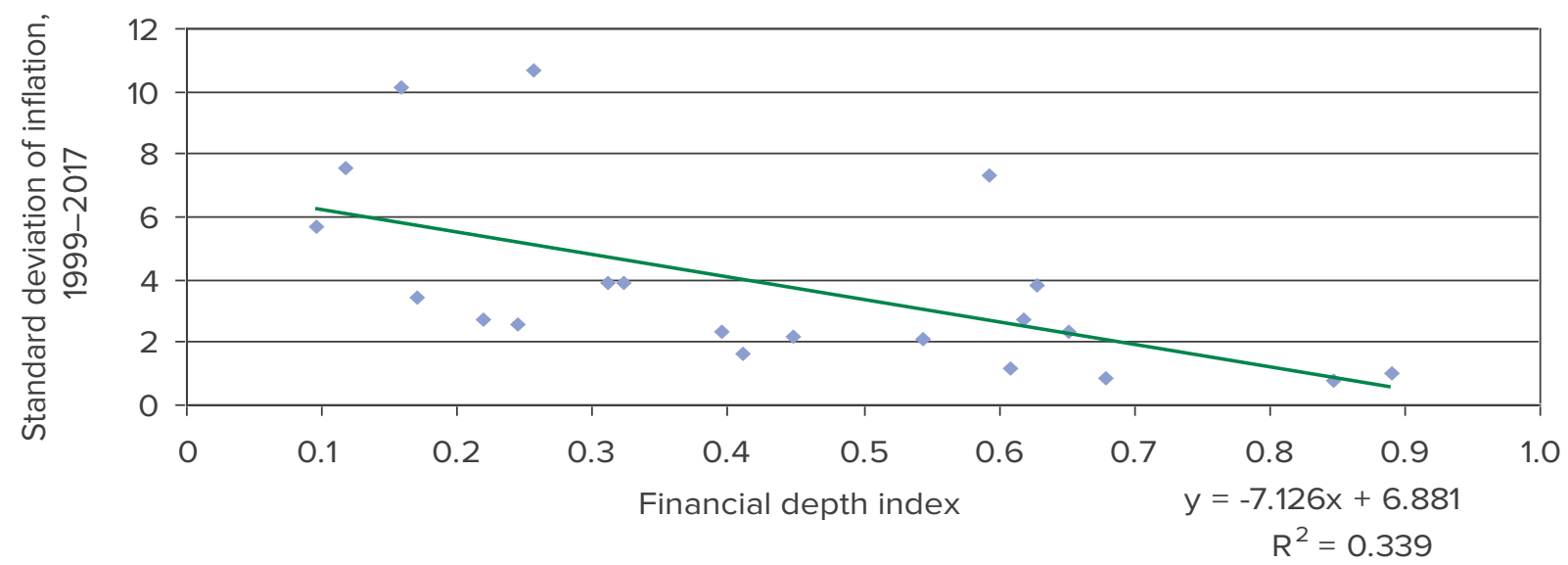

Figure A4. Variation in inflation and financial depth in countries that do not target inflation

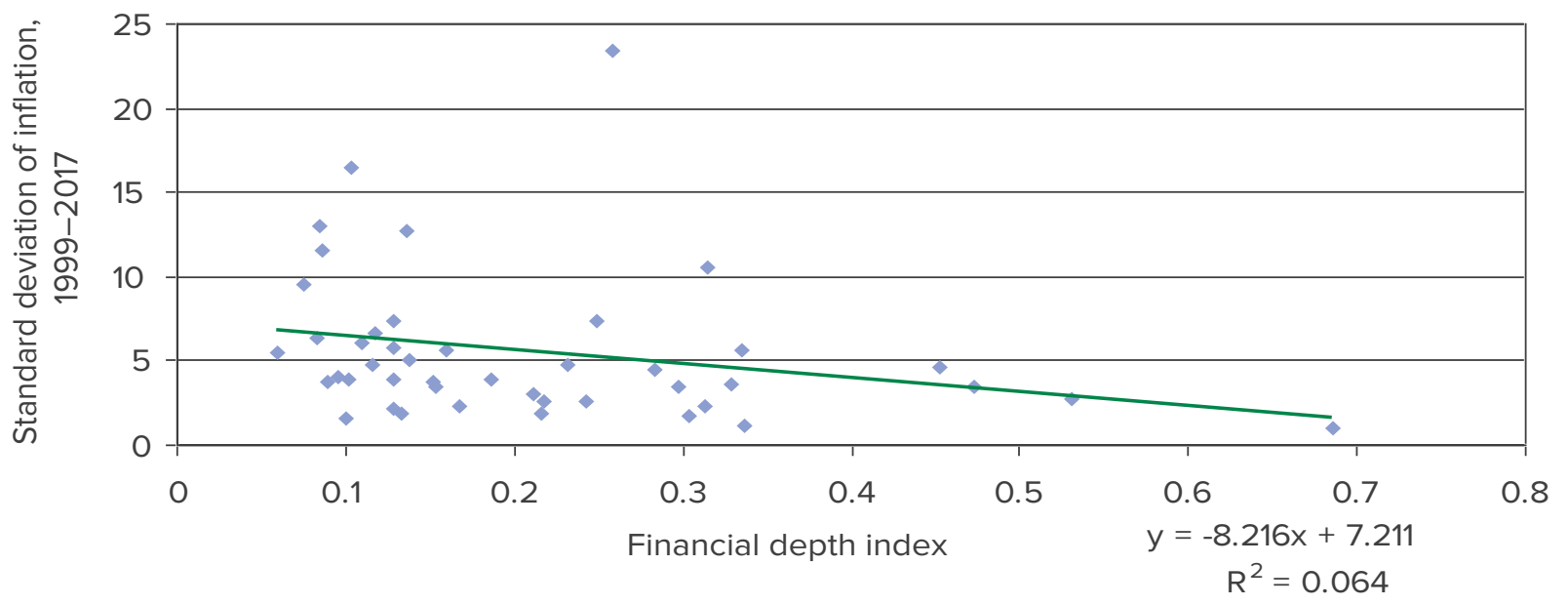


Figure A5. Inflation and economic complexity in inflation-targeting countries

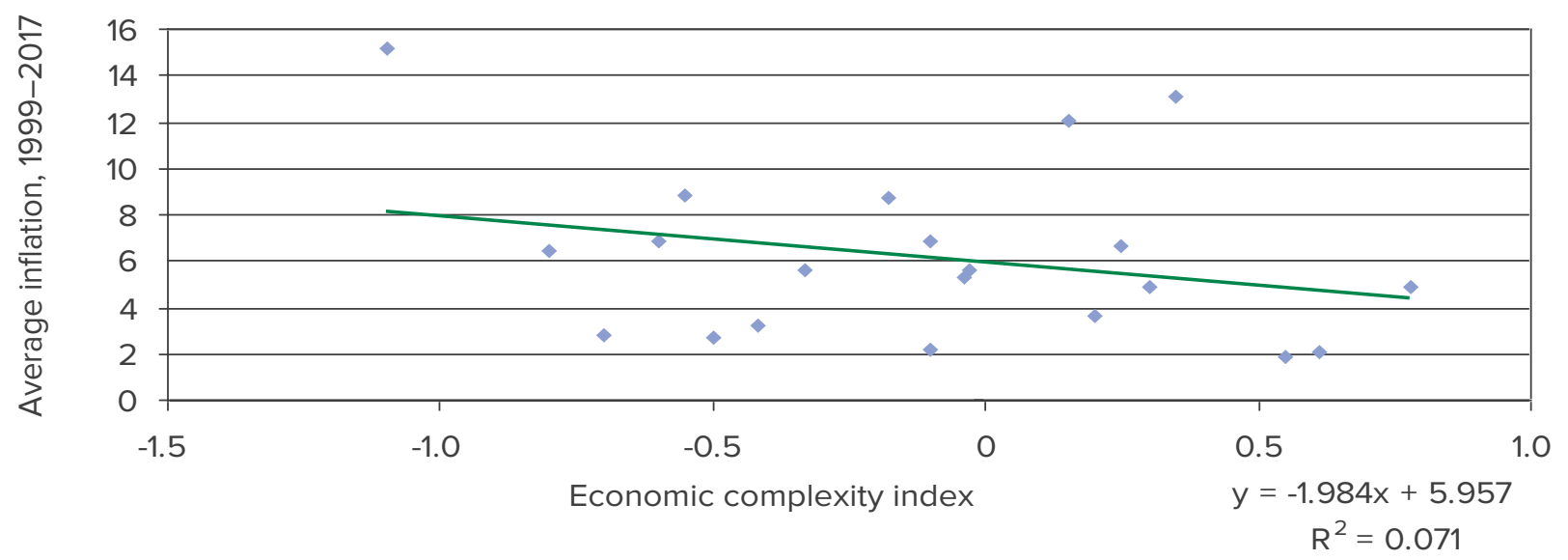

Figure A6. Inflation and economic complexity in countries that do not target inflation

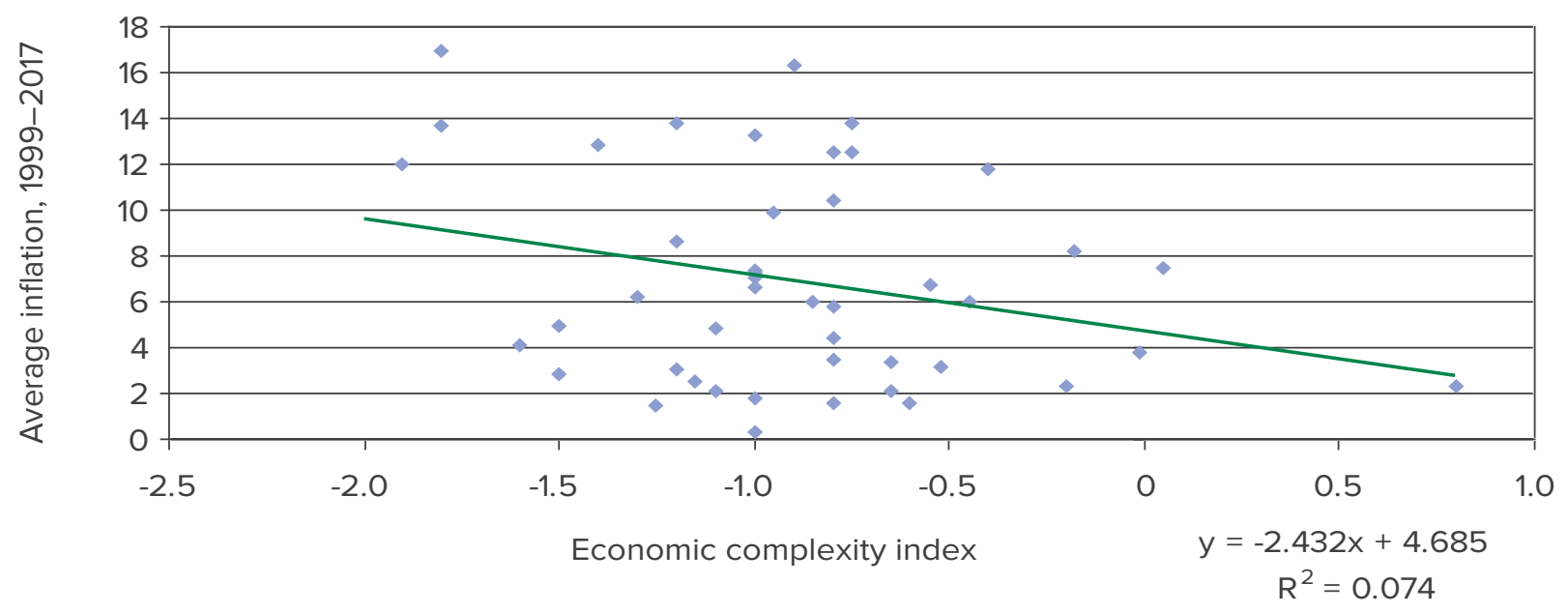


Figure A7. Variation in inflation and economic complexity in inflation-targeting countries

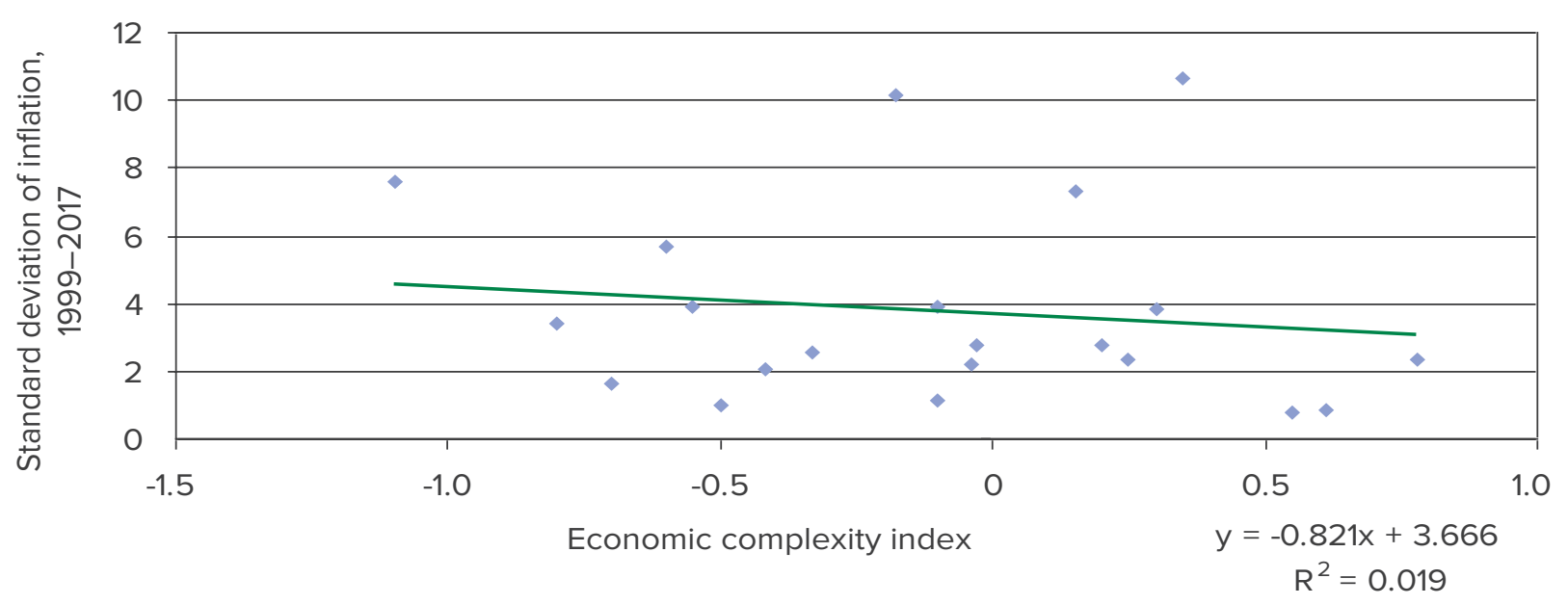

Figure A8. Variation in inflation and economic complexity in countries that do not target inflation

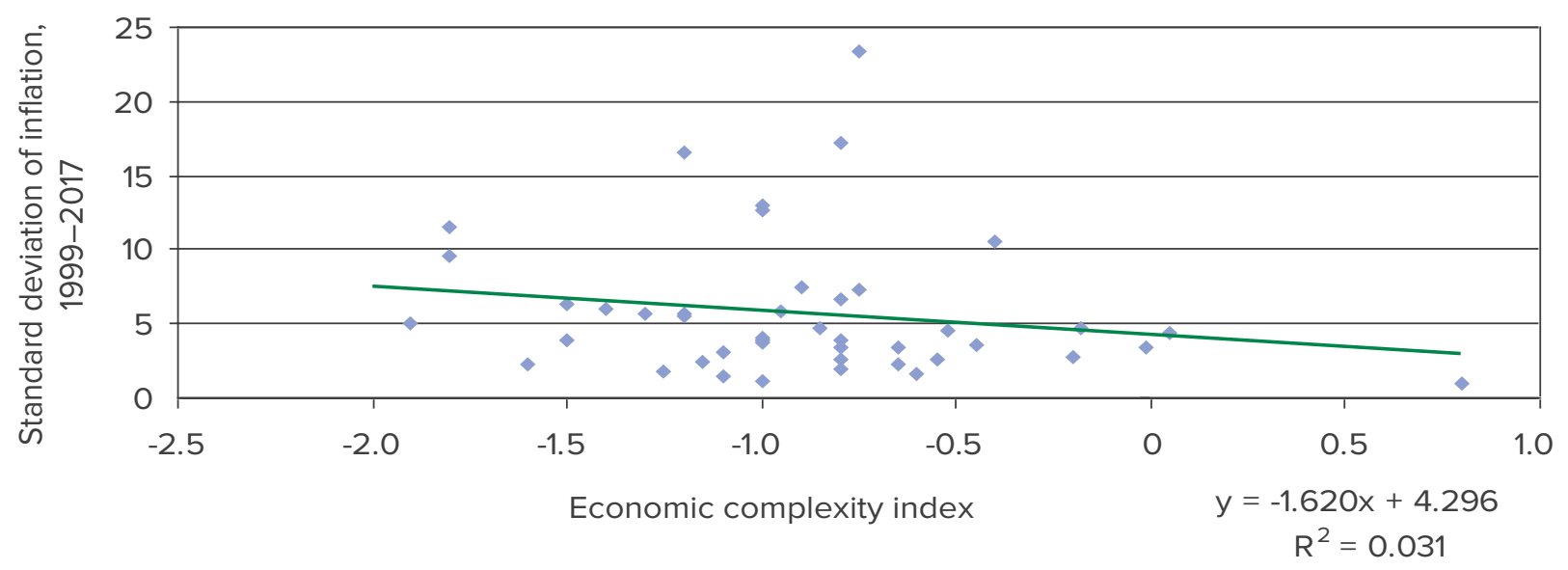


Figure A9. Inflation and central bank independence in inflation-targeting countries

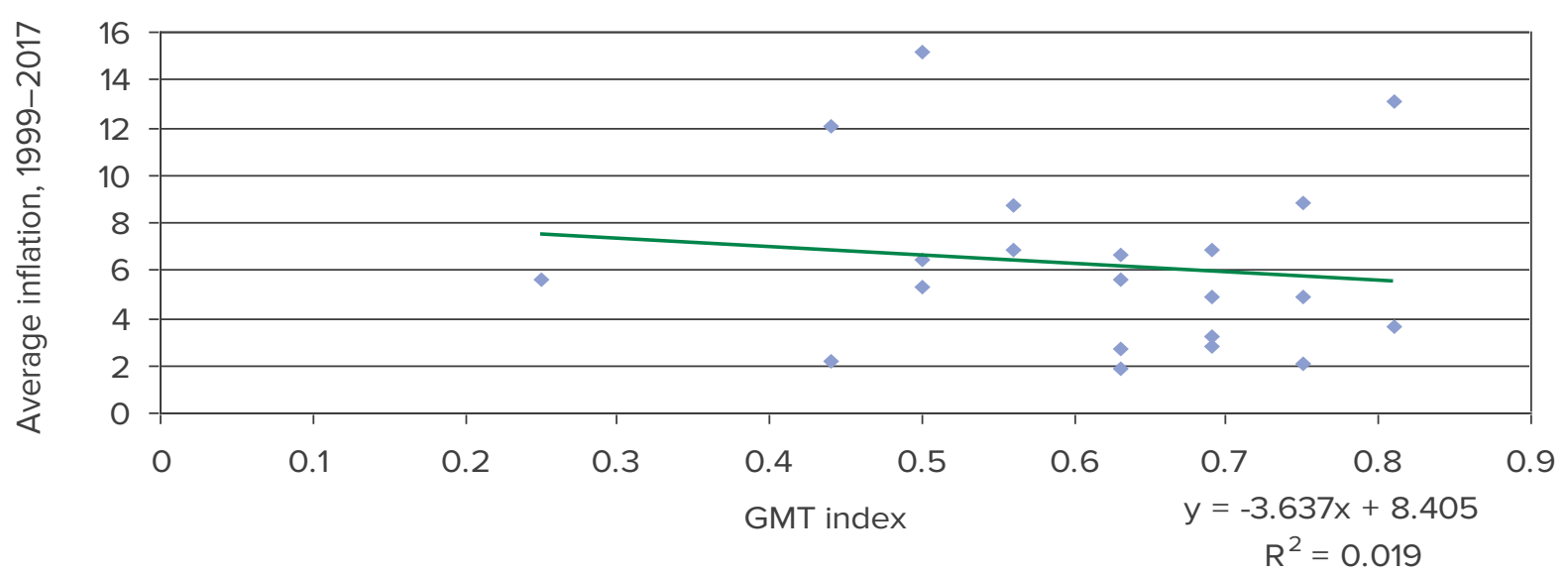

Figure A10. Inflation and central bank independence in countries that do not target inflation

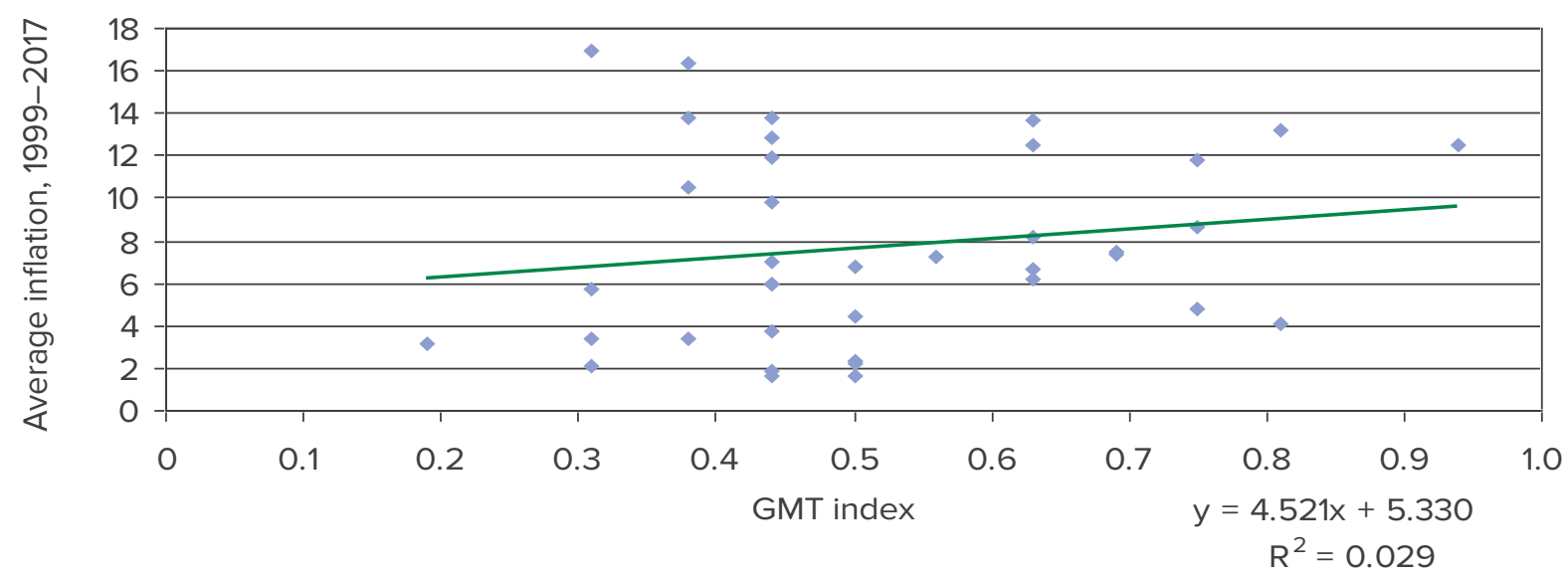


Figure A11. Variation in inflation and central bank independence in inflation-targeting countries

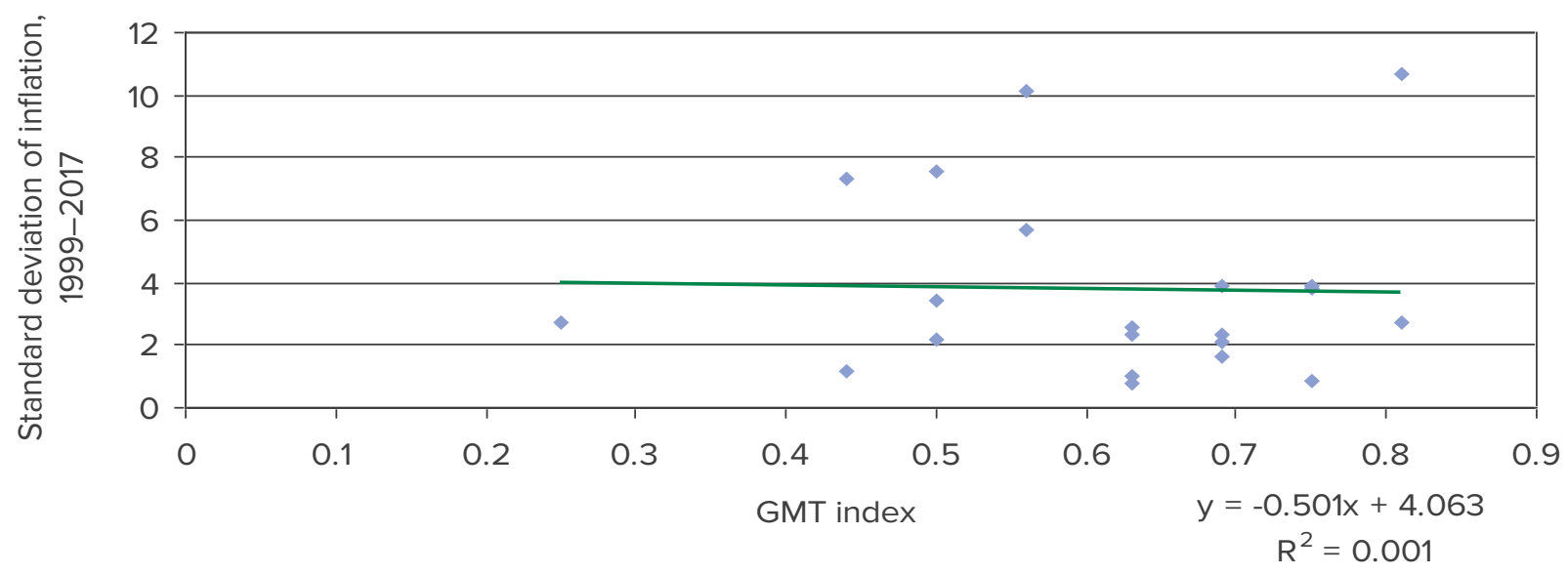

Figure A12. Variation in inflation and central bank independence in countries that do not target inflation

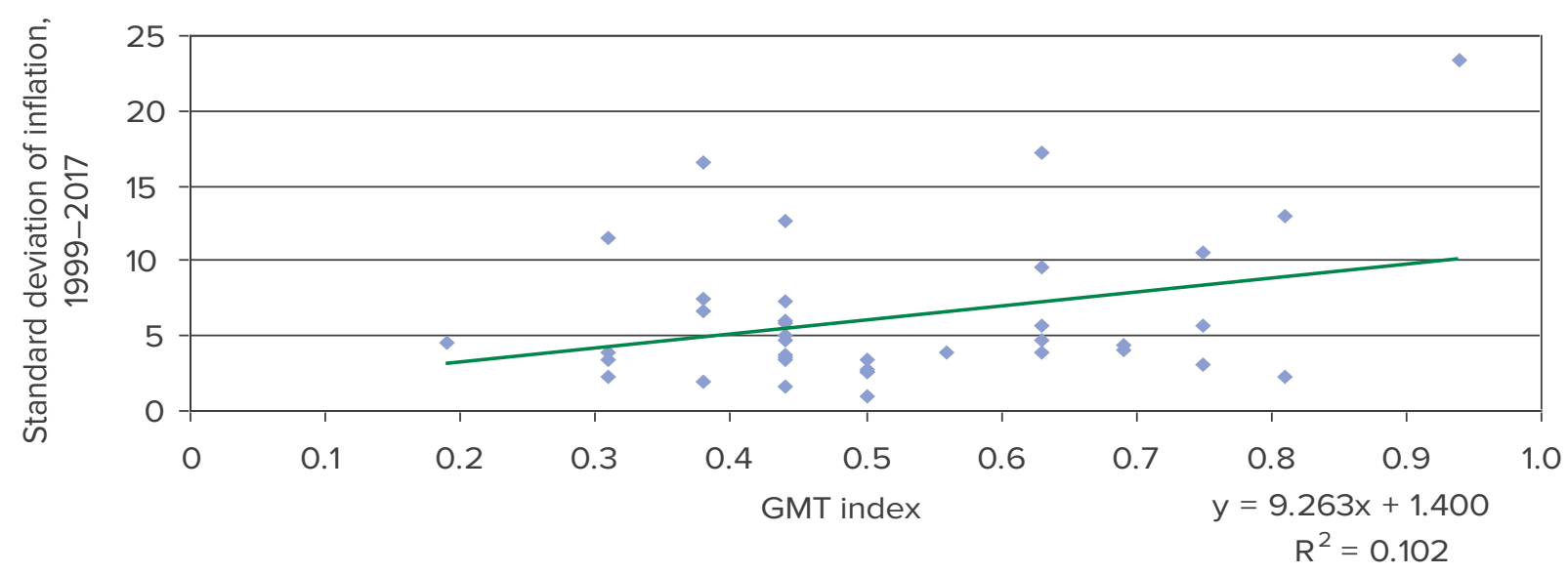




\section{APPENDIX B}

Figure B1. Inflation and resource wealth in inflation-targeting countries

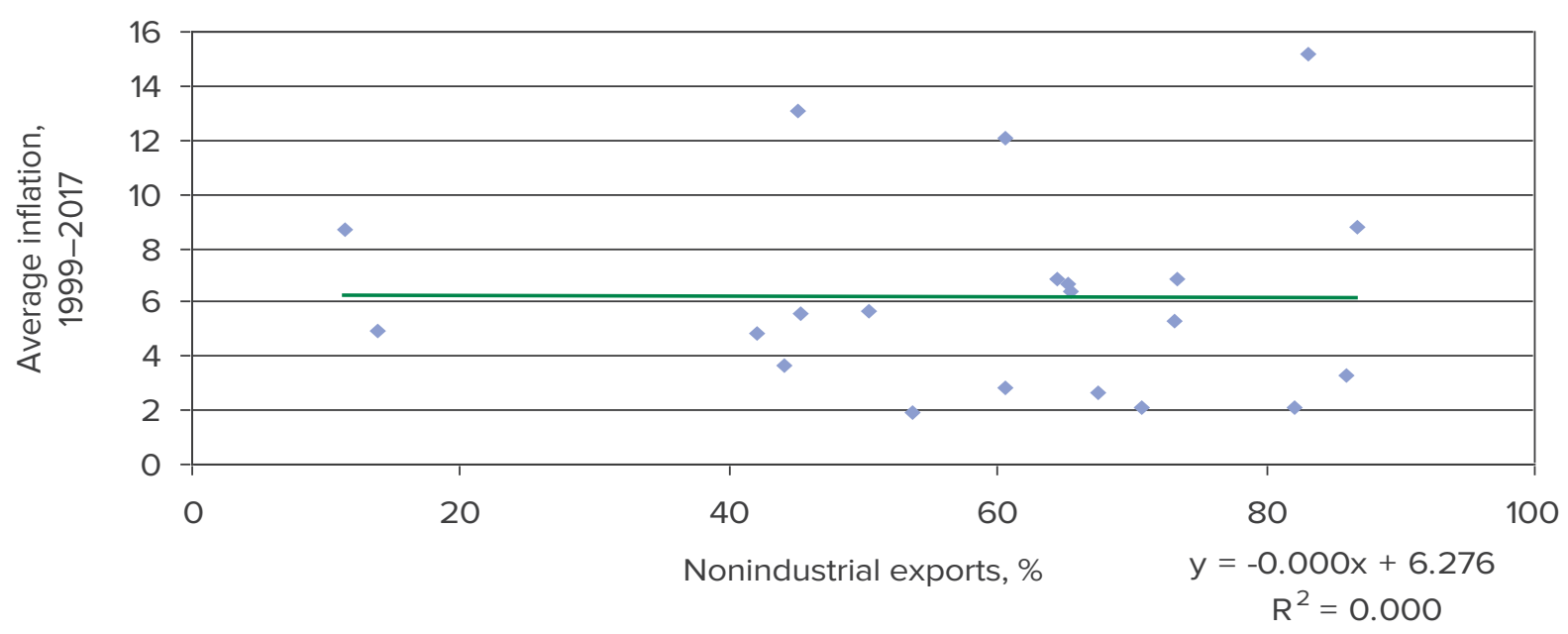

Figure B2. Resource wealth and inflation in countries that do not target inflation (excluding Venezuela and Angola)

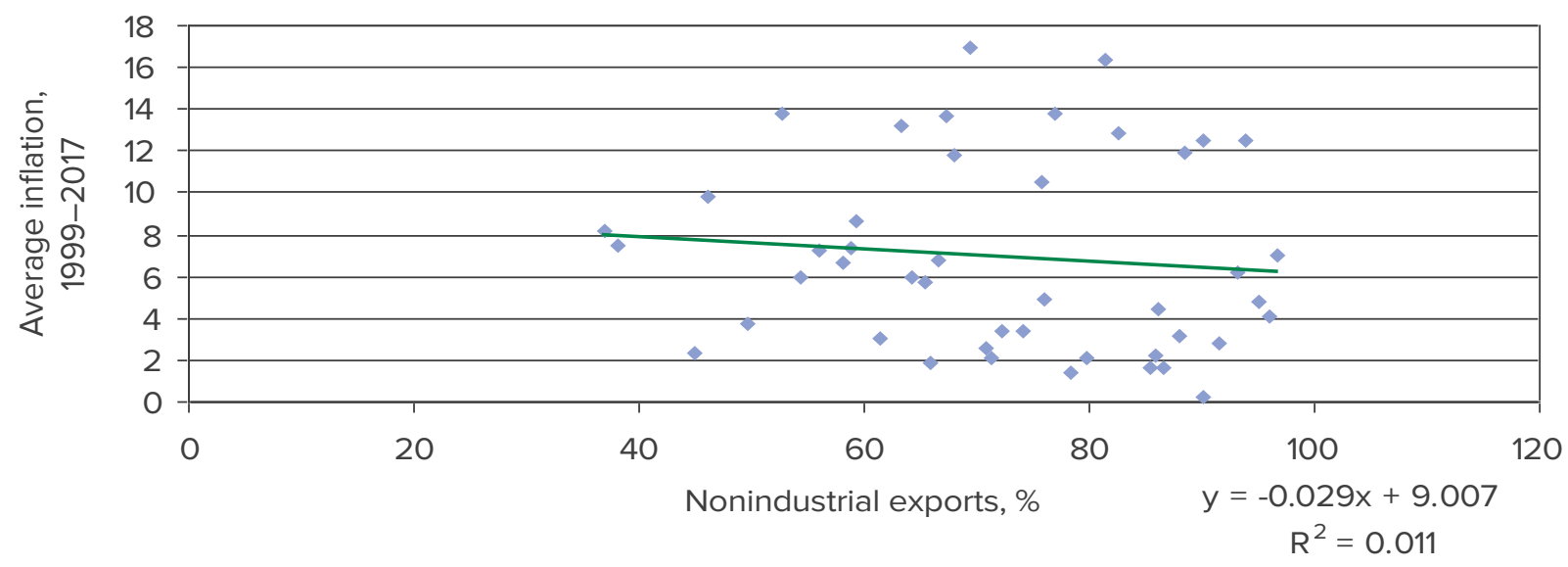


Figure B3. Resource wealth and variation in inflation in countries that target inflation, 1999-2017

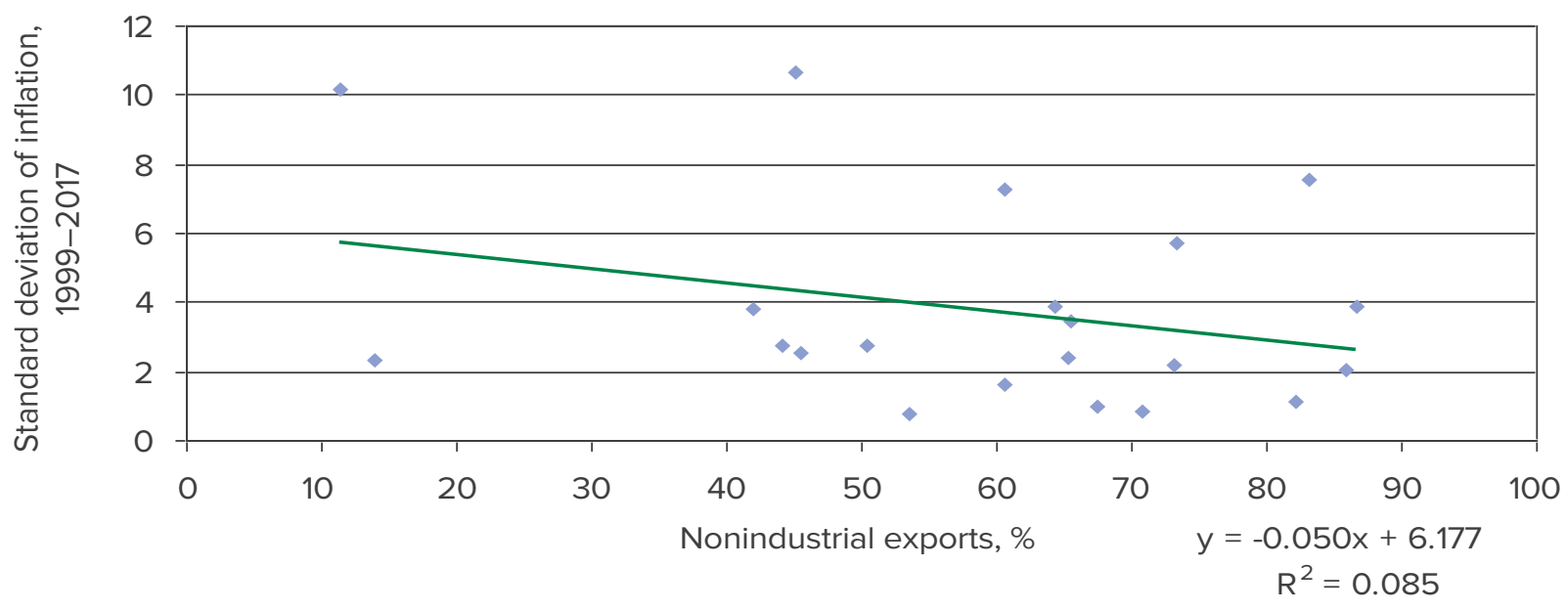

Figure B4. Resource wealth and variation in inflation in countries that do not target inflation (excluding Venezuela and Angola)

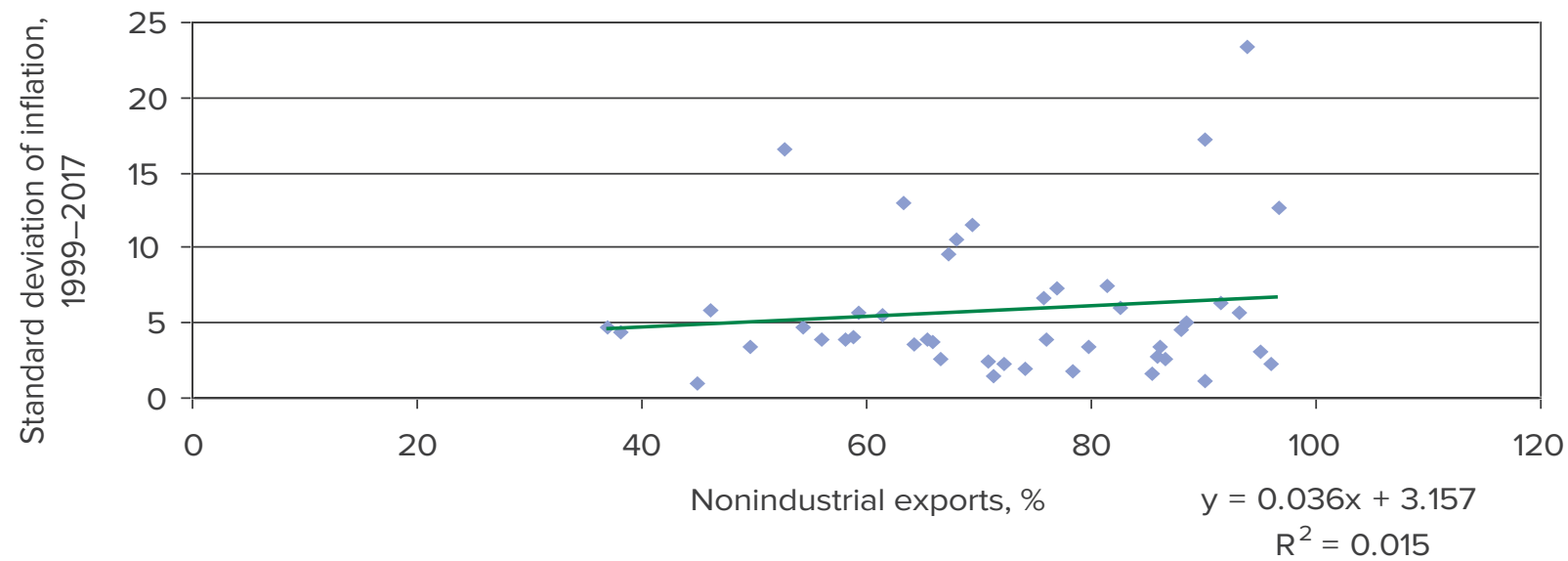




\section{APPENDIX C}

Table C1. Monetary effects of the commodity cycle by political regime

\begin{tabular}{|c|c|c|}
\hline & \multicolumn{2}{|c|}{ Democracies } \\
\hline & Weak & Strong \\
\hline Examples & $\begin{array}{l}\text { Ukraine, Latin } \\
\text { America before the } \\
\text { 2000s, Venezuela }\end{array}$ & $\begin{array}{l}\text { Norway, New Zea- } \\
\text { land, Australia }\end{array}$ \\
\hline General description & $\begin{array}{l}\text { Competition for rent } \\
\text { access. Establish- } \\
\text { ment of such control } \\
\text { is unsustainable. } \\
\text { Social populism } \\
\text { feeds on temporarily } \\
\text { captured rent and is } \\
\text { a way of sustaining } \\
\text { such control }\end{array}$ & $\begin{array}{l}\text { Political institutions } \\
\text { are formed that } \\
\text { reduce the impact of } \\
\text { rent on the existing } \\
\text { political process, } \\
\text { while rent is dis- } \\
\text { tributed according } \\
\text { to a certain social } \\
\text { optimum }\end{array}$ \\
\hline
\end{tabular}

A propensity to seek an optimal policy mix to neutralize impacts of commodity price volatility

The political factor of macro-instability

Monetary effects at the stage of a boom in commodity prices complete or un-
Weak or nonexistent. Discretion constraints by each competitor will be seen as a potential narrowing down of options when taking power

Strong

Inflation acceleration resulting from an extended nominal base of social populism. Overestimation of the real value of the exchange rate and external liabilities
The formation is derway. The policy mix reduces the vulnerability of social welfare to the negative macrofinancial outcomes of the commodity cycle

Weak

Inflation acceleration is possible. But a combination of policy-mix tools holds back the pro-cyclical effects of commodity price growth on major line of pressure commodity price growth stage)

Monetary effects at the stage of a drop in commodity prices
A tendency towards the blocking of counter-cyclical decisions

Inflation acceleration as exchange rate falls, and fiscal dominance, which is intensified after the economy is weaned off the "commodity drug"
Not deemed acceptable

A certain slowdown is possible due to recession, but a decrease in the exchange rate may raise inflationary pressure somewhat in the case of there being strong spillover effects
None. Discretion constraints are incompatible with the very principle of rent conversion into personal wealth

\section{Potentially strong}

More rapid inflation and growth of external debt, due to a newly apparent possibility to expand the expropriation base

A tendency towards the stimulation of pro-cyclicity
The political regime helps neutralize the risk of rent wasting and eliminate negotiation costs. Monopolized rent is distributed to support a certain social welfare level to buy loyalty

The formation is complete or underway. The policy mix allows for savings that lower the vulnerability to shocks and thereby ensure social welfare to an extent

Weak or meager

Inflation can accelerate. But a combination of policy-mix tools holds back the pro-cyclical effects of commodity price growth. However, control over budget talks expands options to support the current account surplus

Counter-cyclical decisions are doled out in the context of the application of external asset accumulation instruments

More rapid inflation and devaluation on the back of a weakening economy and its inability to adjust to shocks

A balance between inflation, devaluation, loss of external assets, and fiscal expansion to preserve a certain political and social status quo during adjustments to shocks 
Table C1. Monetary effects of the commodity cycle by political regime (continuation)

\begin{tabular}{|c|c|c|c|c|}
\hline & \multicolumn{2}{|c|}{ Democracies } & \multicolumn{2}{|c|}{ Autocracies } \\
\hline & Weak & Strong & Expropriatory & Prudent \\
\hline $\begin{array}{l}\text { The major line of pressure } \\
\text { on the central bank (at the } \\
\text { commodity price deflation } \\
\text { stage) }\end{array}$ & $\begin{array}{l}\text { A tendency towards } \\
\text { supporting economic } \\
\text { stimulus measures. } \\
\text { Pro-cyclical mani- } \\
\text { festation of social } \\
\text { populism }\end{array}$ & $\begin{array}{l}\text { Not deemed accept- } \\
\text { able }\end{array}$ & $\begin{array}{l}\text { A tendency towards } \\
\text { economic stimulus } \\
\text { to restore the former } \\
\text { scale of expropria- } \\
\text { tion }\end{array}$ & $\begin{array}{l}\text { Stimuli are doled out } \\
\text { in the context of opti- } \\
\text { mizing the trajectory } \\
\text { of external assets } \\
\text { reduction }\end{array}$ \\
\hline Consequences for inflation & Rapid and unstable & $\begin{array}{l}\text { Slow, with low } \\
\text { volatility }\end{array}$ & Rapid and unstable & $\begin{array}{l}\text { Slow, with low } \\
\text { volatility }\end{array}$ \\
\hline $\begin{array}{l}\text { The set of policy-mix op- } \\
\text { tions }\end{array}$ & $\begin{array}{l}\text { From fixed exchange } \\
\text { rate to a technically } \\
\text { independent central } \\
\text { bank. Discretionary } \\
\text { fiscal policy }\end{array}$ & $\begin{array}{l}\text { Price stability (infla- } \\
\text { tion targeting), flex- } \\
\text { ible exchange rates, } \\
\text { fiscal regulations (+ } \\
\text { fiscal buffers) }\end{array}$ & $\begin{array}{l}\text { Transitional ex- } \\
\text { change rate regimes, } \\
\text { low central bank } \\
\text { independence, } \\
\text { discretionary fiscal } \\
\text { policy }\end{array}$ & $\begin{array}{l}\text { Price stability is } \\
\text { achieved through } \\
\text { limited exchange } \\
\text { rate fluctuations, } \\
\text { counter-cyclical fiscal } \\
\text { buffers, and external } \\
\text { asset accumulation }\end{array}$ \\
\hline
\end{tabular}




\title{
HOW DOES FISCAL POLICY AFFECT GDP AND INFLATION IN UKRAINE?
}

\author{
ARTEM VDOVYCHENKOa* \\ aNational Bank of Ukraine \\ Email: artem.vdovychenko@bank.gov.ua
}

\begin{abstract}
In this study, we apply the Blanchard-Perotti approach to estimating the impact of fiscal policy on GDP and inflation in Ukraine. By disaggregating fiscal data, we were able to determine which items of the budget have the most influence on real GDP and inflation. Our results show that fiscal multipliers in Ukraine in absolute values are higher for budget expenditures than for taxes. In addition, both budget expenditures and taxes have a positive impact on inflation.
\end{abstract}

JEL Codes E62, H3, H61, C22

Keywords fiscal multiplier, fiscal policy, fiscal shocks, VAR

\section{INTRODUCTION}

The assessment of fiscal policy effects becomes an urgent problem, particularly in periods of economic crises, when monetary instruments have exhausted their potential to influence an economy (Bonam et al., 2017). The conventional indicator of the strength and persistence of fiscal policy effects on economic dynamics is the fiscal multiplier, which reflects the transitive effect of discretionary fiscal policy on the level of output of the economy (Batini, Eyraud, and Weber, 2014). The threats of the growth of public debt and the loss of fiscal sustainability restrict the use of fiscal stimuli, so the choice between increasing the budget deficit and the rate of economic growth is often conditioned by the values of fiscal multipliers.

A proper assessment of the values of fiscal multipliers is thus necessary in order to take valid fiscal decisions that will contribute to the achievement of economic goals and that will not cause significant growth in public debt. The results of such assessments can also be used when carrying out a tax (fiscal) reform that involves making decisions about changes in particular taxes and budget expenditures. Understanding of the quantitative impact of fiscal decisions on the economy also provides an opportunity to improve the quality of macroeconomic forecasts, including predictions for inflation. Given that inflation is one of the primary areas of interest for a central bank, estimating fiscal multipliers is of practical value when the National Bank of Ukraine (NBU) is taking monetary policy decisions.

In this study, based on Ukrainian data, we estimate several fiscal multipliers for the most important categories of budget expenditures and revenues, applying the standard SVAR methodology. We also extend the standard model for estimating fiscal multipliers (Blanchard and Perotti, 2002) by including in our analysis inflation, and assess the response of prices to fiscal policy shocks. This work differs from similar studies on emerging market economies (Rukelj, 2009; Ilzetzki et al., 2011) in that the impact of fiscal policy on real GDP and inflation is estimated for a wide range of categories of budget revenues and expenditures. Little attention is paid in the scientific literature to estimating fiscal multipliers for emerging markets, and this article is a contribution to such research in the literature.

The paper is organized as follows. The second section provides an analysis of views on the values of fiscal multipliers, and a review of empirical results on the estimation of the multipliers. In the third section, we describe the method used to analyse the impact of budget items on GDP and inflation. The data are described in the fourth section. In the fifth section, we present empirical results. The sixth section presents conclusions and a discussion of the results.

\section{LITERATURE REVIEW}

The fundamental issue is the ability of fiscal policy to stimulate economic growth, and this discussion boils down to the estimation of fiscal multipliers. According to Fatás and Mihov (2009), adherents of the idea of fiscal stimulation have a set of arguments that can be briefly grouped in the following way:

- empirical studies indicate that, on average, fiscal multipliers have a value higher than one. That means that stimulating economic growth via increasing budget expenditures or decreasing taxes is effective only if one additional dollar of fiscal stimuli causes the growth of real GDP of more than one dollar;

- periods of recession free up factors of production, and under such conditions fiscal multipliers can have heightened values; 
- with respect to the standard Keynesian model, the fiscal multiplier is an increasing function for the marginal propensity to consume (MPC), and thus in low-income economies it is higher in comparison to advanced economies, because MPC is relatively high;

- under conditions in which monetary policy is restricted by the zero lower boundary on the key interest rate, fiscal policy can be used to conduct a counter-cyclical economic policy.

An opposing view on the problem of the effectiveness of fiscal stimulation is based on the following arguments (Hasset, 2009):

- there are neoclassical effects in an economy, in the form of Ricardian equivalence, which means that fiscal stimuli in the current period are taken by economic agents as a signal that there will be an increase in the fiscal pressure on the economy in future, and, resultantly, consumption and investments do not increase due to this negative expectation;

- fiscal stimuli cause crowding-out effects - an increase in interest rates and/or an appreciating exchange rate decelerates the growth rates of an economy;

- a line of research initiated by Giavazzi and Pagano (1990) indicates that there is a positive economic effect from fiscal consolidation;

- the short-run effects of fiscal stimulation are debatable, while there is consensus that they have a negative impact on output in the long-run (Alesina et al., 2002; Barro, 1991);

- fiscal policy is only part of the mechanism for bringing an economy out recession: economic recovery is unlikely to start without a restructuring of the financial sector and changes in monetary policy;

- fiscal incentive programs are hard to remove over the long run because of political considerations. Thus, with time, fiscal stimuli jeopardize fiscal sustainability and act to amplify economic dynamics;

- fiscal policy can be considered ineffective for stimulating economic growth if a fiscal multiplier is less than 1 (1 additional monetary unit of fiscal incentives causes GDP growth of less than 1 monetary unit). However, fiscal multiplier estimates in empirical studies produce such values very often;

- fiscal stimuli are introduced with a significant lag, and as a result cannot react properly to economic parameters;

- markets know better how to restore economic growth;

- fiscal stimulation programs often serve the narrow political and economic interests of certain persons, and are not oriented to macroeconomic requirements.

The values of fiscal multipliers are usually determined by the structural characteristics of an economy, which include the following:

- trade openness. For economies that are less opened to imports, multipliers are higher, because demand is oriented to domestic output;
- labor market rigidity. Economies with more rigid labor markets have higher fiscal multipliers, as increases in demand are not neutralized by wage growth;

- the power of automatic stabilizers. Powerful automatic stabilizers decrease the values of fiscal multipliers because their reaction to exogenous fiscal stimuli leads to the partial neutralization of the effects of an initial fiscal shock on GDP;

- exchange rate regime. States with flexible exchange rates usually have lower fiscal multiplier values, as the reaction of the exchange rate partially diminishes the impact of fiscal shocks;

- the level of public debt. States with a high debt ratio have lower fiscal multiplier values, as in such an environment Ricardian effects are more pronounced. When there is a high public debt, fiscal consolidation (not stimulation) is more likely to have a positive impact on the economy, through rebuilding government credibility and reducing the risk premium;

- the efficiency of the management of budget expenditure and the administration of taxes. Fiscal multiplier values are lower when complicated tax administration procedures and inefficient budget spending restrict the impact of fiscal policy on an economy;

- the phase of the business cycle. In periods of recession, fiscal multipliers are higher than in growth periods. Fiscal stimuli are less effective when there is a positive GDP gap, because the factors of production are at full capacity. This leads to the crowding-out of private demand by the public sector, leaving the level of output unchanged and stimulating inflation. At the same time, fiscal consolidation during downturns causes higher losses for the economy than in other periods, because economic agents under funding constraints are unable to smooth their consumption.

- the reaction of monetary policy to fiscal shocks. Loose monetary policy can mitigate the effect of fiscal consolidation, and vice versa. Fiscal multipliers can also be high at times when monetary instruments cannot be applied - for example in the case of a zero lower bound of interest rates.

An overview of the values of fiscal multipliers in economies of different types is given in Batini, Eyraud, and Weber (2014). For advanced economies in "normal times," the values of multipliers range from 0 to 1 in the first year after a fiscal shock. In periods of recession, multipliers have increased values. The literature suggests that multipliers of budget expenditure are on average higher than tax multipliers.

There is a lack of studies of fiscal multipliers in emerging market economies (EMEs) and low-income countries (LICS). It is also difficult to determine with precision in which direction the fiscal multipliers in such countries will deviate, compared to in advanced economies. The values of fiscal multipliers are increased by a set of factors: higher propensity to consume due to an underdeveloped financial market and uncertainty about the future; the response of monetary policy is less effective; the effect of automatic fiscal stabilizers is weak; and there is a low public debt ratio. On the other hand, some of the following factors reduce the potential value of fiscal multipliers in EMEs and LICs: savings (unorganized) can be higher in an environment with high uncertainty; the inefficient management of budget expenditures and administration of taxes; and the fact that such economies are usually small and open. 
An analysis of the empirical literature indicates that there can be an impact of fiscal policy on GDP and inflation through both the demand and the supply sides of an economy. In Perotti (2002), the author, expanding the technique proposed in Blanchard and Perotti (2002), investigates the effect of fiscal policy not only on GDP but also on inflation and real short-term interest rates. According to the results, the author concludes that after the 1980s fiscal multipliers in OECD member states significantly decreased. A positive impact of government spending on inflation was detected, although it was not always statistically significant. Taxes have a weak impact on price levels, which is usually negative.

Parkyn and Vehbi (2014) use a technique similar to Perotti (2002) with New Zealand data, but include the dynamics of public debt as a separate equation in their model. Their analysis of the effects of fiscal policy indicates a comparatively low but statistically significant fiscal multiplier for budget expenditures, and a low and statistically insignificant multiplier for taxes. At the same time, no significant influence of fiscal policy on price levels was found.

Unal (2015) used an SVAR model to study the effects of various categories of taxes on prices, interest rates and various components of GDP for the United States, Canada, France and the United Kingdom. According to the results, social contribution shocks had a mixed effect on GDP and inflation in different countries, indicating the dominance of a particular macroeconomic effect in a particular country. The shock of indirect taxes in the study leads to a decrease in GDP and inflation, reflecting a decline in demand from households. The shock of the personal income tax (PIT) in the majority of cases leads to a drop in GDP, while the effect on inflation is rather mixed. A corporate income tax (CIT) shock in all countries, apart from in the United Kingdom, leads to a positive response for GDP and inflation. The positive impact on GDP mainly comes through investments. The authors put this reaction down to the predominance of the wealth effect on the supply side. However, such an impact on GDP can also be explained by the fact that investments are usually subtracted from the taxable profits of enterprises, meaning that an increase in investment is a method of optimizing tax payments in response to an increase in tax rates. Similar effects of CIT were found in Arin and Koray (2006) and Guntram et al. (2006).

A study by Nguyen et al. (2016) investigates the macroeconomic effects of income and consumption taxes in the UK. For their analysis, the authors apply a relatively new proxy-SVAR methodology (Mertens and Ravn, 2013). The authors include tax payments that are accrued on individual and corporate income (PIT, CIT, and social contributions) in the group of income taxes. Taxes on consumption include VAT, various duties, and excise taxes. According to the results, an increase in income taxes has a significant negative effect on GDP, while an increase in consumption taxes has a neutral effect. The impact on the price level is positive for both taxes, but is more pronounced for taxes on consumption. The authors state that raising price levels in response to a shock in income taxes is evidence of supply-side effects, since taxes are taken into account when the cost of production is set. At the same time, the positive effect of consumption taxes on prices is an accounting phenomenon, since such taxes are directly included in the price structure.
In Arin et. al. (2016) the authors use a standard SVAR approach to assess multipliers for various taxes in the United States. The results demonstrate that the shocks of distorting taxes (CIT, PIT, social contributions) have long-term negative effects on GDP, and a moderate, positive influence on inflation (mainly through PIT). Shocks in consumption taxes, instead, have a weaker, short-term negative effect on GDP, and a more pronounced positive effect on inflation.

Mertens and Ravn (2013) estimate the impact of individual income taxes (PIT and social contributions) and CIT on a number of macroeconomic variables. They develop a method of estimation (proxy SVAR), which combines the best properties of the Blanchard-Perotti approach and the narrative approach proposed by Romer and Romer (2010). The results indicate that taxes on individual income are more effective in stimulating employment and private consumption than CIT. With regard to GDP, the multiplier of taxes on individual income is also much higher. A shock in CIT has a significant positive effect on price levels, testifying, according to the authors' conclusions, to the dominance of supplyside effects. The impact of individual income taxes on prices is also positive, although not statistically significant.

Researchers from the European Central Bank assessed the impact of fiscal shocks on the Spanish economy in de Castro and de Cos (2006). They applied a standard SVAR approach not only to different categories of taxes, but largely disaggregated budget expenditures as well. According to their results, the impact of aggregate budget expenditures on GDP is positive and fairly persistent. At the same time, the shock of budget expenditures leads to a significant increase in price levels. The impact of tax shocks on GDP is negative in the long run, but the magnitude of the tax multiplier is lower than for budget expenditures. In the study, budget expenditures were disaggregated into consumption, public sector wages, and public investments. According to the study, the effect of the first two categories of expenditures on GDP is positive in the short-run, and negative in the medium-term. The authors conclude that this result was due to the crowding-out effect, and upward pressure of public sector wages on wages in the private sector. The impact of public investments on GDP is positive and more persistent. Shocks to all budget expenditure categories stimulated inflation in the medium-term. Taxes were separated into direct taxes, indirect taxes, and social security contributions. The results indicate that shocks in indirect taxes do not have any pronounced effect on GDP. Shocks in direct taxes and social security contributions have a negative impact on GDP in the mid-term. The impact on prices varies considerably depending on the tax - indirect taxes have a positive effect on inflation, direct taxes are neutral, and social security contributions depress inflation due to their negative impact on GDP.

The general conclusion from the literature is that shocks to budget expenditure stimulate GDP growth through both the supply and demand sides. Expenditures also stimulate the growth of prices, which is consistent with increasing demand in an economy. Shocks in distortive taxes ${ }^{1}$ have a significant negative impact on GDP: this testifies to the predominance of demand-side effects. The exception is basically the corporate income tax, which often demonstrates a positive impact on GDP, indicating the wealth effect on the economy. The impact of taxes on prices is quite mixed. Shocks in consumption taxes usually lead to an increase in prices, which

${ }^{1}$ Taxes on capital and labor. 
is the supply-side effect. In some studies, shocks of taxes on income also cause price hikes, indicating the importance of the supply side in the price determination process.

The final study, and, to our knowledge, the only research done on fiscal multipliers for Ukraine, is a study by Mitra and Poghosyan (2015), in which the authors use an SVAR mode and identification scheme similar to that of Blanchard and Perotti (2002). The estimates were made using quarterly data for the period 2001-2013, which does not include the crisis of 2014-2016 for Ukraine. According to the results, in the first quarter after a shock, the fiscal multiplier of budget expenditures is 0.4 , and $(-0.3)$ for taxes. Tax and expenditure multipliers, which are low and have similar values on impact, are quite different in terms of dynamics. The tax multiplier loses its statistical significance after the first quarter, while the expenditure multiplier is more persistent, and loses its statistical significance only after six quarters, reaching a cumulative value of 2.86 over eight quarters (for the tax multiplier this indicator is insignificant, and equals (-0.96)). Given that the 2014-2016 period was one of crisis for the Ukrainian economy, the values of fiscal multipliers, if estimated using an updated dataset, could be very different. As shown in Auerbach and Gorodnichenko (2012), fiscal multipliers are significantly higher in periods of recession.

While SVAR models are the most popular toolkit for estimating the impact of fiscal policy on real GDP and inflation, the results of these estimations vary widely and can be used in support of completely different economic theories. The variability of the estimates suggests that there are numerous factors in an economy that can both exacerbate and weaken the impact of fiscal policy on the economy. There is some consensus in economic theory that the values of fiscal multipliers are nonlinear, the multipliers of budget expenditures are higher than tax multipliers, and developed economies are more sensitive to fiscal policy shocks than emerging markets. However, little is known about the impact of certain categories of budget expenditures and taxes on real GDP and inflation. Using the example of Ukraine, we are conducting research aimed at filling this gap in knowledge.

\section{METHODOLOGY}

We have divided the description of our methodology into two parts. First, we discuss the estimation of fiscal policy effects on GDP within the framework of an SVAR model with three endogenous variables. After that, we construct a second model, into which we add inflation as a fourth endogenous variable, impose additional identifying restrictions, and assess the impact of fiscal policy on price dynamics. The two models differ in terms of how the variables are converted into real terms. In the first model, budget expenditures, taxes and GDP are converted into 2010 prices via a GDP deflator. In the second case, the fiscal indicators were converted into 2010 prices through the application of the consumer price index. This use of different data transformations greatly simplifies the identification of the system of structural equations for the second model, and makes these restrictions more intuitive.

\subsection{Analysis of the impact of fiscal policy shocks on GDP}

To estimate linear fiscal multipliers, we use SVAR models and identification schemes similar to those used by Blanchard and Perotti (2002). In accordance with this approach, we construct the following VAR model:

$$
\mathrm{Y}_{\mathrm{t}}=\sum_{\mathrm{i}=1}^{\mathrm{k}} \mathrm{C}_{\mathrm{i}} \mathrm{Y}_{\mathrm{t}-\mathrm{i}}+\sum_{\mathrm{j}=1}^{\mathrm{p}} \mathrm{D}_{\mathrm{p}} \mathrm{Z}_{\mathrm{t}}+\mathrm{U}_{\mathrm{t}}
$$

where $Y_{t} \equiv\left[G_{t}, T_{t} X\right]_{t}^{\prime}$ is a three-dimensional vector of observations for budget expenditures, taxes, and GDP, $Z_{t}$ - is a vector of exogenous variables that includes deterministic components (linear and quadratic trends, seasonal variables, dummy variables that denote structural breaks in time series, or excessive deviations) and variables that can be important determinants of endogenous variables, $U_{t} \equiv\left[g_{t} t_{t} x_{t}\right]^{\prime}-$ a vector of normally distributed residuals, which have non-zero correlation, $C_{i}$ - coefficients of endogenous variables, and $D_{p}$ - coefficients of exogenous variables. The residuals of model (1) are interpreted as a linear combination of the simultaneous effects of the variables on each other, and the shocks. At the next stage, according to the Blanchar-Perotti approach, we estimated the parameters of system (2):

$$
\left\{\begin{array}{l}
g_{t}=a_{1} x_{t}+a_{2} e_{t}^{t}+e_{t}^{g} \\
t_{t}=b_{1} x_{t}+b_{2} e_{t}^{g}+e_{t}^{t} \\
x_{t}=c_{1} t_{t}+c_{2} g_{t}+e_{t}^{x}
\end{array}\right.
$$

where $e_{t}^{t}, e_{t}^{g}, e_{t}^{x}$ - are mutually uncorrelated structural shocks with unit variance. ${ }^{2}$ The problem is that the coefficients $a_{1}, b_{1}$ $c_{1}$ and $c_{2}$ cannot be estimated without bias because of endogeneity - there is a mutual instantaneous influence of GDP and taxes (expenditures). To resolve this issue, identifying restrictions are needed. ${ }^{3}$ To impose these restrictions, we use the fact that because of institutional features, governments cannot react to GDP changes by changing budget expenditures within one quarter. That means the coefficient $a_{1}=0$. The coefficient $b_{1}$ indicates the automatic reaction of tax revenues to GDP changes, and is estimated exogenously. In Blanchard and Perotti (2002) this coefficient is estimated as cross-elasticity, calculated as a product of the tax base elasticity of taxes, and the GDP elasticity of tax bases. In some cases, the authors use coefficients calculated by Giorno et al. (1995). In our study, we derive the coefficient $b_{1}$ from a cointegration equation of the corresponding tax revenues and GDP, which is estimated using DOLS (dynamic ordinary least squares) ${ }^{4}$, as proposed in Stock and Watson (1993).

Having information on $a_{1}$ and $b_{1}$ we can apply two-stage least squares (TSLS) to estimate the coefficients $c_{1}, c_{2}$, using as instruments $g_{t}$ and $\hat{t}_{t}=t_{t}-b_{1} x_{t^{\prime}}$ Restrictions on $a_{2}, b_{2}$ are related to assumptions about the ordering of the decisionmaking process for fiscal policy. The restriction $a_{2}=0$ means that at first, decisions are made on budget expenditures $\left(g_{t}\right)$, while the volume of taxes $\left(t_{t}\right)$ responds within a quarter, and the strength and direction of response is determined by the estimated coefficient $b_{2}$. The reverse logic works when the restriction imposed is $b_{2}=0$. Given the realities of the Ukrai-

\footnotetext{
${ }^{2}$ In other words, the variance-covariance matrix is the identity matrix.

${ }^{3}$ To precisely identify the system of equations, we need a number of constraints equal to $K^{2}+K(K-1) \times 0.5$, where $K$ is the number of endogenous variables. That is, to identify the system (2) it is necessary to impose 12 restrictions

${ }^{4}$ The essence of approach is to run a regression: $T_{t}^{r}=\beta_{1}^{r} X_{t}^{r}+\sum_{n=1}^{N} \gamma_{n}^{r} D_{n, t}^{r}+\sum_{i=1}^{I} \gamma_{i}^{r} S_{i, t}^{r}+\sum_{n=1}^{N} \sum_{j=-p}^{q} \alpha_{n, j} \Delta X_{n, t-j}^{r}+\varepsilon_{t}^{r}$, where $T_{t}^{r}-\operatorname{tax}$ receipts $r, X_{t}^{r}-\operatorname{tax}$ base of $r, D_{n, t}^{r}$ - potential deterministics $n$ (constants, linear or quadratic trends), $S_{i, t}^{r}$ - potential structural breaks in the data (impulses, level shifts, trend changes), $\varepsilon_{t}^{r}$ - stationary errors that denote deviations from long-run equilibrium.
} 
nian budget process, we would assume that decisions about budget expenditures are ordered first, and taxes are adjusted in response. Thus, for all models in our study, we impose restriction $a_{2}=0$ and estimate $b_{2}{ }^{5}$

As exogenous variables to control for the economic environment that affects the values of fiscal multipliers, we used the ratio of the current account to GDP, the real money supply (monetary aggregate M3, corrected with a deflator), and the debt-to-GDP ratio. The inclusion of these variables in the analysis is required because the trade openness of an economy, the level of public debt, and the state of monetary policy affect the size of fiscal multipliers. These variables are common exogenous components of empirical models for the estimation of fiscal multipliers (Ilzetzki et al., 2011, Mitra and Poghosyan, 2015).

The VAR models (1) were constructed in levels to take into account the very probable cointegration between endogenous variables. We also included linear and quadratic trends to control for the fit of cointegrating relationship.

The baseline model contains aggregate budget expenditures and taxes as endogenous variables describing fiscal policy. For the disaggregated analysis, we also built a series of models that include revenues from individual taxes instead of aggregated tax revenues (VAT, corporate income tax (CIT), personal income tax (PIT), import duties, social contributions), as well as separate budget expenditure items instead of aggregate expenditures (wages, expenditures on goods and services, capital expenditures, current transfers to the population) and retirement expenses of the Pension Fund of Ukraine (PFU). The initial specification of all VARs contained four lags, which in our opinion is a rational choice, considering the limited number of observations and the annual nature of the payment of some taxes. Information criteria in most cases required a large number of lags, reducing the number of degrees of freedom of the models. At the same time, the Bayesian information criterion usually suggested 1-2 lags in a VAR, but this was not enough to eliminate autocorrelation from errors. To mitigate the issue of limited degrees of freedom, we restricted the individual parameters of the VARs depending on their statistical significance. Appropriate restrictions were imposed through a sequential elimination algorithm based on a top-down procedure, which employed the Akaike information criterion (AIC) for model selection. This allowed statistically insignificant coefficients to be excluded from the model, and to reduce the number of parameters for estimation.

Since the residuals of a VAR model should be normally distributed and not autocorrelated, we added dummy variables to control for structural changes in the economy and to avoid outliers in errors. For example, such dummies were introduced for the $4^{\text {th }}$ quarter of 2008 and $1^{\text {st }}$ quarter of 2014, when Ukraine experienced significant political and economic upheaval. Dummies were also introduced for the 3rd quarter of 2010, when a significant reimbursement of VAT occurred through the emission of VAT bonds, artificially reducing the revenues from this tax.

\subsection{Analysis of the impact of fiscal shocks on inflation}

In a number of studies (Perotti, 2002; Parkyn and Vehbi, 2013), the transmission of fiscal policy shocks to inflation is investigated by adding the interest rate and consumer price index (CPI) to the endogenous variables of the baseline model (1). The inclusion of the interest rate in the model is intended to take into account the monetary policy stance and its response to shocks to other variables in the model. In the Ukrainian case, the inclusion of the interest rate in the model is not relevant, as there is no clear definition of the key interest rate of the National Bank of Ukraine (NBU) for the investigated period (2001-2016) and, during most of this period, monetary policy was not focused on inflation targeting. Another argument against the inclusion of interest rate in our analysis is the scarcity of observations, which would bring into question the consistency of VAR estimates with five endogenous variables.

The inclusion of the CPI as a fourth endogenous variable requires the imposition of new restrictions on the matrices $A$ and $B$ that are used in the SVAR analysis. The system of equations (2) in a matrix form with the inclusion of inflation can be rewritten as follows:

$\left[\begin{array}{cccc}1 & 0 & 0 & \alpha_{\pi}^{g} \\ 0 & 1 & -1,2 & \alpha_{\pi}^{t} \\ \alpha_{g}^{x} & \alpha_{t}^{x} & 1 & \alpha_{\pi}^{x} \\ \alpha_{g}^{\pi} & \alpha_{t}^{\pi} & \alpha_{x}^{\pi} & 1\end{array}\right]\left[\begin{array}{l}g_{t} \\ t_{t} \\ x_{t} \\ \pi_{t}\end{array}\right]=\left[\begin{array}{cccc}\beta_{g}^{g} & 0 & 0 & 0 \\ \beta_{g}^{t} & \beta_{t}^{t} & 0 & 0 \\ 0 & 0 & \beta_{x}^{x} & 0 \\ 0 & 0 & 0 & \beta_{\pi}^{\pi}\end{array}\right]\left[\begin{array}{c}e_{t}^{g} \\ e_{t}^{t} \\ e_{t}^{x} \\ e_{t}^{\pi}\end{array}\right]$

To get a just identified system of equations, $K^{2}+K(K-1) \times 0.5$, restrictions are needed, where $K$ is the number of endogenous variables. In the case of (3), 22 restrictions are necessary. In the system of equations (3), 11 restrictions are imposed on the covariance of the shocks in matrix $B$, four restrictions are given by diagonal elements of matrix $A$, and also four restrictions imposed on the instantaneous impact of variables on each other in matrix $A .{ }^{6}$ The logic of imposing these restrictions is discussed above, with the description of Blanchard-Perotti's approach to the estimation of fiscal multipliers. The remaining three restrictions should be imposed on the coefficients reflecting the impact of inflation on other endogenous variables within one period $\alpha_{\pi}^{g}, \alpha_{\pi}^{t}, \alpha_{\pi}^{x}$. To analyze the impact of fiscal policy on inflation, we have converted budget expenditures and taxes into 2010 prices by applying the CPI. Meanwhile, we left unchanged real GDP, which was converted into 2010 prices with the help of a deflator. Such a transformation of the data makes the restrictions on the parameters $\alpha_{\pi}^{g}, \alpha_{\pi}^{t}, \alpha_{\pi}^{x}$ more intuitive, and makes the results more relevant, because expenditures and taxes primarily affect aggregate consumption. Since expenditures and taxes were converted in real terms by CPI, their inflation elasticity should be (-1) by definition. However, there may be different types of real variables reacting to inflation, which determines the meaning of the restrictions $\alpha_{\pi}^{g}, \alpha_{\pi}^{t}$ (Table 1).

To impose restrictions on $\alpha_{\pi}^{g}, \alpha_{\pi}^{t}$ we employed the logic of Perotti (2002). It is unlikely that wages in the public sector are indexed instantaneously with price increases, so the CPI elasticity of expenditures on wages should be (-1). The same can be said of social expenditures. Expenditures on the purchase of goods and services are partially indexed,

${ }^{5}$ Note that if the estimated coefficient $b_{2}$ is statistically insignificant, then the order of imposing restrictions is not important and the change of assumptions regarding priority of decisions in fiscal policy does not impact the overall result.

${ }^{6}$ Restriction (-1.2) identifies the automatic reaction of taxes to GDP fluctuations within one period. 


\section{Table 1. Variants of restrictions on elasticity of real variable in relation to inflation}

\begin{tabular}{ll}
\hline Elasticity & \\
\hline$\varepsilon_{z, \pi}<-1$ & Variable $z$ decreases when inflation increases \\
$\varepsilon_{z, \pi}=-1$ & Variable $z$ doesn't react \\
$\varepsilon_{z, \pi} \in(-1.0)$ & Variable $z$ increases, with growth rate lower than growth rate of inflation \\
$\varepsilon_{z, \pi}=0$ & Variable $z$ increases, with the same growth rate as inflation \\
$\varepsilon_{z, \pi}>0$ & Variable $z$ increases, with growth rate higher than growth rate of inflation \\
\hline
\end{tabular}

since procurement plans must be implemented, but indexation is not complete due to budget constraints. For such expenses, Perotti proposes imposing a restriction (-0.5). In our study, we impose the following restrictions for $\alpha_{\pi}^{g}$ : aggregate budget expenditures $(-0.8),{ }^{7}$ wages in the public sector $(-1)$ expenditures on goods and services (-0.5), capital expenditures $(-0.5)$, and current transfers to the population $(-1)$.

Tax revenues can also respond differently to CPI. All consumption taxes vary proportionally to price levels, therefore the inflation elasticity of VAT and customs was set at 0 . There is no obvious relationship between CIT and inflation that is fortified by economic logic. Empirical studies (Persson et al., 1996) demonstrate the complexity of identifying a stable statistical relationship between the price level and $\mathrm{CIT}$. For this reason, the elasticity between these variables also was restricted to 0 . Inflation elasticity of PIT and social security contributions can be calculated by subtracting 1 from the elasticity of tax revenues per person to average real earnings (Perotti, 2002). In OECD countries, this elasticity is higher than one, so the specified restriction is usually set at 0.3-0.5. That means there is a quite high correlation between income and $\mathrm{CPI}$, and that the income tax is progressive, since tax revenues grow at a higher pace than income and inflation. These characteristics are non-typical for the tax system of Ukraine. PIT in Ukraine has a flat tax rate, while the tax base mainly consists of wages that are unlikely to be corrected to the level of inflation simultaneously. The direct estimation of PIT elasticity to CPI by running ARDL regression gives a value of (-0.7). This means that the income of the population and the corresponding tax revenues and social security contributions only partially react to changes in $\mathrm{CPI}$ in the same quarter. Other tax revenues are considered not to be sensitive to $\mathrm{CPI}$ fluctuations within a quarter, so for them we assume an elasticity of (-1). The weighted average elasticity of tax revenues to $\mathrm{CPI} \alpha_{\pi}^{\alpha}$ is equal to $(-0.39){ }^{8}$

The last restriction on the coefficient $\alpha_{\pi}^{x}$ indicates the impact of inflation on GDP within a quarter. Since we are operating with real variables, the automatic reaction of GDP in the current quarter should be (-1). However, GDP was converted into real terms by a deflator, while we use the consumer price index as an inflation indicator. Thus, the automatic reaction of the real GDP must be equal to the negative value of deflator elasticity to $\mathrm{CPI}$. We have set the restriction on $\alpha_{\pi}^{x}$ at $(-0.3)$, since such elasticity was obtained when running ARDL with a deflator as an endogenous variable and $\mathrm{CPI}$ as an exogenous one.

\section{DATA}

In our study, we use quarterly data for the period of 2001-2016 years. All variables, except ratios to GDP, were converted into 2010 prices using the deflator for GDP. When estimating their effects on inflation, fiscal variables were converted to real prices using the $\mathrm{CPI}$. Also, all variables, except the public debt ratio and the ratio of the current account balance to GDP, were transformed into logarithms. All of the time series were seasonally adjusted using the Census X-12 algorithm, with the application of a multiplicative seasonal component, except for the current account balance to GDP ratio, where we assume the seasonal component is additive.

To estimate the base model, for budgetary expenditures we used primary budget expenditures minus current transfers and expenditures for the repayment of the pension fund deficit. By eliminating budget expenditures on financing of the pension fund deficit, we deviate from the standard methodology. The presence of such expenditures is a feature of the Ukrainian financial system, so it is not surprising that such adjustments are not made in similar studies. The elimination of expenditures for the repayment of the pension fund deficit is necessary, as they can contain an automatic reaction to GDP fluctuations, since social security contributions have a functional dependence on wages, while wages are correlated with GDP. This automatic reaction would violate the assumption that there is no reaction of budget expenditure to GDP changes within a quarter.

The decomposition of budget expenditures on various categories was conducted according to economic classification:

- budget expenditures on wages. Social security contributions, which are also paid from the budget, were excluded from this category, as the analysis is more suitable for the disposable income of employees in the public sector;

- expenditures on goods and services;

- capital expenditures;

- current transfers to the population, which include pensions, subsidies, scholarships, other payments to the population that also have a potential impact on GDP growth through stimulating consumption.

Also, we distinguish expenditures on pensions from the Pension Fund of Ukraine (PFU) as an individual category of expenditures.

\footnotetext{
${ }^{7}$ Weighted average elasticity according to the weights of wages, expenditures on goods and services, capital expenditures, current transfers to the population in overall budget expenditures.

${ }^{8}$ We set the following restrictions on the coefficient $\alpha_{\pi}^{t}$ for different taxes: VAT -0 , customs -0, CIT -0, PIT $-(-0.7)$, social security contributions $-(-0.7)$, total tax revenues $-(-0.3)$
} 
Taxes in the base model are the sum of all tax receipts of the consolidated budget of Ukraine. For disaggregated estimates, we used VAT, CIT, PIT, import customs and social security contributions.

\section{RESULTS}

\subsection{Fiscal multipliers of taxes and budget expenditures}

Estimated multipliers and graphs of the impulse response functions (IRF) are given in appendix A. ${ }^{9}$ In Table A1 in Appendix $A$ we also report restrictions on the coefficient $b_{1}$, indicating an automatic response of relevant taxes to GDP, and the results of estimates for $b_{2}, c_{1}$ and $c_{2}$. The results presented demonstrate not only the magnitude of the multipliers, but also their persistence. According to the base model, the fiscal multiplier on impact is much higher for taxes $(-0.43)$ than for budget expenditures, reaching a maximum cumulative value of $(-0.9)$ in the second quarter. For aggregate budget expenditures the impact multiplier is 0.26 while maximum cumulative value is 1.5 in the eighth quarter. The persistence of the two multipliers is different. Over a horizon of two years, the cumulative multiplier of budget expenditures remains statistically significant and is higher than unity. The cumulative tax multiplier approximates to zero after two years. This happens due to the values of the tax multiplier becoming positive after the third quarter. The positive effect of a tax shock on GDP after a short-term negative impact has two explanations. The first is the cross-impact of taxes on budget expenditures and GDP. According to the IRFs for tax shocks, budget expenditures respond positively, with a lag of three quarters. Since budget expenditures in our model have a positive multiplier, they also start to have a positive impact on GDP. The second explanation is based on the crowding-out effect. Increasing taxes leads to a drop in demand for money, and with the resulting fall in the level of interest rates GDP growth is stimulated..$^{10}$ However, we cannot confidently state that the crowding-out effect is present in the Ukrainian economy, since we do not include interest rates into our analysis explicitly.

The results for aggregated budget parameters are somewhat different from the values of the multipliers obtained in the IMF study (Mitra and Poghosyan 2015). The difference relates primarily to the budget expenditures multiplier, which cumulatively equals 2.9 after eight quarters and is more persistent than the multiplier for taxes. The discrepancy in the results is explained by the restrictions imposed on the coefficients $c_{1}$ and $c_{2}$ after the preliminary estimation. The coefficient, indicating the simultaneous impact of taxes on $\operatorname{GDP}\left(c_{2}\right)$, in our study approximately corresponds to the IMF value, and is (-0.11). ${ }^{11}$ These coefficients are close in their values, even despite the fact that the restriction on $b_{1}$ (the automatic effect of GDP on tax revenues within a quarter) in our study is $1.21{ }^{12}$ while in the IMF study this coefficient is 1.47. The significant difference relates to the restriction on $c_{1}$, which indicates the elasticity of GDP to budget expenditures within a quarter. In our case, $c_{1}=0.09$, while in Mitra and Poghosyan (2015) this coefficient was restricted to 0.14 Such a discrepancy in estimates may be explained by the differing approaches to the construction of the time series of budget expenditures. To establish the possible reasons for the discrepancies, as an experiment we carried out transformations on our data that made our sample similar to that used in (Mitra and Poghosyan, 2015): we restricted the data sample to the fourth quarter of 2013; eliminated current expenditures from primary budget expenditures, but did not make an adjustment for funding of the deficit of the pension fund. We imposed restriction $b_{1}=1.47$ and constructed a VAR model similar to IMF specifications. The estimations gave a cumulative multiplier for budget expenditures at the level of 2.4 after eight quarters, and an impact multiplier of 0.7. In Mitra and Poghosyan (2015), the respective multipliers are 2.8 and 0.43 . The tax multiplier in our case became very low and not statistically significant. In Mitra and Poghosyan (2015), the cumulative tax multiplier is (-0.96) after the eight quarters, $(-0.3)$ on impact, and also statistically insignificant after the first quarter. The growth of the budget expenditures multiplier and the drop in the tax multiplier, in our opinion, are related to the following factors:

the exclusion of transfers from budget expenditures increases the share of capital expenditures that have a high multiplier;

- the absence of an adjustment for funding of the pension fund deficit introduces potential endogeneity in estimates of structural coefficients;

the data sample in Mitra and Poghosyan (2015) does not cover 2014-2016, when there was a severe economic downturn - during such periods the values of multipliers can vary significantly.

In our estimates we do not exclude transfers from budget expenditures entirely, as this item of expenditure is very large and includes social security payments to the public. Potentially, these expenditures may have the impact on aggregate demand in the economy, and thus affect output.

\subsection{Multipliers of individual tax categories and budget expenditures}

An analysis of multipliers estimated for various categories of budget expenditure indicates that those items that should cause a direct influence on consumption (wages in the public sector, current transfers to the population, and pension expenditures of PFU) have low and statistically not significant multipliers. These results are close to the findings of de Castro and de Cos (2006) and suggest a weak response of consumption to shocks in such expenditures. Such a result may be caused by "Ricardian" sentiments in the economy, and the supply shock that happens when wage increases in the public sector put pressure on the equilibrium level of wages in the economy as a whole, reducing profits and investment (Alesina et al., 2002). The arguments in favor of this explanation are backed up by the strong inflationary effect of wage expenditures, as shown below.

The cumulative multiplier of expenditures on goods and services approaches 1 in the third quarter, and falls to zero

\footnotetext{
${ }^{9}$ Since all endogenous variables are in logarithms, the graphs reflect elasticities. In Table A1, elasticities are multiplied by the ratio of the average values of GDP to the target variable for reporting multipliers.

${ }^{10}$ The logic of the stimulating effect of raising taxes is given in Mankiw and Summers (1984).

11 In Mitra and Poghosyan (2015) this restriction equals (-0.12)

${ }^{12}$ The coefficient was derived from the cointegrating equation of taxes and GDP with inclusion of constant, linear trend, and dummies for the crises of 2004 , 2008, and 2014
} 
after two years. The peculiarity of this multiplier is that it is negative on impact. The values of this multiplier are somewhat abnormal, since budget expenditures of this kind should be drivers of economic growth. According to the results, public procurements have a moderate impact on real GDP and rather quickly stimulate CPI growth, as will be shown below. An analysis of the IRFs indicates that a shock in government procurements has a negative impact on real GDP on impact, because of its accelerating effect on CPI. To explain the causes of this anomaly, we further decomposed expenditures previously classified as expenses on goods and services into subcategories, with respect to the economic classification of these budget items:

- purchase of supplies and materials, payments for services and other expenditures;

- expenditures on business trips;

- materials, inventory, construction, overhaul and specia purpose measures that have national importance;

- expenditures on utilities and energy resources;

- research and development, state programs.

Since a number of expenditures from the list above have no obvious positive impact on GDP, we eliminated expenditures on business trips, research and development, and on state programs. After that, we constructed the IRFs for the shock of adjusted expenditures on goods and services, following the methodology applied in this study. The results in Appendix $B$ indicate that the removal of potentially "unproductive" categories of expenditures from government consumption significantly raises the fiscal multiplier (cumulative multiplier after eight quarters is 3.3 against $(-0.07)$ before the adjustment) and significantly reduces the positive response of inflation (on impact the effect is $0.054 \%$, against $0.13 \%$ before adjustment). These results indicate that government consumption has a high multiplier and a moderate impact on inflation. This experiment also demonstrates that inside the categories of aggregated budget expenditures, there are subcategories that can vary significantly depending on the impact on an economy.

The multiplier of capital expenditures is significantly larger than 1 after eight quarters, and close to the value from results of Mitra and Poghosyan (2015). For capital expenditures, the multiplier is more persistent compared to expenditures on goods and services, as it remains statistically significant after the eight quarters.

The estimates of multipliers for various types of taxes demonstrate that the most negative impact on GDP comes from shocks to labor taxes. The multipliers of PIT and social security contributions are among the highest of all budget items estimated in this study, and do not lose their statistical significance after eight quarters. The multiplier of VAT is moderate, demonstrating a maximum absolute value $(-0.7)$ on impact, and quickly losing its significance. The case of import customs is rather interesting: the multiplier is negative, very high, and statistically significant during the first four quarters, while after that it becomes positive and loses its statistical significance. This behavior of the multiplier can be seen as reflecting the short-term negative effect of a hike on import duties on GDP growth, which becomes positive in the longterm. The CIT shock has low negative impact on real GDP over the first three quarters. In the long run, the impact becomes positive. Such an effect is a consequence of the op- timization of profit before taxation through an increase in investments and other expenses deductible from the tax base.

\subsection{The reaction of inflation to fiscal shocks}

The estimates of the impact of budget parameters on CPI in accordance with the restrictions in matrix (3), are given in Table C1 in Appendix C. According to the estimates, budget expenditures and taxes have a substantial positive impact on the growth rate of $\mathrm{CPI}$. Budget expenditures affect $\mathrm{CPI}$ significantly more strongly than taxes. Tax shocks rapidly transform into higher inflation, but because taxes also depress economic growth, a gradual deflationary effect also occurs. Inflation also instantaneously reacts to the shock of budget expenditures, with a gradually decreasing effect in subsequent periods.

Among budget expenditures, the highest inflationary effect is produced by wages in the public sector. Expenditures on goods and services also have a significant positive effect on CPI, although this is short-lived. Capital budget expenditures have a negligible short-term effect on inflation. Transfers to the population do not have a clearly expressed influence on inflation in the short term, but the impact is moderately positive after six quarters. The pension expenditures of PFU have a moderate instantaneous impact on the CPI, which quickly falls and becomes statistically insignificant.

The estimates for various categories of taxes indicate that the PIT has the highest inflationary effect. For VAT, PIT and social security contributions, the impact on inflation is fairly persistent and still positive during the first three quarters after the shock. In the case of import duties, all positive effects take place during the first two quarters. The impact of CIT on inflation is negative during the first three quarters, and it becomes neutral afterwards. This effect is explained by the short-term negative impact of CIT on GDP, after which a positive impact on GDP is produced by investments, which have a weak impact on inflation.

\section{CONCLUSIONS}

In this study, we estimated the impact of specific budget expenditures and tax categories on GDP and inflation in Ukraine. For this purpose, we applied the standard SVAR, with a Blanchard-Perotti identification scheme.

The estimated multipliers for aggregated budget expenditures are consistent with the values that are common for emerging markets, and are rather low (at the level of 0.1 - 0.5) during the first year (Batini, Eyraud, and Weber, 2014). Our results are somewhat different from the findings of Mitra and Poghosyan (2015) for Ukraine, who determine the cumulative multiplier of budget expenditures to be 2.9 after eight quarters. In our opinion, the reason for this discrepancy lies in the differences in the methods of forming budget expenditures as a variable for analysis, and the different sample of data used for research. The fiscal multiplier of tax revenues corresponds to similar empirical estimates for emerging economies (Batini, Eyraud, and Weber, 2014). However, unlike in previous studies, the standard value (close to $(-1)$ ) is reached in the second quarter. Such values usually match cumulative multipliers after two years. The less persistent negative effect of the tax shock suggests the existence of "non-Keynesian" mechanisms in the Ukrainian economy. 
The analysis of the impact on GDP from individual budget items demonstrated that the highest multipliers are associated with capital investment and expenditures on goods and services. The multiplier of capital expenditures is the most persistent. The multipliers with low estimates are those of categories of budget expenditures that, theoretically, should stimulate consumption directly. This is an indicator of "non-Keynesian" mechanisms in action, among which is the "crowding-out" effect, "Ricardian" behavior, and negative supply shocks (Baxter and King, 1993; Unal, 2015). The same factors create a "non-Keynesian" form of GDP response to a tax shock, which becomes positive in the long term. This indicates short-term economic losses during fiscal consolidation episodes, with the subsequent adaptation of economic agents to new fiscal realities, and GDP growth under conditions of a sustainable fiscal policy and reduced debt levels. Among the various categories of tax revenues, the highest cumulative multipliers are associated with taxes on labor (PIT and social security contributions), what means the most significant losses are suffered by the economy when these taxes are raised. This result is in line with standard economic theory, which sees these taxes as being the most distorting (Nguyen et al., 2016). Another distorting tax, CIT, has a short-term negative impact on GDP, which becomes positive in the medium term. The positive effect of this tax on GDP is reported quite often in the literature (Unal, 2015; Arin and Koray, 2006; Guntram et al., 2006), and can be explained by the redistribution of enterprises' incomes in favor of investments and other productive expenses (Mertens and Ravn, 2013).

The impacts of individual budget items on inflation are rather varied, but on average budget expenditures place higher inflationary pressure on the economy than taxes. For both sides of a budget, the highest inflationary pressure on the economy is associated with wages in the public sector, and PIT.

Budget expenditures can be divided into productive and unproductive. Productive expenditures are characterized by having a positive and sustained influence on real GDP and a moderate impact on inflation. This group includes capital expenditures and expenditures on government purchases. The group of unproductive expenditures includes expenditures of a social nature, namely transfers to the population, pensions, and expenditures on wages in the public sector. Unproductive expenditures do not have a statistically significant impact on real GDP and inflation, or affect only inflation. The latter is typical for wages in the public sector, which, according to the estimates, cause a shock of supply but not demand.

The positive response of inflation to shocks in most taxes (except CIT) indicates that taxes have a significant influence on the cost of production and affect prices from the supply side. This conclusion is consistent with the literature (de Castro and de Cos 2006, Mertens and Ravn, 2013; Unal, 2015; Nguyen et al., 2016; Arin et al., 2016), where the effects of different budget items on an economy were analyzed.

One avenue for subsequent studies of this topic would be to analyze the factors that create the "non-Keynesian" reaction of Ukraine's economy to fiscal shocks. These factors reduce the values of fiscal multipliers and raise questions about the effectiveness of fiscal stimulus in the Ukrainian economy. 


\section{REFERENCES}

- Alesina A., Ardagna S., Perotti R., and Schiantarelli F. (2002). Fiscal Policy, Profits, and Investment. American Economic Review, Vol. 92, No. 3, pp. 571-589. https://doi. org/10.1257/00028280260136255

- Arin K., Helles P., Koyuncu M., Reich O. (2016). Should We Care About The Composition Of Tax-Based Stimulus Packages? Contemporary Economic Policy, Vol. 34, No. 3, pp. 430-445. https://doi.org/10.1111/coep.12131

- Arin K., Koray F. (2006). Are Some Taxes Different Than Others? An Empirical Investigation of The Effects of Tax Policy in Canada. Empirical Economics, Vol. 31, No.1, pp. 183193. https://doi.org/10.1007/s00181-005-0032-7

- Auerbach A. J., Gorodnichenko Y. (2012). Measuring the Output Responses to Fiscal Policy. American Economic Journal: Economic Policy, Vol. 4, No. 2, pp. 1-27. https://doi. org/10.1257/pol.4.2.1

- Barro R. J. (1991). Economic Growth in a Cross-Section of Countries. Quarterly Journal of Economics, Vol. 106, No. 2, pp. 407-443.

- Batini P., Eyraud L., and Weber A. (2014). A Simple Method to Compute Fiscal Multipliers. IMF Working Paper, No. $14 / 93$.

- Baxter M., King R. (1993). Fiscal Policy in Genera Equilibrium. American Economic Review, Vol. 83, No. 3, pp. 315-334.

- Blanchard O., Perotti R. (2002). An Empirical Characterization of the Dynamic Effects of Changes in Government Spending and Taxes on Output. Quarterly Journal of Economics, Vol. 117, No. 4, pp. 1329-1368.

- Bonam D., de Haan J., and Soederhuizen B. (2017). The effects of fiscal policy at the effective lower bound. DNB Working Paper, No. 565.

- de Castro Fernández F., de Cos P. (2006). The Economic Effects of Exogenous Fiscal Shocks in Spain: a SVAR Approach. ECB Working Paper Series, No. 647.

- Fatás A., Mihov I. (2009). Why Fiscal Stimulus is Likely to Work. International Finance, Vol.12, No. 1, pp. 57-73. https:// doi.org/10.1111/j.1468-2362.2009.01235.x

- Giavazzi F., Pagano M. (1990). Can Severe Fiscal Contractions Be Expansionary? Tales of Two Small European Countries. CEPR Discussion Paper, No. 417.

- Giorno C., Richardson P., Roseveare D., and van der Noord P. (1995). Estimating Potential Output, Output Gaps, and Structural Budget Deficits. OECD Economics Department Working Papers, No. 152.
- Guntram W., Tenhofen J., Heppke-Falk K. (2006). The Macroeconomic Effects of Exogenous Fiscal Policy Shocks in Germany: A Disaggregated Analysis. Deutsche Bundesbank Discussion Paper, No.41.

- Hasset K. (2009). Why Fiscal Stimulus is Unlikely to Work. International Finance, Vol. 12, No. 1, pp. 75-91.

- Ilzetzki E., Mendoza E., Vegh C. (2011). How Big (Small) Are Fiscal Multipliers? IMF Working Papers, No. 11/52.

- Mankiw G., Summers L. (1984). Are Tax Cuts Really Expansionary? NBER Working Papers, No. 1443.

- Mertens K., Ravn M. (2013). The Dynamic Effects of Personal and Corporate Income Tax Changes in the United States. American Economic Review. Vol. 103, No. 4, pp. 12121247. https://doi.org/10.1257/aer.103.4.1212

- Mitra T., Poghosyan T. (2015). Fiscal Multipliers in Ukraine. IMF Working Papers. No. 15/71.

- Nguyen A., Onnis L., Rossi R. (2016). The Macroeconomic Effects of Income and Consumption Tax Changes. Centre for Growth and Business Cycle Research Discussion Paper Series, No. 227.

- Parkyn O., Vehbi T. (2014). The Effects of Fiscal Policy in New Zealand: Evidence from a VAR Model with Debt Constraints. Economic Record, Vol. 90, No. 290, pp. 345364. https://doi.org/10.1111/1475-4932.12116

- Perotti R. (2002). Estimating the Effects of Fiscal Policy in OECD Countries. ECB Working Paper, No. 168.

- Persson M., Persson T., Svensson L. (1996). Debt, Cash Flow and Inflation Incentives: a Swedish Example. NBER Working Papers. No. 5772.

- Romer C., Romer D. (2010). The Macroeconomic Effects of Tax Changes: Estimates Based on a New Measure of Fiscal Shocks. American Economic Review, Vol. 100, No. 3, pp.763-801. https://doi.org/10.1257/aer.100.3.763

- Rukelj D. (2009). Modelling Fiscal and Monetary Policy Interactions in Croatia Using Structural Vector Error Correction Model. Economic Trends and Economic Policy, Vol. 19, No. 121, pp. 27-59.

- Stock J., Watson M. (1993). A Simple Estimator of Cointegrating Vectors in Higher Order Integrated Systems. Econometrica, Vol. 61, No. 4, pp. 783-820.

- Unal U. (2015). Rethinking The Effects Of Fiscal Policy On Macroeconomic Aggregates: A Disaggregated SVAR Analysis. Journal for Economic Forecasting, Vol. 18, No. 3, pp. 120-135. 


\section{APPENDIX A}

Table A1. Fiscal multipliers for various categories of budget expenditures and tax revenues

\begin{tabular}{|c|c|c|c|c|c|c|c|c|}
\hline $\begin{array}{c}\text { Budget } \\
\text { category }^{13}\end{array}$ & $b_{1}$ & $c_{1}$ & $c_{2}$ & $b_{2}$ & $\begin{array}{l}\text { Impact } \\
\text { multiplier }\end{array}$ & $\begin{array}{c}\text { Cumulative } \\
\text { multiplier after } 8 \\
\text { quarters }\end{array}$ & $\begin{array}{l}\text { The highest } \\
\text { multiplier within } \\
\text { 8-quarter period, } \\
\text { absolute value }\end{array}$ & $\begin{array}{l}\text { The highest } \\
\text { cumulative } \\
\text { multiplier within } \\
\text { 8-quarter period, } \\
\text { absolute value }\end{array}$ \\
\hline$G_{t}$ & 1.20 & 0.09 & -0.11 & $\begin{array}{c}0.04 \\
\left(0.12^{14}\right)\end{array}$ & $0.26^{*}$ & 1.50 & $0.35^{*}(2)^{15}$ & 1.50 (8) \\
\hline$T_{t}$ & 1.20 & 0.09 & -0.11 & $\begin{array}{l}0.04 \\
(0.12)\end{array}$ & $-0.43^{*}$ & -0.01 & $-0.43^{*}(2)$ & $-0.9(2)$ \\
\hline$G_{t}^{\text {wage }}$ & 1.20 & 0.07 & -0.10 & $\begin{array}{l}0.28 \\
(0.12)\end{array}$ & 0.40 & 0.43 & 0.40 (1) & $0.80(2)$ \\
\hline$G_{t}^{g} g_{-}$cons & 1.20 & -0.01 & -0.13 & $\begin{array}{c}0.19 \\
(0.12)\end{array}$ & $-0.46^{*}$ & -0.07 & $0.60(2)$ & 0.95 (3) \\
\hline$G_{t}^{c a p}$ & 1.20 & 0.02 & -0.11 & $\begin{array}{l}-0.07 \\
(0.12)\end{array}$ & $0.61^{*}$ & 2.80 & $0.70^{*}(3)$ & $2.95(5)$ \\
\hline$G_{t}^{\text {transf }}$ & 1.20 & 0.01 & -0.32 & $\begin{array}{l}0.04 \\
(0.12)\end{array}$ & 0.01 & 0.01 & -0.01 (1) & $0.03(2)$ \\
\hline$G_{t}^{\text {pens }}$ & 1.20 & 0.02 & -0.01 & $\begin{array}{l}-0.13 \\
(0.12)\end{array}$ & $0.20^{*}$ & -1.00 & $-0.49^{*}(3)$ & -1.17 (6) \\
\hline$T_{t}^{v a t}$ & 1.80 & -0.03 & -0.06 & $\begin{array}{l}-1.06 \\
(0.12)\end{array}$ & $-0.70^{*}$ & -0.40 & $-0.70^{*}(1)$ & $-1.50(2)$ \\
\hline$T_{t}^{c i t}$ & 1.80 & 0.06 & -0.02 & $\begin{array}{l}0.27 \\
(0.13)\end{array}$ & $-0.57^{*}$ & 1.50 & $0.72^{*}(7)$ & 1.50 (7) \\
\hline$T_{t}^{p i t}$ & 0.60 & 0.01 & -0.09 & $\begin{array}{l}0.05 \\
(0.12)\end{array}$ & $-1.90^{*}$ & -3.60 & $-2.85^{*}(1)$ & -7.30 (3) \\
\hline$T_{t}^{\text {cust }}$ & 0.90 & 0.02 & 0.06 & $\begin{array}{l}0.26 \\
(0.12)\end{array}$ & $-1.10^{*}$ & -6.60 & $-2.70 *(3)$ & $-8.90(4)$ \\
\hline$T_{t}^{s o c}$ & 0.90 & -0.01 & -0.18 & $\begin{array}{l}0.05 \\
(0.12)\end{array}$ & $-1.60^{*}$ & -4.10 & $-1.60 *(0)$ & $-4.15(8)$ \\
\hline
\end{tabular}

* Statistical significance on 95\% confidence interval, Efron and Hall bootstrap percentile confidence intervals, 1000 replications.

${ }^{13} G_{t}^{\text {wage }}$ - wages in the public sector, $G_{t}^{\text {g_cons }}$ - expenditures on goods and services, $G_{t}^{\text {cap }}$ - capital expenditures, $G_{t}^{\text {transf }}-$ current transfers to the population,

${ }^{15}$ Relevant quarter given in parentheses. 
Figure A1. Impulse response functions for $1 \%$ shock in model with three endogenous variables (budget expenditures, taxes, GDP), \%
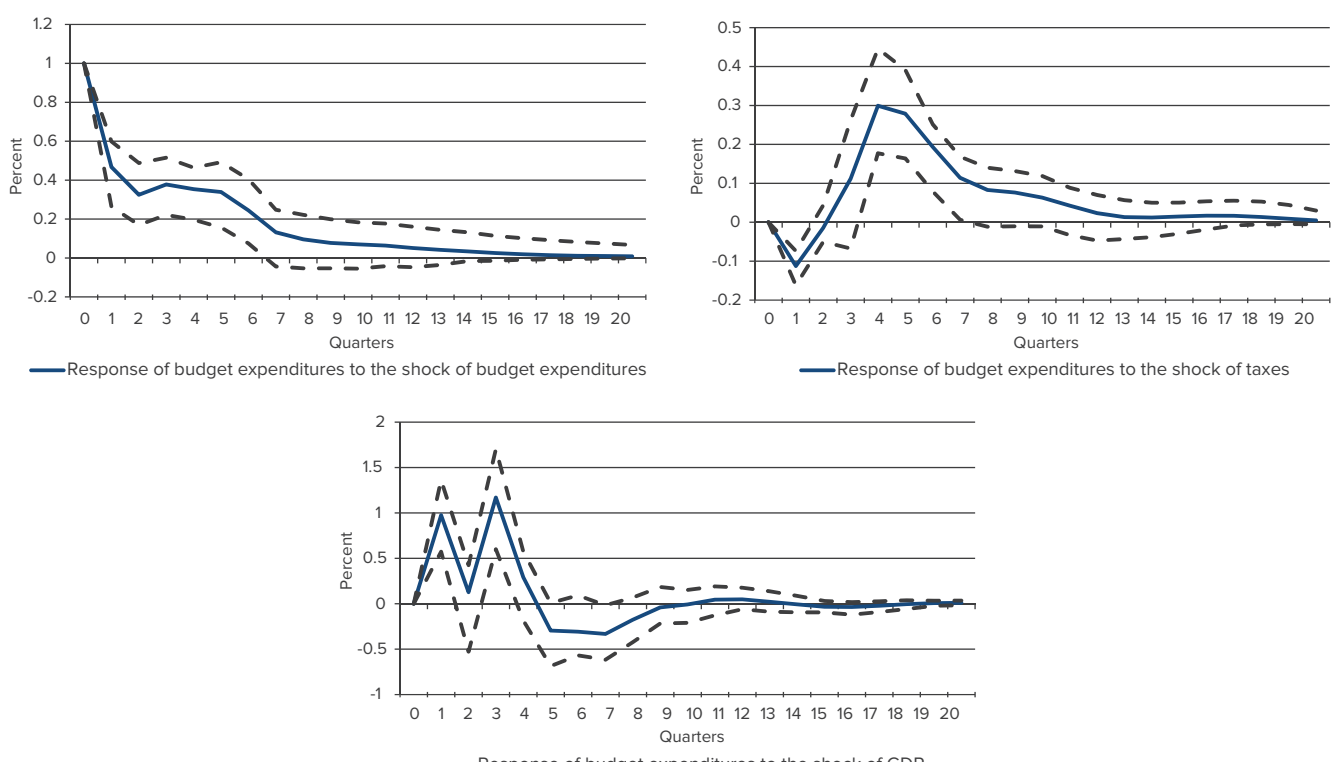

— Response of budget expenditures to the shock of GDP

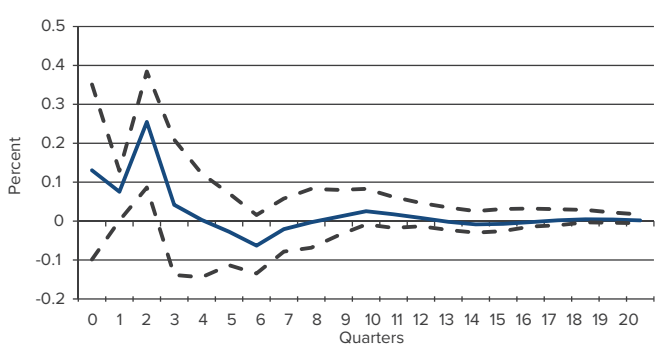

— Response of taxes to the shock of budget expenditures

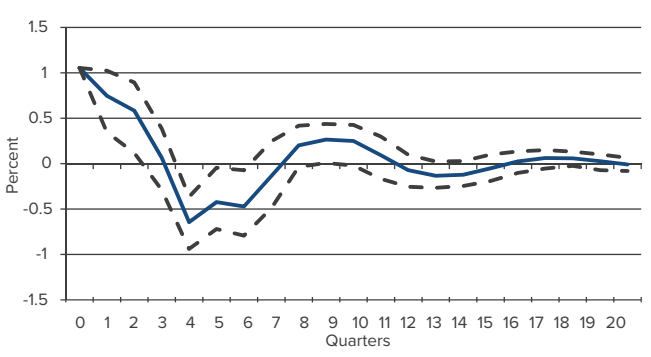

—Response of taxes to the shock of GDP

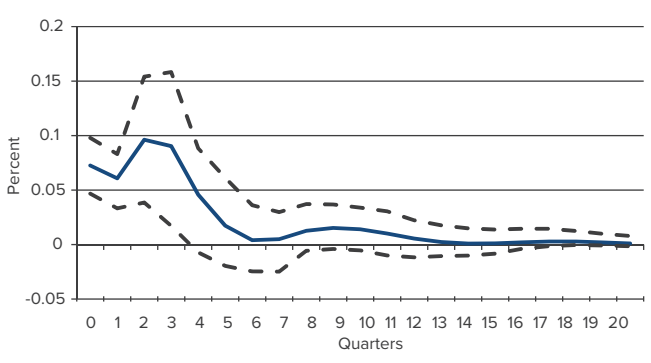

— Response of GDP to the shock of budget expenditures

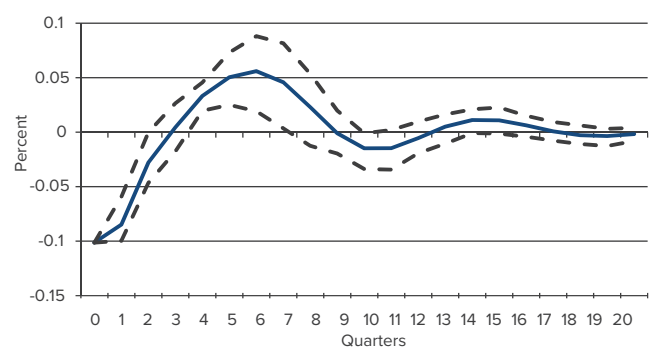

— Response of GDP to the shock of taxes

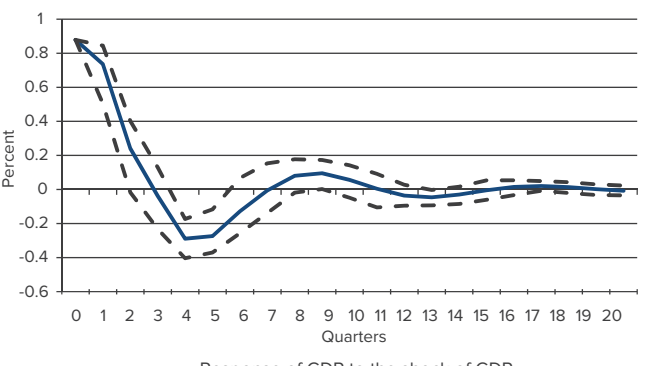


Figure A2. Impulse response functions of real GDP to $1 \%$ shock to various budget expenditures, $\%$
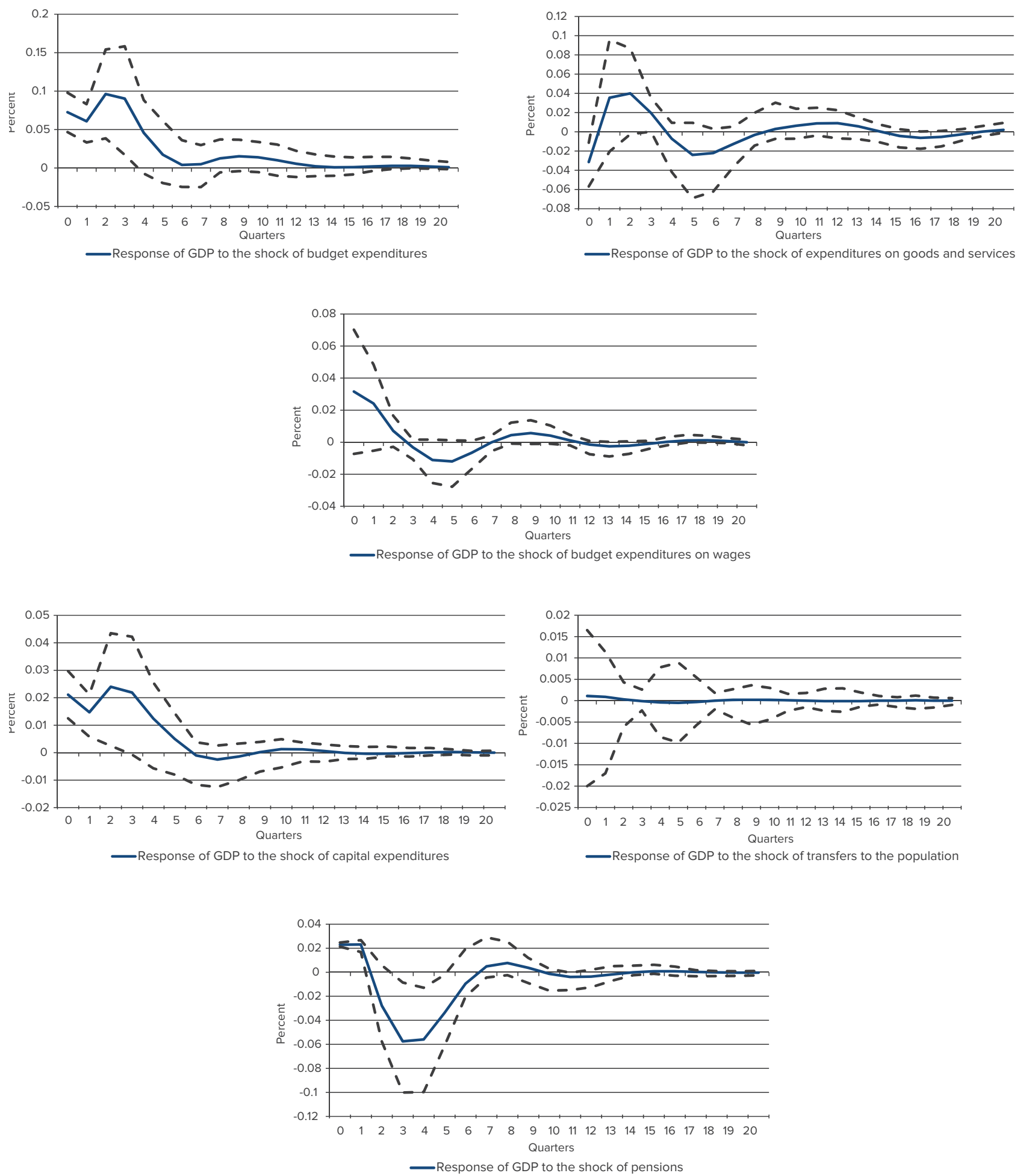
Figure A3. Impulse response functions of real GDP to $1 \%$ shock to various taxes, $\%$
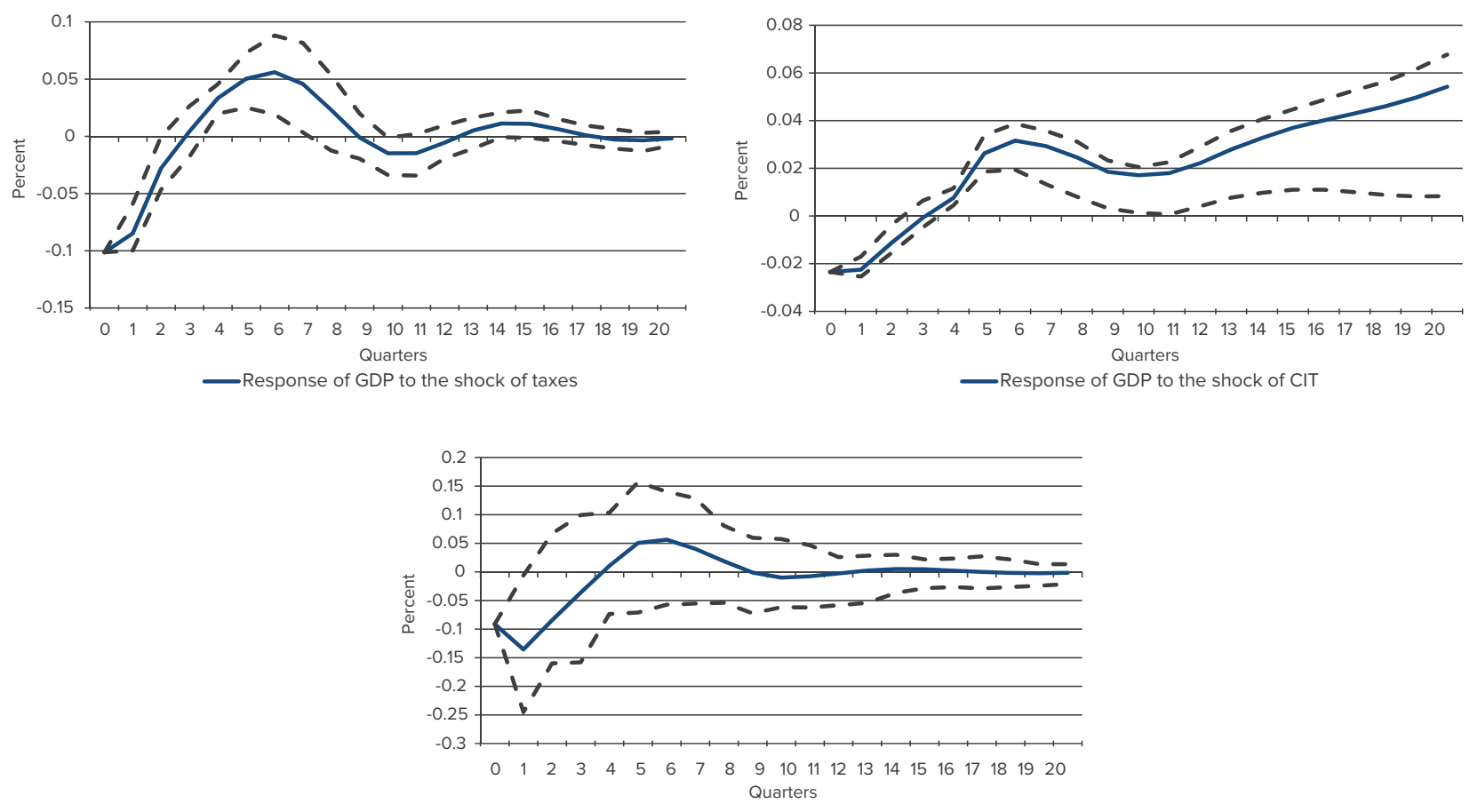

- Response of GDP to the shock of PIT

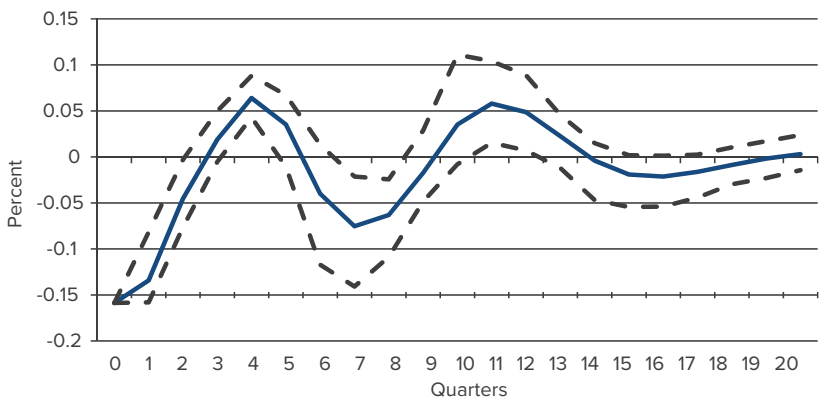

- Response of GDP to the shock of social security contributions

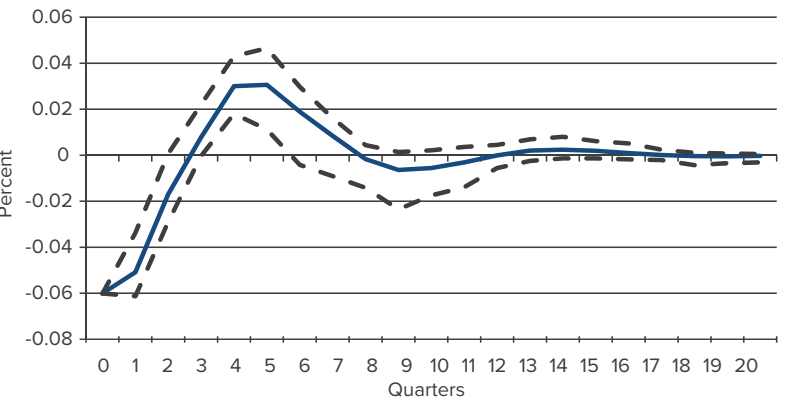

- Response of GDP to the shock of VAT

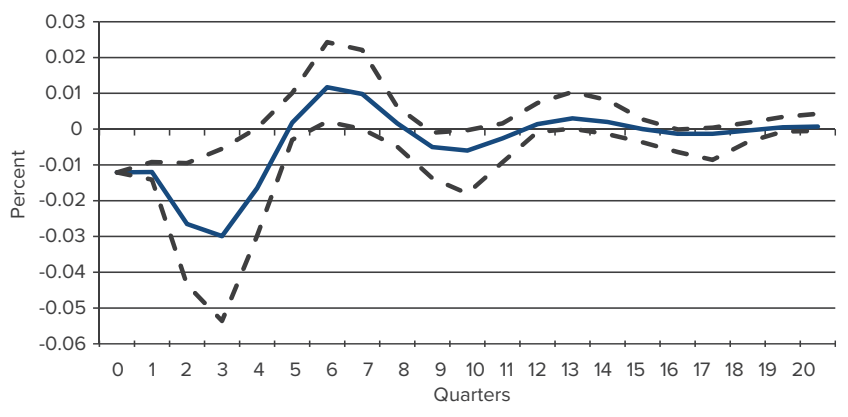

—Response of GDP to the shock of import customs 


\section{APPENDIX B}

Figure B1. Impulse response functions of real GDP and inflation to shocks to different types of expenditures on goods and services

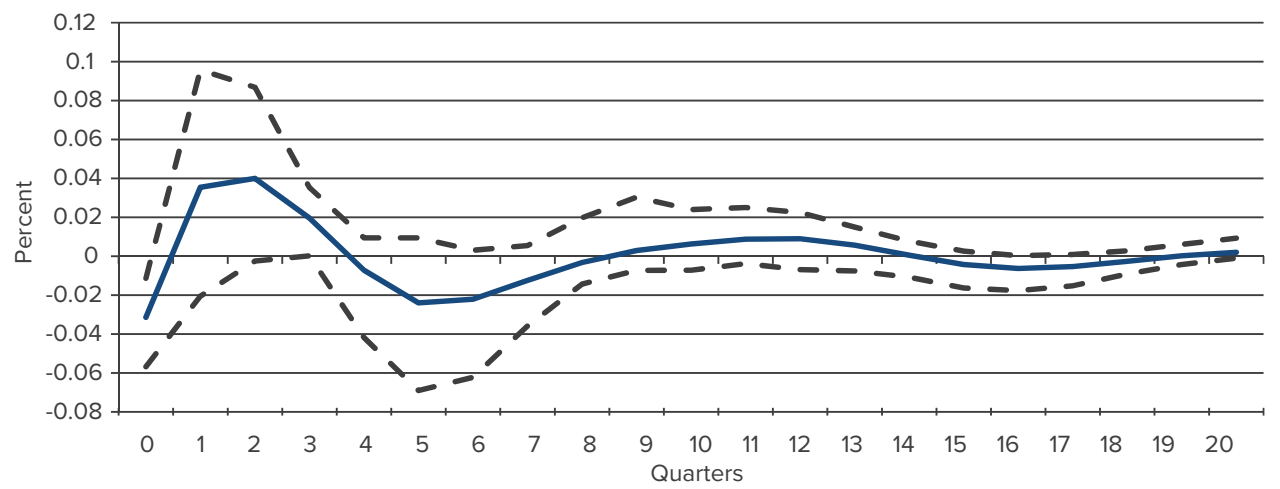

- Response of GDP to the shock of expenditures on goods and services

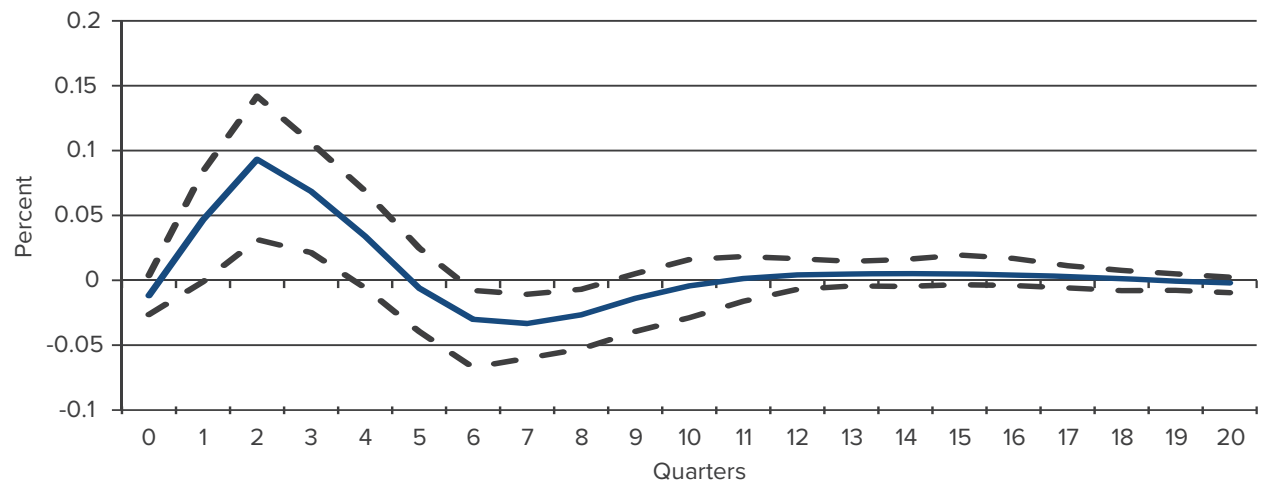

Response of GDP to the shock of adjusted expenditures on goods and services

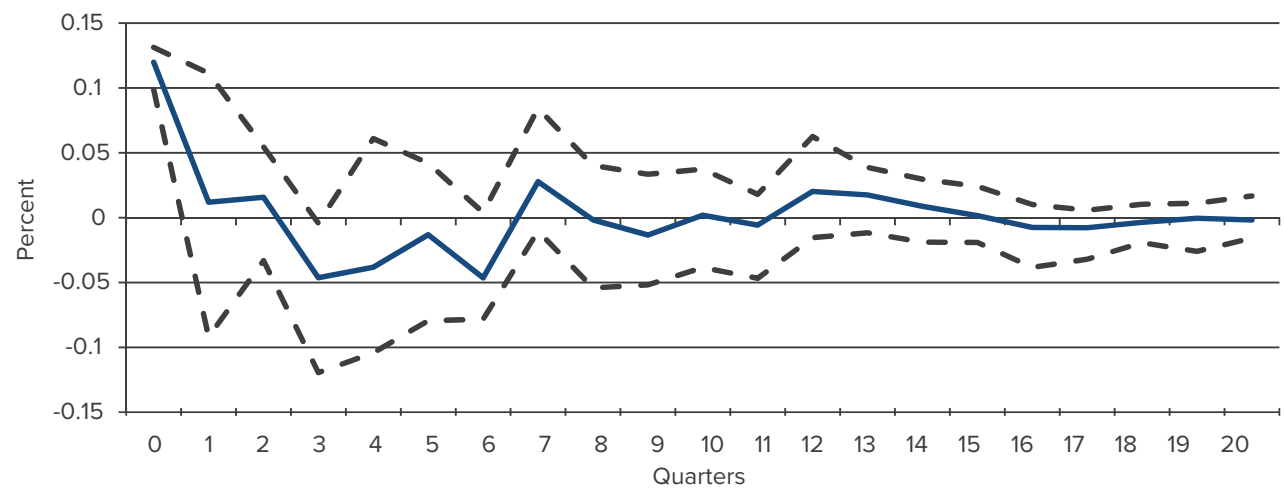

Response of CPI to the shock of expenditures on goods and services

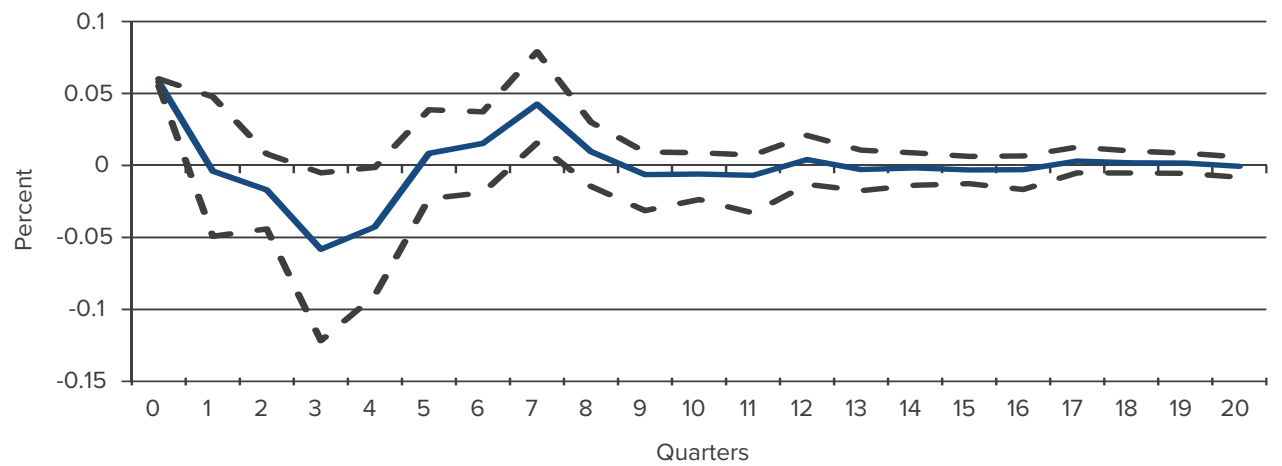

- Response of CPI to the shock of adjustedon goods and services 


\section{APPENDIX C}

Table C1. Response of CPI to $1 \%$ shock to various categories of budget expenditures and taxes

\begin{tabular}{|c|c|c|c|c|}
\hline Budget category ${ }^{16}$ & Impact multiplier & $\begin{array}{l}\text { Cumulative multiplier } \\
\text { after } 8 \text { quarters }\end{array}$ & $\begin{array}{c}\text { The highest multiplier } \\
\text { within } 8 \text { - quarter } \\
\text { period, absolute } \\
\text { values }\end{array}$ & $\begin{array}{c}\text { The highest } \\
\text { cumulative multiplier } \\
\text { within } 8 \text {-quarter } \\
\text { period, absolute } \\
\text { values }\end{array}$ \\
\hline$G_{t}$ & $0.16^{*}$ & 0.13 & $0.16(0)^{17}$ & 0.26 (1) \\
\hline$T_{t}$ & $0.02^{*}$ & -0.12 & $0.06^{*}(1)$ & $-0.23(6)$ \\
\hline$G_{t}^{\text {wage }}$ & $0.45^{*}$ & 0.20 & $0.45(0)$ & $0.67(1)$ \\
\hline$G_{t}^{g} g_{c}$ cons & $0.11^{*}$ & -0.10 & $0.12(0)$ & 0.13 (1) \\
\hline$G_{t}^{c a p}$ & $0.01^{*}$ & -0.09 & 0.04 (1) & $-0.1(7)$ \\
\hline$G_{t}^{\text {transf }}$ & $-0.02^{*}$ & 0.05 & $-0.05(2)$ & $0.06(7)$ \\
\hline$G_{t}^{\text {pens }}$ & $0.04^{*}$ & -0.01 & $0.05(0)$ & $-0.11(8)$ \\
\hline$T_{t}^{v a t}$ & $0.03^{*}$ & 0.04 & $0.04^{*}(1)$ & $0.08(3)$ \\
\hline$T_{t}^{c i t}$ & $-0.00^{*}$ & -0.14 & $-0.10^{*}(2)$ & $-0.18(5)$ \\
\hline$T_{t}^{p i t}$ & $0.23^{*}$ & 0.74 & $0.25^{*}(1)$ & $0.78(4)$ \\
\hline$T_{t}^{\text {cust }}$ & $0.02 *$ & -0.21 & $0.09 *$ (1) & $0.11(1)$ \\
\hline$T_{t}^{s o c}$ & $0.05^{*}$ & -0.02 & $0.05^{*}(0)$ & 0.09 (3) \\
\hline
\end{tabular}

* Statistical significance on 95\% confidence interval, Efron and Hall bootstrap percentile confidence intervals, 1,000 replications. 
Figure C1. Impulse response functions to $1 \%$ shock in the model with inflation, $\%$
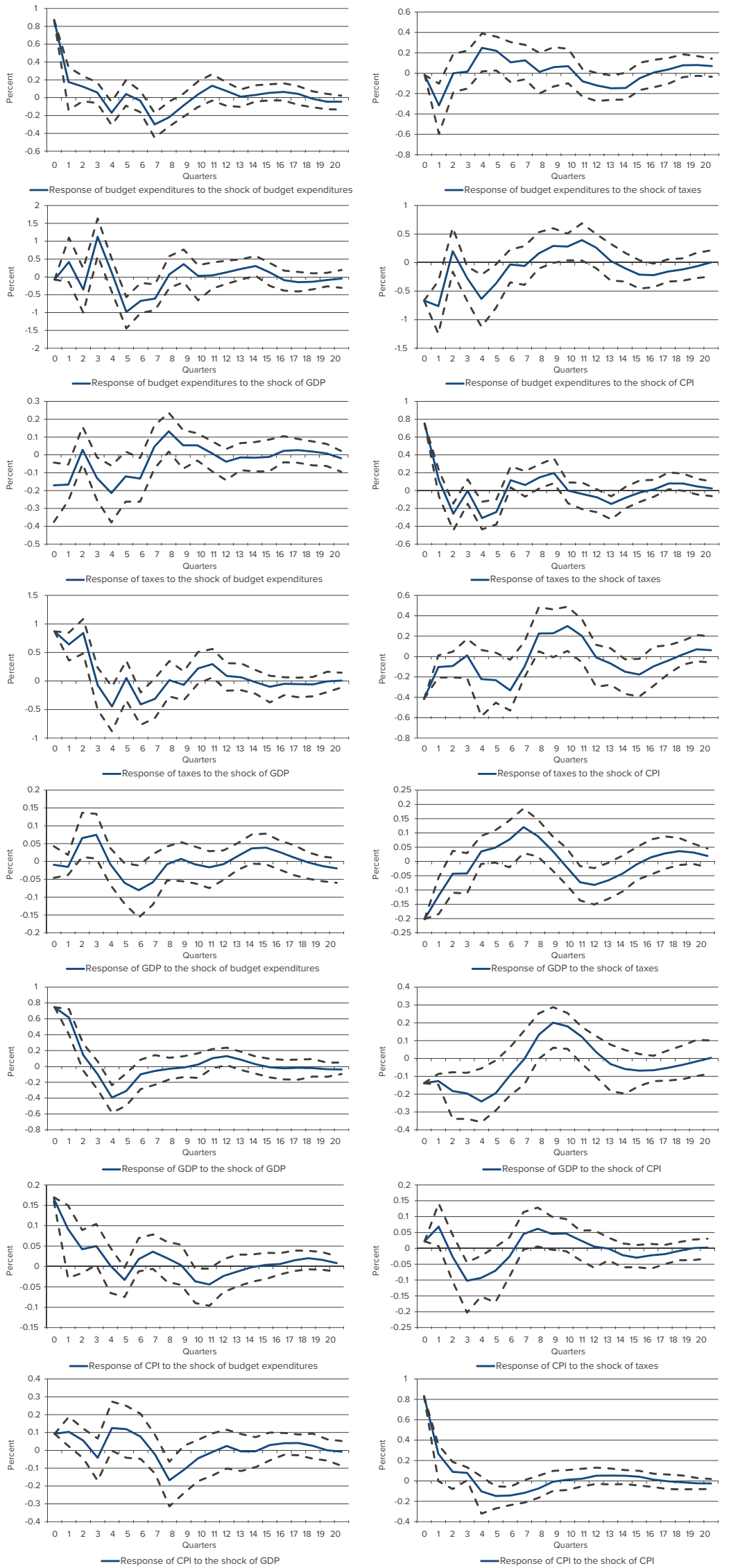
Figure C2. Impulse response functions of inflation to $1 \%$ shock to various budget expenditures, \%
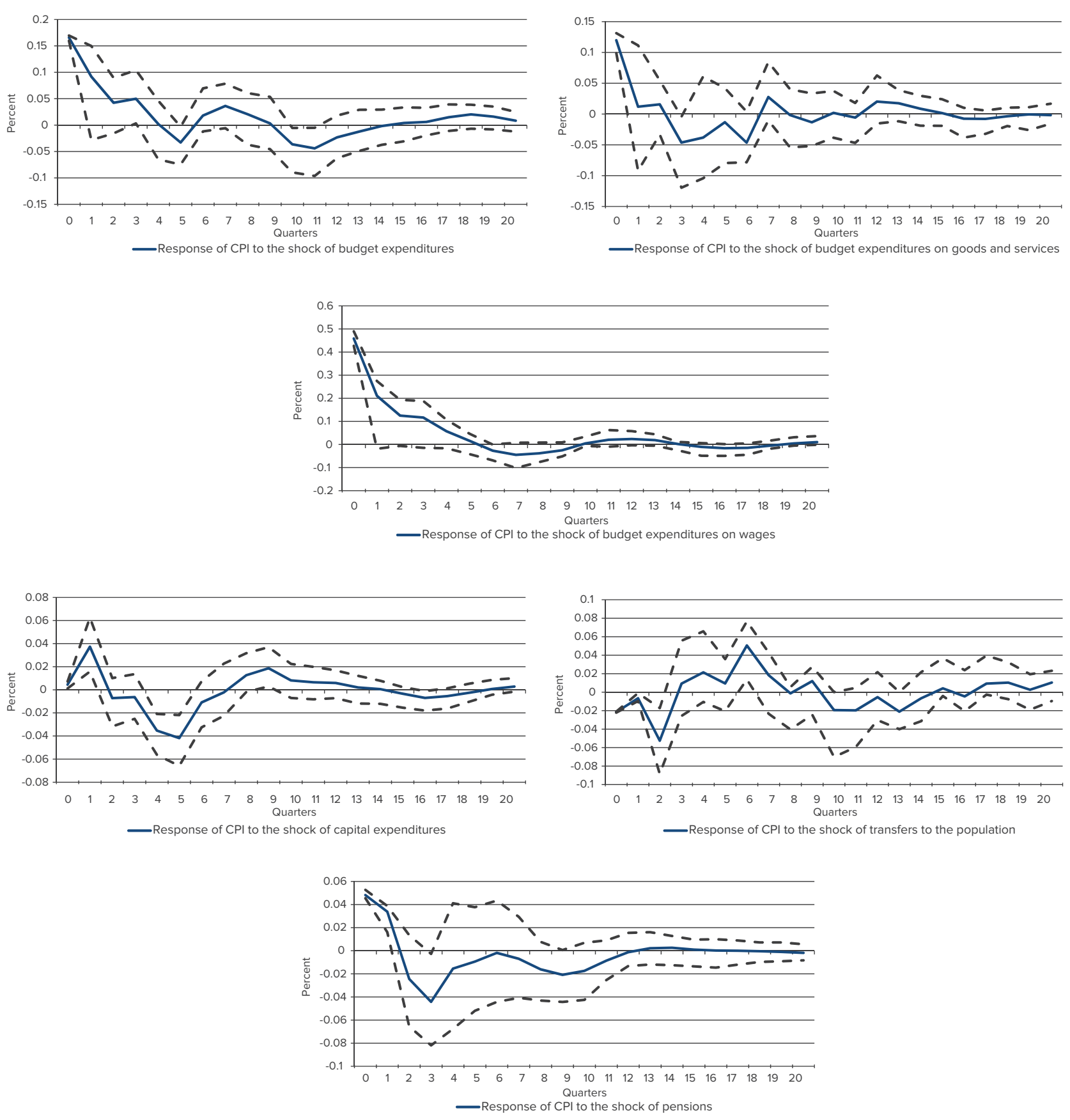
Figure C3. Impulse response functions of inflation to $1 \%$ shock to various taxes, $\%$
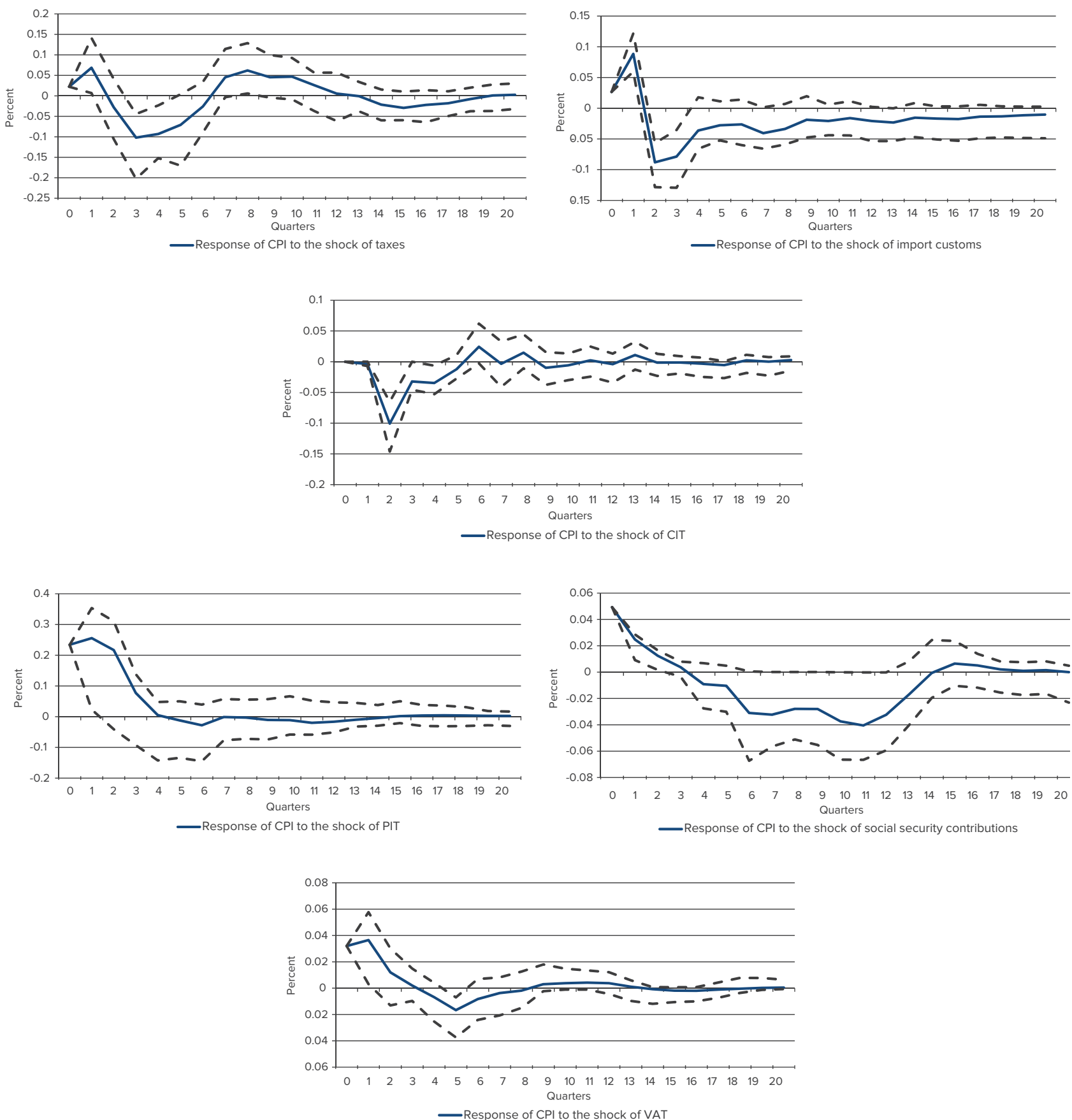


\title{
THE REDISTRIBUTIVE EFFECTS OF MONETARY POLICY ACROSS GENERATIONS
}

\section{OLGA BONDARENKOa}

aNational Bank of Ukraine

Email: Olha_Bondarenko@bank.gov.ua

\begin{abstract}
The paper revises the redistributive channels of monetary policy transmission and their impact on income and wealth distributions in a New-Keynesian Overlapping Generations (OLG) model. The model mimics total asset holdings and earnings processes of several types of households across generations, based on their attitude to saving and income group. In this environment, expansionary monetary shocks stimulate capital and debt accumulation to a larger extent for middle-aged individuals, contributing to intergenerational inequality. Heterogeneity of labor income augments this effect, benefitting richer and more productive workers.
\end{abstract}

JEL Codes

D31, E12, E21, E52

Keywords monetary policy, wealth redistribution, overlapping generations, heterogeneous agents

\section{INTRODUCTION}

The conventional understanding of monetary policy entails its long-run neutrality with respect to real variables, such as output, consumption, and capital. From this perspective, the influence of monetary policy on the distribution of wealth is implicitly assumed to be negligible over the business cycle, as benefits earned during economic rebounds entirely offset any losses incurred during downturns. However, with asymmetric responses of aggregate expenditure and prices, when unanticipated contractionary interest rate changes tend to exhibit a more pronounced effect during expansions than recessions (Tenreyro and Thwaites, 2016), the validity of this statement becomes highly questionable.

Until recent years, central banks typically failed to properly consider the distributional consequences of monetary policy. An analysis based on representative agent models (RANK) was not able to capture and quantify the contribution of interest rate changes in reversing the downward inequality trend that dominated the 20th century. The sound of silence has now been broken, with central banks having to employ unconventional monetary policy tools in response to financial crisis, bringing discussion about the inequality they entail to new heights (Ohlsson, 2017; Constancio, 2017; Haldane, 2018). Nevertheless, the absence of a firm starting point, i.e. a clear-cut understanding of the impact of traditional monetary policy instruments, has flicked out of sight.

One might argue that wealth redistribution, or inequality in general, is not within a central bank's mandate, and rightly so. However, evidence that redistribution is a channel of aggregate stabilization, which policymakers intend to achieve, is becoming increasingly available. The intuition behind this is based on an argument outlined by Tobin as far back as 1982: debtors, who typically benefit from an expansionary policy, tend to consume more out of their disposable income than savers, who lose. Along with net wealth, other household characteristics, including age and income type, lead to asymmetries in responses to interest rate changes, and hence, amplify its effect on macroeconomic aggregates. Quantifying this impact on heterogeneous agents can deepen the understanding of aggregate responses, and hence, improve a central bank's approach to interventions. As the RANK model relies basically on a direct interest rate channel, it presupposes that real interest rate changes can generate a strong enough stimulus to boost aggregate expenditures. In contrast, heterogeneous agent (HANK) models show that the fine-tuning of the economy is far more complex, given that the income effect (instead of intertemporal substitution) plays a prominent role in shaping agents' decisions. As either substitution or income effects can be dominant during the various stages of a household's life, considering redistributive forces within the life-cycle framework can potentially assist in developing better policy advice.

A dynamic stochastic general equilibrium (DSGE) model, featuring heterogeneity of agents in the income, wealth, and age dimensions, is considered to be a suitable tool for modeling the reaction of markets to unanticipated shifts in monetary stance. Built on models elaborated in Heer and Maussner (2012), Andrés et al. (2018), it includes nine types of household, each consisting of 60 age cohorts (equivalent to 60 years of life, from the age of 20 to 80 ). In constructing other model components, the traditional New-Keynesian literature is followed. Income and wealth profiles of agents are 
calibrated using the Panel Study of Income Dynamics (PSID) for 2001 to 2015. The model simulations are performed in Matlab and Dynare 4.4.3 toolbox.

The rest of the paper is organized as follows. Chapter 2 provides an extensive literature review on the theoretical concept of monetary policy transmission to consumption. Chapter 3 presents the model. Chapter 4 specifies the calibration values. Finally, chapter 5 compares the model distributions and IRFs. Chapter 6 provides conclusions.

\section{LITERATURE REVIEW}

Effectiveness in reaching the objective of price stability depends crucially on timing and proper understanding of the underlying monetary policy transmission mechanism, based on analysis of channels propagating the impact of central banks actions.

The literature generally divides the transmission mechanism into two complementary views operating under different model setting, namely neoclassical (with perfect financial markets) and non-neoclassical, assuming the presence of financial market imperfections. The traditional neoclassical, or money, view lies in the heart of core macroeconomic models, elaborated in the mid-20th century. It entails three basic channels, through which monetary policy affects aggregate demand: direct interest rate channel; asset price effect, following from Jorgenson (1963) and Tobin (1969); intertemporal substitution channel, rooted in the Ando and Modigliani (1963) permanent income hypothesis; and exchange rate channel, described primarily by the model of Mundell (1963) and Fleming (1962).

The discussion on a parallel non-neoclassical, or credit, view has started when Bernanke and Gertler (1995) questioned the ability of traditional transmission mechanism to explain the evidence of how relatively small interest rate changes can generate relatively huge fluctuations in output. Standing on the assumption that external and internal financing are imperfect substitutes, this channel implies a considerable effect of monetary policy on the premium on external funds, leading to contraction of banks credit supply (bank lending channel), on the one hand, and deterioration of borrowers net worth (balance sheet channel), on the other.

Either view, however, disregard any distributional effects by adopting a representative agent. This approach can yet be questioned when confronted with the empirical studies that quantitatively evaluate the effect of monetary policy stance on the distribution of wealth.

Recent literature distinguishes five channels of monetary transmission, entailing redistributive consequences across economic agents. Heathcote et al. (2010) provide empirical evidence that earnings of households, belonging to opposite ends of the distribution, respond differently to business cycle fluctuations. While changes in labor income of 90th percentile are driven primarily by wage adjustments, earnings of 5th and 10th percentiles reflect unemployment rate developments, falling excessively upon these groups. Accompanied by labor market imperfections and varying extents of wage rigidity for high- and low-income households, these stylized facts give rise to earning heterogeneity channel of monetary policy. In so far loose financial conditions contribute to a larger decline in unemployment than to the growth in hourly wages, inequality is reduced.

Income heterogeneity channel is closely related to earnings heterogeneity, but encompass as well other sources of income, such as financial proceeds, dividends, and transfers from the government. It can potentially amplify or dampen reduction in inequality, outlined above, depending on households' primary sources of income. Whenever transfers from the government, having a countercyclical nature, occupy a larger share of households' budget, redistributive forces tend to decrease inequality. On the contrary, the presence of a substantial fraction of capital returns - a distinctive feature of income, received by rich economic agents - that grows faster than wages on the impact of interest rate cuts, augment negative impact on inequality by widening the gap between those in the top percentiles of distribution and in the middle ones. Gornemann et al. (2012), based on a NewKeynesian model with market incompleteness and labor market search and matching frictions, confirm an uneven effect of monetary tightening on households with different income structure due to a notable reduction in labor earnings and employment across firms.

Access to financial markets plays a crucial role in the financial segmentation channel, determining the timeline and succession of monetary policy impact on trading and nontrading agents. It contributes to an upswing in inequality, provided that households, connected and participating in financial markets, have higher average earnings than unconnected ones. Being able to respond first to changes in policy stance, they benefit more than those, who face these changes after a chain of transactions in both financial and goods markets occurs (Williamson, 2008). Similarly, Ledoit (2011) proves this effect using topological notions within a social network economy, where the most intensive trade occurs with the closest counterparties. As the central bank injects money into the financial system, liquidity permeates the whole economy, yet unevenly with a larger effect on entities, located closer to the "place of injection".

Income inequality might be further propagated through portfolio channel, proportionally to the share of nominal assets (typically, cash) possessed by the household. On assumption that poorer agents tend to hold higher money balances compared with richer ones, they become primary payers of the socalled inflation tax, as in Erosa and Ventura (2002). Additionally, limited substitutability between cash and other financial instruments expose them to the larger adverse impact of the expansionary monetary policy.

Yet, an unexpected inflationary pressure redistributes wealth not only from holders of nominal assets but also among them, provided some holders are borrowers while others - savers. Initially proposed in Fisher (1933), this wellknown impact of interest rate change has been quantified in the seminal paper of Doepke and Schneider (2006), assessing the potential impact of moderate inflation shock on wealth. Using the records on distribution and duration of nominal asset holdings in the U.S., it explicitly shows that inflation benefits young indebted households, generally representatives of the middle class, at the expense of the old and rich. Furthermore, prolonged episodes of inflationary pressure tend to have larger redistributive consequences for holders of long-term rather than short-term bonds, as they have a lower possibility to adjust to inflation. 
Although channels appear to be defined pretty well, two measurement issues arise on an attempt to quantify the corresponding effects: differentiating between correlation and causality and matching low-frequency data in the Survey of Consumer Finance or PSID to regular changes in the key policy rate. Both issues are addressed by the study of Coibion et al. (2017), based on quarterly Consumer Expenditure Survey, within the framework, separating surprise changes in monetary stance from forecast-driven ones. The analysis provides empirical evidence of a functioning income heterogeneity channel, having particularly disproportionate effect for rich households with a large share of financial proceeds. On the contrary, the impact of interest rate changes on labor income appears to be negligible, assigning a limited role to earnings heterogeneity channel.

The existence of empirical confirmation of the distribution channel has stimulated research in this field that remains largely overlooked from the policymaking perspective. A prominent example of the recent studies setting a theoretical background of monetary policy transmission is Auclert (2017). This paper unambiguously identifies three basic redistribution channels (earnings heterogeneity, Fisher (saving redistribution), and interest rate exposure channels) and claims that each of these mechanisms exacerbates the aggregate effects on consumption.

Kaplan et al. (2018) elaborate upon the study of Auclert (2017), incorporating heterogeneous agents, explicitly modeled production sector, uninsurable income shocks, and imperfect substitutability between liquid and illiquid assets. Yielding an empirically realistic joint distribution of income and wealth, the model attributes a pivotal impact of the expansionary monetary policy to labor demand shifts that drive consumption upward.

Luetticke (2017) employs a similar type of model to replicate empirical evidence. The study shows that consumption response is amplified by the contractionary shock while investment response - dampened, compared with the standard RANK model. This impact occurs as far as monetary policy differently affects households' portfolios and consumption decisions. Rich agents, holding primarily real assets, are able to stabilize investment and even increase demand for final goods due to a sizable income effect, dominating the substitution effect. Middle income and poor households, on the contrary, experience a sharp drop in consumption, partially offset by reducing holdings of liquid wealth. As in Kaplan et al. (2018), the direct transmission channel explains only $25 \%$ of the aggregate effect, pointing to significant flaws in standard RANK models, fully relying on the operations of this channel.

Still, the outlined HANK framework reproduces agents' earnings and wealth heterogeneity with respect to income status only, not age. The concept developed to approach the issue is an overlapping-generations model, which can include the required number of age cohorts. Although typically such models account for only two generations, limiting the scope of discussion to the young and the old in general, the paper of Heer and Maussner (2012) proposes dynamic optimizing sticky price model, where 240 cohorts of agents, heterogeneous with respect to the age and productivity, are present. Their study reveals that dynamics of aggregate variables are generally similar in both representative agent and overlapping generation models, yet not fully identical. The slight increase in a wedge between labor earnings of different cohorts in response to monetary shock is present. This effect, however, is largely tolerated through the means of taxation system, leading to an equalization of wealth distribution.

Thus, to quantify the redistributive effects of monetary policy in the life-cycle framework, the model of Heer and Maussner (2012) is adopted and adjusted to fit the purposes of research by dividing all households into 3 groups, depending on their attitudes to saving, similarly to Andres et al. (2018). Liquid assets in form of bonds are also introduced in the framework, calibrated to mimic wealth distribution and earnings processes across generations.

The present paper, however, is only a first step to develop a fully-fledged life-cycle model. There are a number of limitations, necessary to ensure a tractability of the model, which can potentially influence the result. First, the markets are complete, so that all households (except for exogenously defined hand-to-mouth households) can insure themselves against adverse income shocks and do not have an incentive to accumulate precautionary savings. Moreover, although the model includes both liquid and illiquid assets, agents have no choice among them; instead, patient agents are prescribed to accumulate illiquid assets while impatient - liquid ones. Thus, the captured Fisher effect is basically one-sided while portfolio effect is shown only in aggregated form. Additionally, the paper does not consider financial segmentation channel and unemployment effects on earnings heterogeneity at all.

\section{MODEL}

The model is a New-Keynesian DSGE model with overlapping generations, combining the features of Heer and Maussner (2012) and Andres et al. (2018). It consists of four basic sectors: households, firms, the government, and the central bank. Households solve the problem of lifetime utility maximization with regard to their intertemporal consumption, saving, and labor supply. Final goods producers operate in a competitive market, while intermediate goods producers maximize their profits in a monopolistically competitive environment and set prices in a staggered way a la Calvo (1983). The government sector is reduced to the pension fund, collecting social security taxes and providing retirees with pension benefits. The monetary authority controls the money supply, which grows at a constant rate. Aggregate firm productivity and monetary policy are stochastic.

\subsection{Households}

The lifespan of a household includes $T+T^{R}=60$ periods, lasting 1 year each. The first $T=42$ periods agents work and earn labor income while the remaining $T^{R}=18$ periods they are retired and receive pensions, which reflects average retirement age of 62 years in the U.S. and average lifetime on the retirement of 18 years (U.S. Office of Personnel Management, 2017). Each type of agent enters the model without wealth at age of 20 and leaves no bequests after dying at age of 80 .

The productivity of agents $e(s ; j ; h)$ depends on several factors: their type $j \in\{1,2,3\}$, corresponding to the individual's income status, namely poor, middle-class, and rich; wealth composition type, denoted by $h$; and cohort they belong to. Agents cannot switch their productivity type $j$ over the lifetime. The share of type- $j$ agents in each cohort is fixed at $\mu(j ; h)$. 
Household's type $h$ depends primarily on its attitude towards saving and, as a result, the structure of non-housing wealth. According to this criterion, households within each income group were subdivided into patient savers, impatient borrowers, and impatient hand-to-mouth consumers.

\subsubsection{Working households}

At time $t$, working patient household with productivity type $j$ holds capital $K_{t-1}$ from the previous period. It maximizes the expected life-time utility at age 1 in period $t$ with regard to consumption $C_{t}^{S ; j ; P}$, labor supply $N_{t}^{S ; j ; P}$, and nextperiod capital $K_{t+1}^{S+1 ; j ; P}$ :

$$
u\left(C_{t+S-1}^{S}, N_{t+s-1}^{S}\right)=E_{t} \sum_{s=1}^{T} \beta^{s-1}\left(\frac{\left(C_{t+s-1}^{S}\right)^{1-\sigma}-1}{1-\sigma}-\frac{\varphi_{0}\left(\left(N_{t+s-1}^{S}\right)^{1+\varphi}\right)}{1+\varphi}\right),
$$

subject to the real budget constraint

$$
\begin{gathered}
C_{t+s-1}^{s}+\left(K_{t+s-1}^{s+1}-(1-\delta) K_{t+s-2}^{s}\right)= \\
=\left(1-\tau_{t}^{s c}\right) W_{t+s-1} e(s ; j ; h) N_{t+s-1}^{s}+R_{t+s-1}^{k} K_{t+s-2}^{s}+D_{t+s-1},
\end{gathered}
$$

where expectations are based on the agent's information set as of period $t, \beta$ is a discount factor, and $\sigma>0$ stands for the parameter defining relative risk aversion. The worker earns income from the effective labor $e(s ; j ; h) N_{t+s-1}^{s}$ and return on capital $R_{t}^{k}$, pays social security tax $\tau_{t}^{s c}$, which is used to provide income for retirees, and receives profits $D_{t+s-1}$ in the form of dividends.

Impatient households maximize the same utility function, as patient households, but subject to a different budget constraint. As the mean of saving and borrowing they use liquid nominal bonds $B_{t-1}$, so that budget constraint in real terms is defined as

$$
\begin{gathered}
C_{t+s-1}^{s}+Q_{t+s-1} b_{t+s-1}^{s+1}= \\
=\left(1-\tau_{t}^{s c}\right) W_{t+s-1} e(s ; j ; h) N_{t+s-1}^{s}+\frac{b_{t+s-2}^{s}}{\pi_{t+s-1}}+D_{t+s-1},
\end{gathered}
$$

where $b_{t+s-2}^{s}$ denotes the real value of nominal debt, and $\pi_{t+s-1}$ stands for inflation rate.

Hand-to-mouth consumers, in line with Gali et al. (2007), fully consume their labor income and neither smooth their consumption with changes in labor income, nor substitute intertemporally with shifts in interest rates. Accordingly, their consumption is fully determined by the (real) budget constraint

$$
C_{t+s-1}^{s}=\left(1-\tau_{t}^{s c}\right) W_{t+s-1} e(s ; j ; h) N_{t+s-1}^{s} .
$$

The presence of such households, stemming typically from the lack of access to liquid financial markets or constantly binding borrowing constraints (in case of rich and poor households, respectively), and their impact on aggregate stabilization is outlined in Kaplan, Moll, and Violante (2018). As they do not face trade-offs between current and future consumption, the direct channel of monetary policy is ineffective to influence their behavior while indirect effects appear to be large.

\subsubsection{Retired households}

All patient and impatient retired household have labor supply $N_{t+s-1}^{s ; j h}=0$, so they maximize

$$
u\left(C_{t+s-1}^{S}\right)=E_{t} \sum_{s=T+1}^{T+T^{R}} \beta^{s-1}\left(\frac{\left(C_{t+s-1}^{S}\right)^{1-\sigma}-1}{1-\sigma}\right),
$$

subject to the real budget constraints

$$
\begin{aligned}
& C_{t+s-1}^{s}+\left(K_{t+s-1}^{s+1}-(1-\delta) K_{t+s-2}^{s}\right)= \\
& =P_{e n} n_{t+s-1}+R_{t+s-1}^{k} K_{t+s-2}^{s}+D_{t+s-1},
\end{aligned}
$$

for patient ones or

$$
C_{t+s-1}^{s}+Q_{t+s-1} b_{t+s-1}^{s+1}=P e n_{t+s-1}+\frac{b_{t+s-2}^{s}}{\pi_{t+s-1}}+D_{t+s-1}
$$

for impatient, where $P e n_{t+s-1}$ is a real pension income and is distributed lump-sum. The government sets pensions according to

$$
P e n_{t+s-1}=\zeta e(s ; j ; h) \bar{W}_{t} \bar{N}_{t},
$$

depending on the households' life-time productivity level, where $\bar{W}_{t}$ and $\bar{N}_{t}$ represent average wage and average labor supply of working cohorts, belonging to particular $j$ and $h$ types. The size of pension relative to income is defined by a parameter $\zeta$.

Consumption of hand-to-mouth retirees is financed solely by their state-provided pension, so that

$$
C_{t+s-1}^{s}=\operatorname{Pen}_{t+s-1} \text {. }
$$

\subsection{Producers}

The supply side of the economy is represented by two types of firms, which are final goods and intermediate goods producers. A continuum of perfectly competitive firms aggregates differentiated intermediate inputs distributed on $[0,1]$ according to a CES technology. The imperfect substitutability of the intermediates in the aggregation process causes a downward-sloping demand for each such input, allowing producers to set their own prices while treating all other prices as given. To replicate nominal rigidity in the economy, we use a staggered price setting a la Calvo (1983), so that each period only a random fraction of firms could reoptimize prices.

\subsubsection{Final good firms}

These firms aggregate a continuum of intermediate goods $Y_{t}(i)$ distributed on $[0,1]$ into a homogenous consumption good using the constant elasticity of substitution technology

$$
Y_{t}=\left(\int_{0}^{1} Y_{t}(i)^{\frac{\epsilon-1}{\epsilon}} d i\right)^{\frac{\epsilon}{\epsilon-1}},
$$

where the price elasticity of demand $\epsilon>1$. Under assumption of perfect competition, final goods producer solves the profit maximization problem, which solution defines the relative demand function for the $i^{\text {th }}$ intermediate good

$$
Y_{t}(i)=\left(\frac{P_{t}(i)}{P_{t}}\right)^{-\epsilon} Y_{t}
$$

where $P_{t}(i)$ and $P_{t}$ stand for the price of good $\mathrm{i}$ and the average level of prices, respectively. Then, aggregate price level is

$$
P_{t}=\left(\int_{0}^{1} P_{t}(i)^{1-\epsilon} d i\right)^{\frac{1}{1-\epsilon}}
$$




\subsubsection{Intermediate good firms}

A representative intermediate firm indexed by $i \in[0,1]$ produces output $Y_{t}(i)$ according to a Cobb-Douglas CRS technology using capital $K_{t-1}(i)$ and effective labor $N_{t}(i)$ according to

$$
Y_{t}(i)=A_{t} K_{t-1}(i)^{\alpha} N_{t}(i)^{1-\alpha},
$$

where $A_{t}$ is a common productivity shock, following $\mathrm{AR}(1)$ process

$$
\ln A_{t}=\rho_{a} \ln A_{t-1}+\varepsilon_{a t},
$$

where $\varepsilon_{a t}$ is i.i.d., $\varepsilon_{a t} \sim N\left(0, \sigma_{a}^{2}\right)$.

The optimization problem of each intermediate goods producer consists of two stages. At the first stage, the firm minimizes its real cost of renting $K_{t-1}(i)$ and $N_{t}(i)$ in perfectly competitive factor markets at price $r_{t}$ and $W_{t}$, respectively:

$$
\min _{N_{t}(i), K_{t-1}(i)} r_{t} K_{t-1}(i)+\left(1+\tau_{t}^{s c} W_{t} N_{t}(i),\right.
$$

subject to

$$
Y_{t}(i)=A_{t} K_{t-1}(i)^{\alpha} N_{t}(i)^{1-\alpha},
$$

in order to determine optimal input quantities.

At the second stage, intermediate goods producers solve the problem of discounted real profit maximization by setting the price. The presence of market power allows modeling nominal price rigidity, following Calvo (1983). Each firm is able to change its price with a constant probability 1- $\theta$ and maintains the price set previously with probability $\theta$ in a given period. Hence, the producer accounts for the possibility of being stuck with today's price several periods ahead in solving profit maximization problem. The reoptimizing firm solves

$$
\max _{P_{t}(i)} E_{t} \sum_{k=0}^{\infty}(\beta \theta)^{k} \frac{\lambda_{t+k}}{\lambda_{t}}\left\{\left(\frac{P_{t}(i)}{P_{t+k}}-M C_{t+k}\right) Y_{t+k}(i)\right\},
$$

subject to its demand function

$$
Y_{t}(i)=\left(\frac{P_{t}(i)}{P_{t}}\right)^{-\epsilon} Y_{t}
$$

where $\frac{\lambda_{t+k}}{\lambda_{t}}$ represent stochastic discount factor, which is the multiplier on the nominal budget constraint of household in a $t+k$ period. Since the households hold ownership rights on the intermediate good firms and receive the firm profits, the firms weigh future profits using the factor, incorporating demand. that

Under a symmetric equilibrium, optimal price $P_{t}^{*}(i)=P_{t}^{*}$ so

$$
\begin{gathered}
\frac{P_{t}^{*}(i)}{P_{t}}=\frac{P_{t}^{*}}{P_{t}}= \\
=\frac{\epsilon}{\epsilon-1} \frac{E_{t} \sum_{k=0}^{\infty}(\beta \theta)^{k} \lambda_{t+k}\left(\prod_{s=1}^{k} \pi_{t+s}\right)^{\epsilon} M C_{t+k} Y_{t+k}}{E_{t} \sum_{k=0}^{\infty}(\beta \theta)^{k} \lambda_{t+k}\left(\prod_{s=1}^{k} \pi_{t+s}\right)^{\epsilon-1} Y_{t+k}} .
\end{gathered}
$$

Given Calvo's pricing, the aggregate price level in the period tcan be calculated as follows

$$
P_{t}^{1-\epsilon}=\int_{0}^{1} P_{t}(i)^{1-\epsilon} d i=\theta P_{t-1}^{1-\epsilon}+(1-\theta) P_{t}^{* 1-\epsilon},
$$

where the price $P_{t}^{*}$ is set by a fraction of producers (1- $\left.\theta\right)$ who are able to choose the optimal price in that period, and a fraction $\theta$ holds the price $P_{t-1}$ from the previous period. Dividing by $P_{t}^{1-\epsilon}$,

$$
1=\theta\left(\frac{1}{\pi_{t}}\right)^{1-\epsilon}+(1-\theta)\left(\pi_{t}^{*}\right)^{1-\epsilon},
$$

where $\pi_{t}^{*}=\frac{P_{t}^{*}}{P_{t}}$.

\subsection{Monetary authority}

The central bank controls the money supply following the money growth rule

$$
g_{m}=\ln \left(\frac{M_{t}}{M_{t-1}}\right)
$$

where $M_{t}$ is the nominal stock of money, which grows at rate $g_{m}$. The growth rate $g_{m}$ is subject to exogenous shock i.i.d. $\varepsilon_{m, \nu^{\prime}} \varepsilon_{m, t} \sim$ $N\left(0, \sigma_{m}^{2}\right)$, and follows $A R(1)$ process of the form

$$
g_{m, t}=\rho_{m} g_{m, t-1}+\varepsilon_{m, t} .
$$

A positive (negative) realization of $\varepsilon_{m, t}$ should be interpreted as a expansionary (contractionary) monetary policy shock, leading to a decline (rise) in the nominal interest rate, given inflation, and the output gap.

\subsection{Government}

The government uses the revenues from taxing labor in order to finance its expenditures on social security

$$
\tau_{t}^{S C} W_{t} N_{t}-\frac{T^{R}}{T+T^{R}} \sum_{h=1}^{3} \sum_{j=1}^{3} \sum_{s=T+1}^{T+T^{R}} P e n_{t}=P F_{t},
$$

where $P F_{t}$ is a balance of pension fund. Pensions are set according to the rule, specified by

$$
P e n_{t+s-1}=\zeta e(s ; j ; h) \bar{W}_{t} \bar{N}_{t},
$$

where $\zeta$ is a predetermined replacement ratio of pension income with respect to average wage earnings for each type of household.

\subsection{Aggregation}

Aggregate and individual behaviors are consistent, i.e. the sum of the individual consumption, labor supply, and capital and bond holdings is equal to the aggregate level of consumption, labor supply, and capital and bond holdings, respectively

$$
\begin{gathered}
C_{t}=\sum_{h=1}^{3} \sum_{j=1}^{3} \sum_{s=1}^{T+T^{R}} C_{t}^{S ; j ; h} \frac{\mu(j)}{T+T^{R}} \\
N_{t}=\sum_{h=1}^{3} \sum_{j=1}^{3} \sum_{s=1}^{T} N_{t}^{s ; j ; h} \frac{\mu(j)}{T} \\
K_{t}=\sum_{j=1}^{3} \sum_{S=1}^{T+T^{R}} K_{t}^{S ; j ; P} \frac{\mu(j)}{T+T^{R}} \\
B_{t}=\sum_{j=1}^{3} \sum_{s=1}^{T+T^{R}} B_{t}^{s ; j ; I} \frac{\mu(j)}{T+T^{R}} .
\end{gathered}
$$


Under Calvo's pricing, expression for aggregate demand is transformed from the standard

$$
Y_{t}=C_{t}+I^{\prime}
$$

into

$$
\frac{A_{t} K_{t-1}^{\alpha} N_{t}^{1-\alpha}}{v_{t}^{p}}=\left(C_{t}+I_{t}\right)
$$

where

$$
v_{t}^{p}=\int_{0}^{1}\left(\frac{P_{t}(i)}{P_{t}}\right)^{-\epsilon} d i=\theta\left(\frac{1}{\pi_{t}}\right)^{-\epsilon} v_{t-1}^{p}+(1-\theta)\left(\pi_{t}^{*}\right)^{-\epsilon} .
$$

The model is closed by demand for real money balances

$$
M_{t}^{\text {real }}=\frac{Y_{t}}{\left(\frac{1}{Q_{t}}-1\right)^{\eta}} .
$$

\section{CALIBRATION}

There is a set of objectives that should be achieved in calibrating the model. Primarily, the simulated distribution of positive and negative wealth should correspond to the actual one, observed in the data. Additionally, stochastic productivity factor should replicate the earnings patterns for each specific type of household. The rest of parameters are set to values, which are commonly accepted in the New Keynesian literature.

\subsection{Wealth distribution}

Calibration of household wealth relies primarily on the classification of households according to their income group and asset structure. Following Andres et al. (2018), the paper employs PSID data for the year 2015 to assign each household to patient/impatient categories based on their holdings of liquid and illiquid non-housing wealth, as well as a size of this wealth relative to their income. Although mortgages occupy a notable portion of agents' balance sheets, investment in housing, signaling a high rate of time discounting (delivers utility immediately), is not considered. The identification strategy is summarized in Table 1 below. For the rest of the paper, a $50 \%$-threshold is applied.

Next, using the percentiles of income distribution as of 2015 , the households are assigned the status of poor, middle-income, and rich if they belong to bottom 25th percentile, from 25 th to 75 th percentile, and the top 25th percentile, respectively. The relative weights of each household type by income group consequently correspond to the $25 \%$ for top and bottom quantiles and $50 \%$ for the middle class.

Table 2 recapitulates the aggregate shares of households in the data, derived by multiplying shares of patient and impatient households on their wealth percentiles. However, as the model contains 60 cohorts of agents within each classified group, parameters $\mu(j ; h ; s)$ take into account shares of each age group within outlined relative weights.

The calibrated model generally matches the distribution of wealth across generations (Figure A1 and A2 in Appen$\operatorname{dix}$ A). There are, however, several drawbacks, associated primarily with the model logic. As agents are born without capital and leave no bequests, the simulated distribution of wealth of poor patient households in earlier and later years of their lifetime is below the levels observed in real data. On the contrary, asset holdings of the rich are overestimated for the retired individuals, which might occur due to a rather small number of observations for this group.

For impatient households, who mainly borrow in liquid bonds, because of embedded prudency requirements (agents cannot default on their debts), mismatch between observed and simulated wealth is more pronounced. Within the model framework, income dynamics of the poor impatient households deters them from rapid debt accumulation during their early years. Accordingly, reduction in income of middle class at retirement reduces their borrowings.

Table 1. PSID sample weights for year 2015, in \%

\begin{tabular}{lcccc}
\hline & Threshold & $\mathbf{a}=\mathbf{2 5 \%}$ & $\mathbf{a}=\mathbf{5 0 \%}$ & $\mathbf{a}=\mathbf{7 5 \%}$ \\
\hline Patient (P) & $W \geq a \cdot I$ & 45.5 & 33.4 & 27.0 \\
Impatient (HTM) & $0<W<a \cdot I$ & 32.2 & 44.3 & 50.7 \\
Impatient (I) & $W \leq 0$ & 22.3 & 22.3 & 22.3 \\
\hline
\end{tabular}

Table 2. Relative weights of households in the population, in $\%$

\begin{tabular}{lccc}
\hline & p0 - p25 & p26 - p74 & p75 - p100 \\
\hline Patient (P) & 12.6 & 16.7 & 5.0 \\
Impatient (HTM) & 9.0 & 28.4 & 6.6 \\
Impatient (I) & 5.3 & 9.2 & 7.3 \\
\hline
\end{tabular}




\subsection{Earnings dynamics}

Provided that wage, determined by the cost-minimization problem of intermediate producers, is identical for all agents, the idiosyncratic productivity becomes a key factor, driving heterogeneity in labor income across households. Hence, the productivity is calibrated in a way, related to the literature on earnings processes rather than any human capital accumulation theories. The traditional approach to evaluate income dynamics, originating from the work of Friedman and Kuznets (1954), involves a decomposition of shocks into permanent and transitory components. The simplest model takes the form

$$
y_{i, t}=\alpha_{i}+v_{i, t^{\prime}}
$$

where $\alpha_{i}$ represents the individual time-invariable element with variance $\sigma_{\alpha}^{2}$ and $v_{i, t}$ is independently identically distributed and serially uncorrelated temporary shock with variance $\sigma_{v}^{2}$. By assumption, $\operatorname{cov}\left(\alpha_{i}, v_{i, t}\right)=0$.

The productivity is calibrated using data on total labor income of households head from the PSID for 2001-2015 years, containing surveys of a representative sample of U.S. households every odd year. Due to the specificity of a dataset, each individual is characterized by 8 consecutive observations with a break every second year; moreover, there is no person with a full earnings profile, covering required 42 years. Therefore, before the estimation of general permanent-transitory models, time and age factors are extracted from deflated (log) labor income, $y_{i, t}$,

$$
y_{i, t}=\beta_{0}+\beta_{1} \text { age }_{i, t}+\beta_{2} \text { time }+\varepsilon_{i, t} .
$$

The residuals $\varepsilon_{i, t}$, representing average labor earnings along the individuals' lifecycle, are then disentangled into components according to the following set of equations (Doris et al., 2011):

$$
\begin{gathered}
\varepsilon_{i, t}=p_{t}\left(\alpha_{i}+\omega_{i, t}\right)+\lambda_{t} v_{i, t^{t}} \\
\omega_{i, t}=\omega_{i, t-1,}
\end{gathered}
$$

where $p_{t}$ and $\lambda_{t}$ are parameters, capturing a common pattern of changes in the permanent and transitory components across agents.

Given an insufficient number of observations with nonzero values for work experience, required to characterize the changes in permanent component of income in the data, $\omega_{i, t}$ is assumed to be persistent across time. Transitory shocks follow an ARMA(1,1) process, with AR parameter $\rho$ and MA parameter $\gamma$ :

$$
v_{i, t}=\rho v_{i, t-1}+\gamma \epsilon_{i, t-1}+\epsilon_{i, t^{\prime}}
$$

where $\epsilon_{i, t}$ is a random variable, $\epsilon_{i, t} \sim N\left(0, \sigma_{\epsilon}^{2}\right)$.

The model parameters, estimated in Stata, using generalized method of moments for a household of each type and income group separately, serve as inputs to the Matlab program, generating idiosyncratic productivity paths (Figure A3 in Appendix A).

The resulting productivity profiles are suitable to replicate salient features of wealth distribution. However, as financial markets are complete, simulated deviations from the general trend have no considerable impact on wealth dynamics and can be easily insured against.

\subsection{Remaining model parameters}

The rest of the OLG model is calibrated in line with other New-Keynesian literature, reflecting basic characteristics of the U.S. post-war economy (Table 3). Since the periods in model correspond to years instead of quarters, some conventional parameter values are taken to the power of 4 .

Following lacoviello (2005), discount factors for the patient and impatient households, reflecting annual timespan, are $0.99^{4}=0.9606$ and $0.95^{4}=0.8145$, respectively. The parameter $\sigma$ is equal to the conventional value of 2.0. The previous studies on labor market specify a conservative value of 0.3 for the Frisch labor supply elasticity that corresponds to $\varphi=7.0$. Social security tax $\tau^{s c}$ is set to 0.1530 .

Table 3. Calibrated parameter values

\begin{tabular}{lcc}
\hline Parameter name & Notation & Value \\
\hline Discount factor (patient households) & $\beta_{P}$ & 0.961 \\
Discount factor (impatient households) & $\beta_{I}$ & 0.815 \\
Relative risk aversion coefficient & $\sigma$ & 2.000 \\
Frisch labor supply elasticity & $\varphi$ & 7.000 \\
Relative disutility from labor & $\varphi_{o}$ & 0.260 \\
Social security tax rate & $\tau^{s c}$ & 0.153 \\
Capital share & $\alpha$ & 0.360 \\
Depreciation & $\delta$ & 0.076 \\
Calvo parameter & $\theta$ & 0.202 \\
Elasticity of substitution & $\epsilon$ & 6.000 \\
\hline
\end{tabular}


The growth of nominal money supply is an $A R(1)$ process with a standard autocorrelation parameter $\rho_{m}=0.5$ (Heer and Maussner, 2012). In steady state, both inflation and money growth are set to zero.

The capital's share of income $\alpha$ is calibrated to 0.36 and the yearly depreciation rate $\delta$ is $0.019 * 4=0.076$. The nominal rigidity is modeled under the assumption that each quarter producers are unable to adjust their prices with the probability 0.67 . It implies that yearly Calvo parameter $\theta$ is equal to 0.2015 . Total supply chain markup considered to be about $20.0 \%$ so the markup in the model $\frac{1}{M C_{t}}$ is equal to 1.2 which corresponds to the elasticity of substitution between intermediate products $\epsilon=6.0$. Technology follows an $A R(1)$ process with parameter $\rho_{a}$ set to a conventional value of 0.95

\section{REDISTRIBUTIVE EFFECTS OF MONETARY POLICY}

The results and implications of expansionary monetary shock are presented in two blocks. First, the impact on the aggregate economy and household sector, split along income quantiles, is discussed and compared with the previous findings. Next, heterogeneity in responses for each population segment is examined along theoretical underpinnings on distributive transmission channels. The results of model simulation point to a widening intergenerational inequality gap, which is a consequence of simultaneous impact all considered channels except one.

\subsection{Aggregate responses}

On the impact of 5 percentage point unanticipated increase in yearly inflation (Figure A4 in Appendix A), initial response of output is slightly negative, as some firms cannot adjust their prices while marginal costs scale up (an immediate hike in real wage is accompanied by protracted decrease in return on capital). The equilibrium employment falls as a result of both substitution effect on the demand side of the labor market (producers substitute labor by relatively cheaper capital) and income effect on the supply side. Provided that labor earnings increase, consumption is affected positively.

As investment becomes less expensive, patient agents in all income percentiles respond by increasing capital stock (Table 4); the dynamics of capital accumulation creates the major difference between them. Whereas the largest share of total wealth gain is attributed to the rich, inequality among patient households widens slightly.

An emerging inflationary pressure benefits impatient households, who are net borrowers, by decreasing their stock of debts borne from previous periods, as in Doepke and Schneider (2006). Although it makes real disposable income higher, current borrowing decline disproportionately across income groups because of the high substitution effect. However, as savers among holders of liquid assets are virtually absent, the way transmission occurs between borrowers can only partially comparable with the Fisher channel, traditionally transferring wealth from savers to borrowers.

Income and earnings heterogeneity channels exhibit additional impact on the aggregate model dynamics. Table 5 shows the split of gains and losses for each part of the households' budget constraints, depending on their income quantile.

Provided that the model does not consider unemployment and staggered wage setting (typically regarded as the main driving forces of increase in labor earnings of the poor), growing wage becomes the key impetus for labor earnings. In line with previous empirical findings, agents in top 25th percentile benefit the most from loose financial conditions. These factors combined, inequality tends to increase, as the magnification of hourly wages is larger than the decline in unemployment (equal to zero here).

The inflationary episode, leading to a decline in both real returns on capital and real interest on bonds, have fairly

\section{Table 4. Wealth gains/losses arising from an unexpected increase in money supply, by income group, in \%}

\begin{tabular}{lcc}
\hline Households & Illiquid wealth & Liquid wealth \\
\hline Poor & 4.309 & -0.424 \\
Middle-income & 4.861 & -0.105 \\
Rich & 5.060 & -0.818 \\
\hline
\end{tabular}

\section{Table 5. Income gains/losses arising from an unexpected increase in money supply, by income group, in \%}

\begin{tabular}{lcccc}
\hline Households & Labor income & $\begin{array}{c}\text { Real return } \\
\text { on capital }\end{array}$ & $\begin{array}{c}\text { Real interest } \\
\text { on bonds }\end{array}$ & Real pension \\
\hline Poor & 0.075 & 0.021 & -9.388 & -0.421 \\
Middle-income & 0.105 & 0.064 & -7.053 & -0.265 \\
Rich & 0.163 & 0.074 & -8.560 & -0.236 \\
\hline
\end{tabular}


similar implications for consumption of patient and impatient households in spite of the essential difference in the modalities of operation. Illiquid wealth accumulation, driven up by lower cost of investment, is strong enough to offset the reduction of the rate of return, so that total financial income increase. Disproportionality of this increase is primarily driven by the difference in total capital stock, distribution of which is skewed to the right. In the meantime, bondholders with short positions face a lower implicit cost of borrowing across periods. In other words, they have to pay lower interest to get next-period bond, and hence, have more disposable income.

Transfers from the government, represented here by pensions, have a countercyclical nature, and hence, shrink on the impact of $5 \%$ inflation shock. The change is relatively higher for low-income households, as retirement income, which depends on both contemporary and past earnings dynamics, respond more to a decline in average work hours.

Generally, income heterogeneity channel, in line with theoretical notions, contributes to inequality in so far real returns on illiquid assets of the rich agents are exposed to stronger positive effect while transfers - smaller negative, in comparison with those of individuals in the bottom 25th percentile of the income distribution. Thus, all 4 out of 5 theoretical transmission channels (financial segmentation is dropped from consideration because of model limitations) contribute to an increase in inequality among households, belonging to different income quantiles, after a positive money supply shock. Although this partially contrasts with the evidence, such result can be attributed primarily to the particular setting of the model, which allows only for onesided Fisher and earnings heterogeneity channels.

\subsection{Individual responses}

The aggregate responses, however, mask notable discrepancies in reactions of agents of different age. To the extent asset holdings, labor earnings, and interest income (or expense) vary across generations, the observed impact of transmission channels is likely to be augmented.
Among poor patient households (Table 6), two sets of cohorts benefit the most from expansionary policy shock: of pre-retirement age (57 - 62 years), who hold the highest capital stock on expectation of a drop in income after the retirement, and agents from 27 to 32 years old, facing a temporary reduction in productivity (Appendix A, Figure A3). The difference in illiquid wealth gains of working-age generations is, however, relatively insignificant, so the observed distributional effects are small.

On the contrary, the benefit of retirees is lower and diminishes with age. In essence, this dynamics is primarily influenced by the gradual reduction of capital stock held by the elderly, as they do not leave bequests to their offspring.

Disproportionality in changes of bond holdings is driven by a varying exposure of agents to income and substitution effects. As higher inflation reduces the real value of debt, held from the previous period, households have higher disposable income; furthermore, the intensity of such impact depends on the total amount of negative wealth: high debts devaluate by more. Hence, middle-age cohorts receive relatively larger upsurge in disposable income after inflationary episode than younger or older agents.

Additionally, increase in labor income, which constitutes a considerable share of the household budget, varies across age groups, benefitting individuals of pre-retirement age to a greater extent (discussed in details further; see Table 9). Compared with younger workers and retirees, these cohorts get the highest addition to disposable income, so income effect dominates the substitution, and they increase both consumption and debt.

In contrast, provided that price of bonds turn out to be higher as yield drops, agents to 38 years and above 63 years old, who experience both a minor decrease in the value of previous debts and get lower increase in labor earnings (pensions even cut on inflation hike), tend to consume more while borrowing less.

Table 6. Wealth gains/losses of poor households arising from an unexpected increase in money supply, by age, in \%

\section{Poor households}

\begin{tabular}{ll}
\hline $21-26$ years & 4.00 \\
$27-32$ years & 4.75 \\
$33-38$ years & 4.73 \\
$39-44$ years & 4.69 \\
$45-50$ years & 4.64 \\
$51-56$ years & 4.638 \\
$57-62$ years & 4.759 \\
$63-68$ years & 4.31 \\
$69-74$ years & 3.831 \\
$75-80$ years & 2.34 \\
\hline
\end{tabular}

Liquid wealth

$-1.048$

$-0.739$

$-0.279$

0.239

0.777

1.050

0.525

$-2.427$

$-1.889$

$-0.612$ 


\section{Table 7. Wealth gains/losses of middle-income households arising from an unexpected increase in money supply, by age, in \%}

\begin{tabular}{lcc}
\hline $\begin{array}{l}\text { Middle-income } \\
\text { households }\end{array}$ & Illiquid wealth & Liquid wealth \\
\hline $21-26$ years & 4.624 & -1.098 \\
$27-32$ years & 4.849 & -0.690 \\
$33-38$ years & 4.916 & -0.150 \\
$39-44$ years & 5.001 & 0.415 \\
$45-50$ years & 5.100 & 0.931 \\
$51-56$ years & 5.248 & 1.314 \\
$57-62$ years & 5.465 & 1.123 \\
$63-68$ years & 4.965 & -1.110 \\
$69-74$ years & 4.317 & -1.127 \\
$75-80$ years & 2.508 & -0.634 \\
\hline
\end{tabular}

The pattern, outlined for the poor, equally applies to the middle class (Table 7); the difference primarily lies in the size of positive effects both on capital holdings and current-period debt accumulation by cohorts from 39 to 62 years.

Although the dynamics of capital accumulation in the life-cycle framework is as well repeated for rich households (Table 8), due to relatively lower gain from debt devaluation, they are less inclined to extend borrowing for the future. Thus, only two cohorts of middle age tend to marginally increase short positions in bonds.

Therefore, monetary policy tends to exhibit similar impact on wealth distribution across generations, regardless of the type of assets, dominating households' portfolios (yet, this is not purely a portfolio channel, which presupposes the pres- ence of money balances as a form of liquid wealth). Provided that within each income group generations of pre-retirement age, already holding the largest share of capital, tend to benefit the most, inequality among patient households widens. Additionally, as agents of 39-62 years can increase borrowing to finance future consumption, contrary to younger and older individuals, impatient households are also exposed to growing intergenerational inequality.

Turning to the analysis of earnings heterogeneity channel, a specific pattern can be observed for households belonging to all three income groups (Table 9, Table 10, and Table 11): though the wage grows substantially, agents from 21 to 44 years old get only slight increase in labor income while older (and more productive) workers receive generally three to five times more.

Table 8. Wealth gains/losses of rich households arising from an unexpected increase in money supply, by age, in \%

\begin{tabular}{lcc}
\hline Rich households & Illiquid wealth & Liquid wealth \\
\hline $21-26$ years & 4.717 & -1.557 \\
$27-32$ years & 4.787 & -1.222 \\
$33-38$ years & 4.860 & -0.803 \\
$39-44$ years & 4.955 & -0.323 \\
$45-50$ years & 5.084 & 0.009 \\
$51-56$ years & 5.274 & 0.117 \\
$57-62$ years & 5.550 & -0.623 \\
$63-68$ years & 5.047 & -4.779 \\
$69-74$ years & 4.378 & -4.797 \\
$75-80$ years & 2.578 & -2.461 \\
\hline
\end{tabular}


Table 9. Income gains/losses of poor households arising from an unexpected increase in money supply, by age, in \%

\begin{tabular}{lccc}
\hline Poor households & Labor income & Real return on capital & Real interest on bonds \\
\hline $21-26$ years & 0.022 & 0.004 & -19.591 \\
$27-32$ years & 0.022 & 0.012 & -9.375 \\
$33-38$ years & 0.028 & 0.021 & -6.335 \\
$39-44$ years & 0.025 & 0.027 & -5.092 \\
$45-50$ years & 0.151 & 0.031 & -4.368 \\
$51-56$ years & 0.138 & 0.033 & -3.915 \\
$57-62$ years & 0.256 & 0.031 & -3.086 \\
$63-68$ years & & 0.027 & -1.748 \\
$69-74$ years & & 0.023 & -2.045 \\
$75-80$ years & & 0.011 & -4.371 \\
\hline
\end{tabular}

The disproportionality is an outcome of interaction of several factors: productivity, which determines the labor income for each cohort and income percentile, increases from earlier to later years of working life, and thus, magnifies any positive effect on homogeneous wage; minor decline in labor hours of hand-to-mouth households, whose decisions are not influenced by the change in interest rate due to absence of intertemporal optimization; shares of patient and hand-to-mouth agents increase with age in the data while of impatient - falls. Without effect from unemployment reduction, earnings heterogeneity channel increases inequality not solely between the poor and the rich, but among older and younger workers (who could potentially benefit more if unemployment dynamics has been taken into account).
The real return on capital augments across cohorts for all income groups proportionately to the positive response of their asset holdings. Hence, the largest benefits are acquired by the agents of pre-retirement age while the youngest individuals obtain the lowest percentage increase in this type of income.

On the contrary, a decline in the real interest on bonds as a result of monetary policy shock is the most notable for agents from 21 to 32 years old, which is likely to be the outcome of both lower interest rate and debt deflation. The absolute value of decline diminishes with age, leading to an equalization of income distribution, initially impaired by the dynamics of capital returns.

\section{Table 10. Income gains/losses of middle-income households arising from an unexpected increase in money supply, by age, in \%}

\begin{tabular}{lccc}
\hline $\begin{array}{l}\text { Middle-income } \\
\text { households }\end{array}$ & Labor income & Real return on capital & Real interest on bonds \\
\hline $21-26$ years & 0.113 & 0.008 & -16.712 \\
$27-32$ years & 0.007 & 0.021 & -8.426 \\
$33-38$ years & -0.003 & 0.035 & -5.906 \\
$39-44$ years & 0.056 & 0.051 & -4.857 \\
$45-50$ years & 0.139 & 0.065 & -4.305 \\
$51-56$ years & 0.249 & 0.081 & -3.879 \\
$57-62$ years & 0.296 & 0.096 & -3.872 \\
$63-68$ years & & 0.097 & 0.024 \\
$69-74$ years & & 0.073 & 0.086 \\
$75-80$ years & & 0.032 & -1.142 \\
\hline
\end{tabular}




\section{Table 11. Income gains/losses of rich households arising from an unexpected increase in money supply, by age, in \%}

\begin{tabular}{lccc} 
Rich households & Labor income & Real return on capital & Real interest on bonds \\
\hline $21-26$ years & -0.023 & 0.007 & -23.757 \\
$27-32$ years & 0.003 & 0.022 & -12.364 \\
$33-38$ years & 0.089 & 0.035 & -8.136 \\
$39-44$ years & 0.087 & 0.050 & -6.342 \\
$45-50$ years & 0.247 & 0.067 & -5.622 \\
$51-56$ years & 0.262 & 0.085 & -5.535 \\
$57-62$ years & 0.407 & 0.105 & -4.154 \\
$63-68$ years & & 0.109 & -2.093 \\
$69-74$ years & & 0.082 & -2.227 \\
$75-80$ years & & 0.037 & -3.097 \\
\hline
\end{tabular}

\section{CONCLUSIONS}

The use of unconventional tools to conduct monetary policy has increased the attention of the public and, consequently, policymakers to the redistributive effect they entail. However, the primary issue that still remains to be extensively scrutinized is the impact of traditional interest rate changes on the distribution of income and wealth. While researchers are increasingly engaged in incorporating heterogeneous agents into otherwise standard New-Keynesian models to replicate the salient features of wealth and earnings dynamics across households, belonging to different income percentiles, and the impact of the central bank's actions, monetary transmission mechanism in the life-cycle framework remain relatively unstudied.

The present paper is an attempt to take some first steps in filling this gap by employing a heterogeneous agent NewKeynesian model with overlapping generations to study the redistributive effects caused by an expansionary monetary policy. It mimics the observed distribution of wealth and earnings dynamics across households, clustered according to their income percentile and attitude to saving. By explicitly defining 60 cohorts, equal to 60 years of agents' lives, the model provides a convenient tool to disentangle the responses of aggregate variables into a spectrum of individual reactions to changes in policy stance. However, as of now, it accounts only for a limited number of transmission channels.

Generally, the findings reveal that an expansionary monetary shock tends to increase inequality among generations by benefitting agents of middle and pre-retirement age the most. Emerging inflationary pressure deflates their debts, held from previous periods, to a higher extent than for any other cohort, leading to a notable increase in their real disposable income. This triggers a strong positive response in both current and future consumption, financed through additional borrowing. Holders of illiquid wealth aged 51 to 62 years build up the highest additional capital stock as real interest rate falls, making investment cheaper. Although the overall dynamics cannot be attributed to a particular channel of monetary transmission because of the model's limitations, separately the effects are in line with one-sided portfolio and Fisher channels.

A disproportional increase in labor income also tends to contribute to growing inequality. Provided that the model does not account for a reduction in unemployment, wages become the key driving force of earnings dynamics. In so far that older (and more productive workers) get a higher increase in their salaries, the gap between generations widens. The divergence of this result from a traditional understanding of the earnings heterogeneity channel is primarily explained by the absence of employment consequences and an immediate response of wages (in contrast to staggered wage adjustment, benefitting the poor and the young).

Financial income differences work in opposite directions for patient and impatient households. While the former observe a proportional increase in their real return on capital relative to illiquid asset holdings, the latter pay lower real interest on their bonds, and the magnitude of this reduction in interest payments falls (in absolute terms) from younger to older agents, smoothing differences in total income.

However, a fully-fledged life-cycle framework would require a better reflection of traditional monetary transmission channels. Moreover, the analysis could be further enriched by quantifying the MPC of every cohort and household type exhibiting a substantial impact on aggregate stabilization, and by adding mortgage debts, which make up a substantial part of a household's assets. 


\section{REFERENCES}

Andrés J., Bosca J.E., Ferri J., Fuentes-Albero C. (2018). Household's Balance Sheets and the Effect of Fiscal Policy. Finance and Economics Discussion Series 2018-012. Washington: Board of Governors of the Federal Reserve System. Available at https://www.federalreserve.gov/ econres/feds/files/2018012pap.pdf

Ando A., Modigliani F. (1963). The "Life Cycle" Hypothesis of Saving: Aggregate Implications and Tests. American Economic Review, Vol. 53, No. 1, Part 1 (Mar., 1963), pp. 55-84. Available at https://www.jstor.org/stable/1817129

Auclert A. (2017). Monetary Policy and the Redistribution Channel. NBER Working Papers, No. 23451, National Bureau of Economic Research, Inc. Available at https://www.nber. org/papers/w23451.pdf

- Bernanke B. S., Gertler M. (1995). Inside the Black Box: The Credit Channel of Monetary Policy Transmission. Journal of Economic Perspectives, Vol. 9, No. 4, pp. 27-48. https://doi. org/10.1257/jep.9.4.27

Calvo G. A. (1983). Staggered Prices in a Utilitymaximizing Framework. Journal of Monetary Economics, Vol. 12, No. 3, pp. 383-398. https://doi.org/10.1016/03043932(83)90060-0

- Coibion O., Gorodnichenko Y., Kueng L., Silvia J. (2017). Innocent Bystanders? Monetary Policy and Inequality. Journal of Monetary Economics, Vol. 88, No. C, pp. 70-89. https://doi. org/10.1016/j.jmoneco.2017.05.005

- Constancio V. (2017). Inequality and Macroeconomic Policies. Intervention, the Annual Congress of the European Economic Association, Lisbon, August 22, 2017. Available at https://www.ecb.europa.eu/press/key/date/2017/html/ecb. sp170822.en.html

Doepke M., Schneider M. (2006). Inflation and the Redistribution of Nominal Wealth. Journal of Political Economy, Vol. 114, No. 6, pp. 1069-097. https://doi.org/10.1086/508379

- Doris A., O’Neill D., Sweetman O. (2011). GMM Estimation of the Covariance Structure of Longitudinal Data on Earnings. Stata Journal, Vol. 11, No. 3, pp. 439-459.

Erosa A., Ventura G. (2002). On Inflation as a Regressive Consumption Tax. Journal of Monetary Economics, Vol. 49, No. 4, pp. 761-795. https://doi.org/10.1016/S03043932(02)00115-0

- Fisher I. (1933). The Debt-Deflation Theory of Great Depressions. Econometrica, Vol. 1, No. 4, pp. 337-357.

- Fleming J. M. (1962). Domestic Financial Policies under Fixed and under Floating Exchange Rates. IMF Staff Papers, Vol. 9, No. 3, pp. 369-380.

Friedman M., Kuznets S. (1954). Income from Independent Professional Practice. National Bureau of Economic Research, Inc.

• Galí J., López-Salido J. D, Vallés J. (2007). Understanding the Effects of Government Spending on Consumption. Journal of the European Economic Association, Vol. 5, No. 1, pp. 227-270. https://doi.org/10.1162/JEEA.2007.5.1.227

Gornemann N., Kuester K, Nakajima M. (2012). Monetary Policy with Heterogeneous Agents. Working Papers, No. 12-21, Federal Reserve Bank of Philadelphia. Available at https://www.philadelphiafed.org/-/media/research-and-data/ publications/working-papers/2012/wp12-21.pdf
- Haldane A. (2018). How Monetary Policy Affects Your GDP. Finch Lecture, University of Melbourne, April 10, 2018. Available at https://www.bankofengland.co.uk/-/media/boe/ files/speech/2018/how-monetary-policy-affects-your-gdpspeech-by-andy-haldane.pdf

- Heathcote J., Perri F., Violante G. L. (2010). Unequal We Stand: An Empirical Analysis of Economic Inequality in the United States: 1967-2006. Review of Economic Dynamics, Vol. 13, No. 1, pp. 15-51. https://doi.org/10.1016/j. red.2009.10.010

- Heer B., Maussner A. (2012). The Burden OfUnanticipated Inflation: Analysis Of An Overlapping-Generations Model With Progressive Income Taxation And Staggered Prices. Macroeconomic Dynamics, Vol. 16, No. 2, pp. 278-308. https://doi.org/10.1017/S1365100510000490

lacoviello M. (2005). House Prices, Borrowing Constraints, and Monetary Policy in the Business Cycle. American Economic Review, Vol. 95, No. 3, pp. 739-764. https://doi.org/10.1257/0002828054201477

Jorgenson D. (1963). Capital Theory and Investment Behavior. American Economic Review, Vol. 53, No. 2, pp. 247-259.

Kaplan G., Moll B., Violante G.L. (2018). Monetary Policy According to HANK. American Economic Review, Vol. 108, No. 3, pp. 697-743. https://doi.org/10.1257/aer.20160042

- Ledoit O. (2011). The redistributive effects of monetary policy. ECON - Working Papers 044, Department of Economics, University of Zurich. Available at http://www. econ.uzh.ch/static/wp/econwp044.pdf

Luetticke R. (2017). Transmission of Monetary Policy with Heterogeneity in Household Portfolios. Working paper, Department of Economics, University College London. Available at https://www.dropbox.com/ s/22m9w42hzr6ykyw/Luetticke\%202017.pdf

Mundell R. (1963). Capital Mobility and Stabilization Policy under Fixed and Flexible Exchange Rates. The Canadian Journal of Economics and Political Science, Vol. 29, No. 4, pp. 475-85. http://doi.org/10.2307/139336

- Ohlsson H. (2017). The Distributional Effects of Monetary Policy. Speech, Swedish Trade Union Confederation, Stockholm, April 7, 2017. Available at https://www.riksbank. se/globalassets/media/tal/engelska/ohlsson/2017/tal_ ohlsson_170407_eng.pdf

- Tenreyro S., Thwaites G. (2016). Pushing on a String: US Monetary Policy Is Less Powerful in Recessions. American Economic Journal: Macroeconomics, Vol. 8, No. 4, pp. 43-74. https://doi.org/10.1257/mac.20150016

Tobin J. (1969). A General Equilibrium Approach To Monetary Theory. Journal of Money, Credit and Banking, Vol. 1, No. 1, pp. 15-29. http://doi.org/10.2307/1991374

- United States Office of Personnel Management (2017). Retirement Age \& Trend Analysis of the Executive Branch. Available at https://www.opm.gov/policy-data-oversight/ data-analysis-documentation/federal-employment-reports/ reports-publications/retirement-age-trend-analysis.pdf

Williamson S. D. (2008). Monetary Policy and Distribution. Journal of Monetary Economics, Vol. 55, No. 6, pp. 1038-1053. https://doi.org/10.1016/j.jmoneco.2008.07.001 


\section{APPENDIX A}

Figure 1. Wealth of patient households, by income group and generation
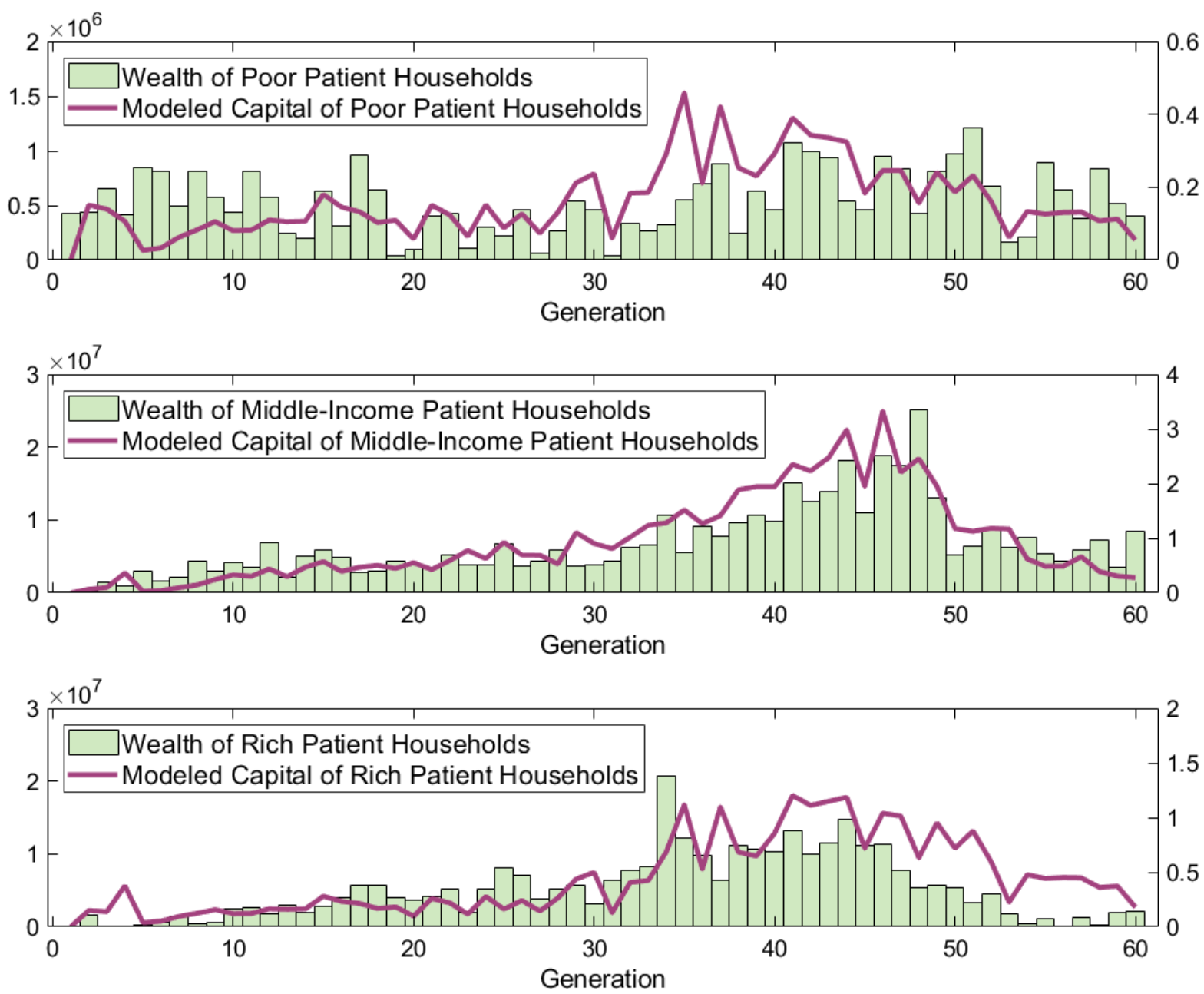
Figure 2. Wealth of impatient households, by income group and generation
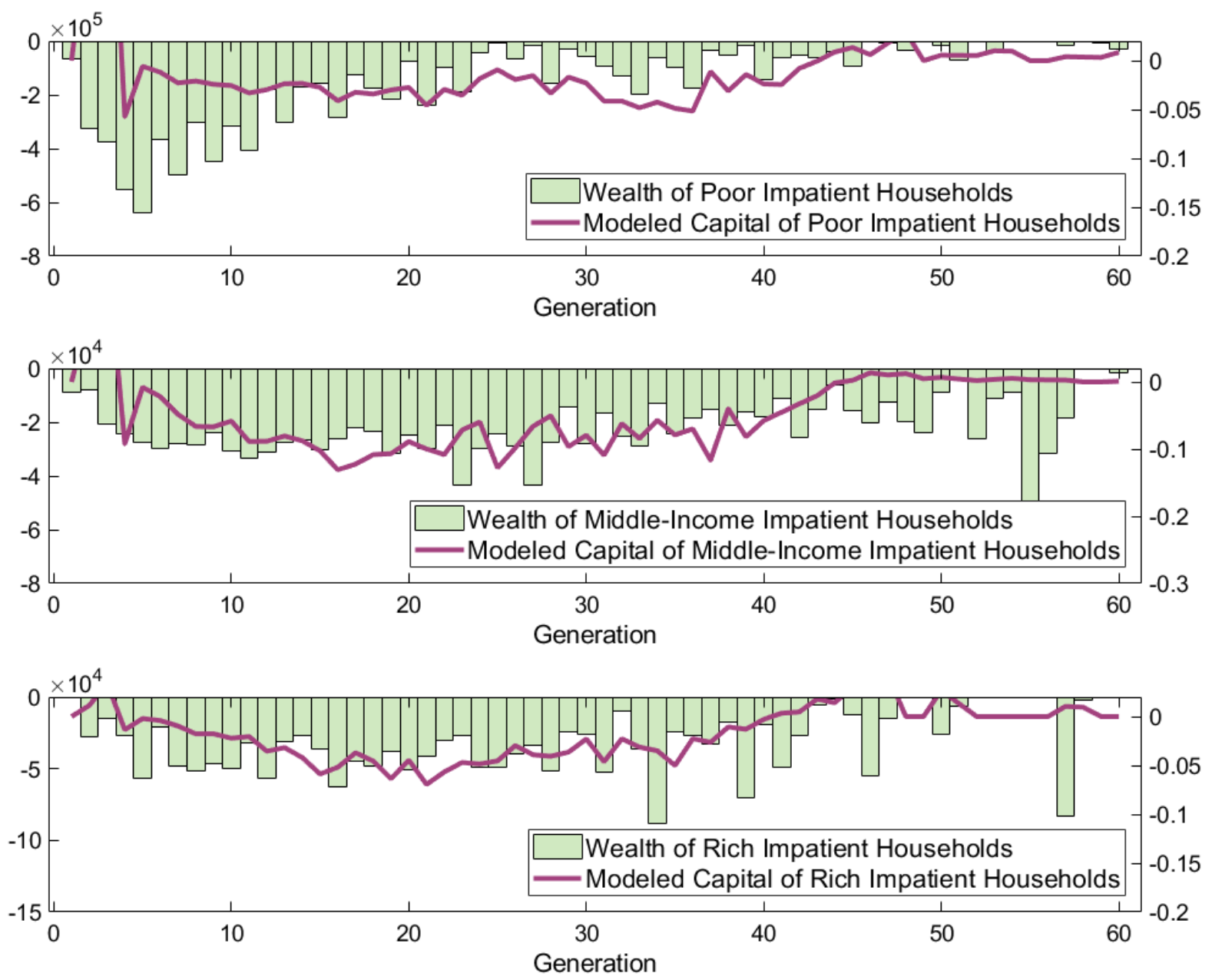
Figure 3. Idiosyncratic productivities of households

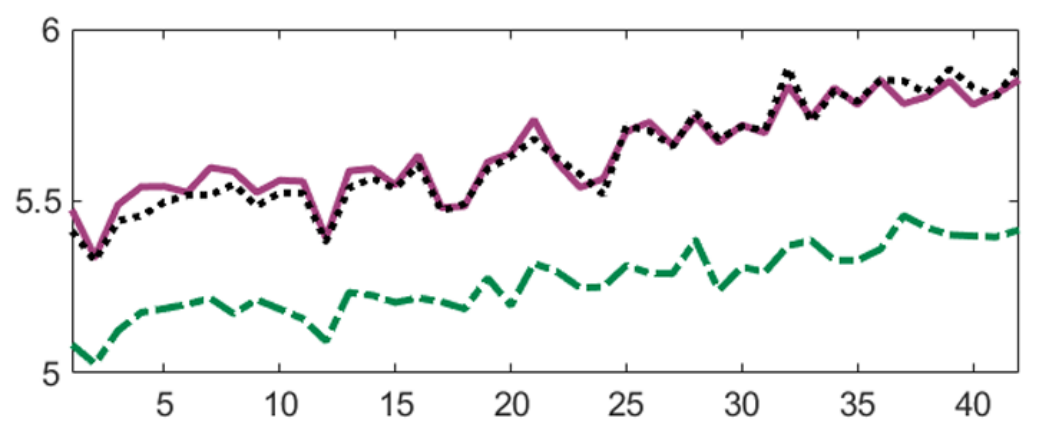

\begin{tabular}{|l|}
\hline -Poor Patient \\
---.-Poor Hand-to-Mouth \\
\hline
\end{tabular}

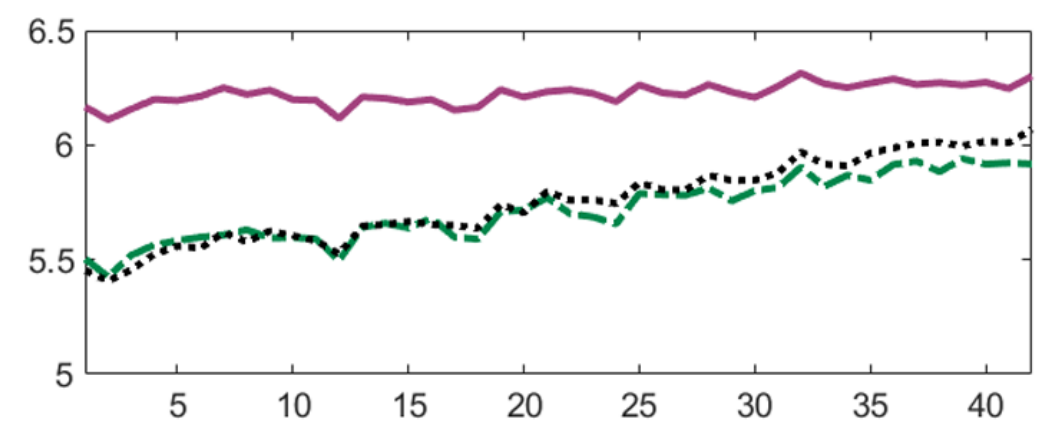

-Middle-Income Patient
---Middle-Income Hand-to-Mouth
.... Middle-Income Impatient

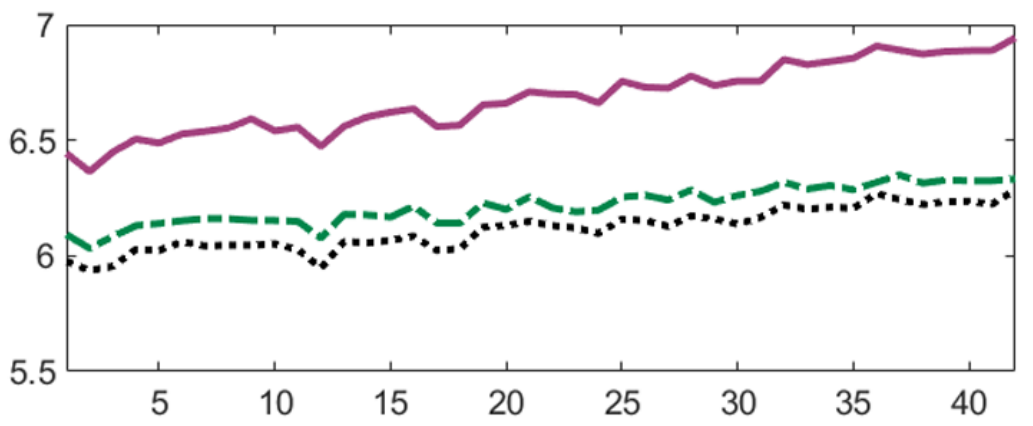

- Rich Patient

---Rich Hand-to-Mouth

..... Rich Impatient 
Figure A4. Responses of key macroeconomic variables
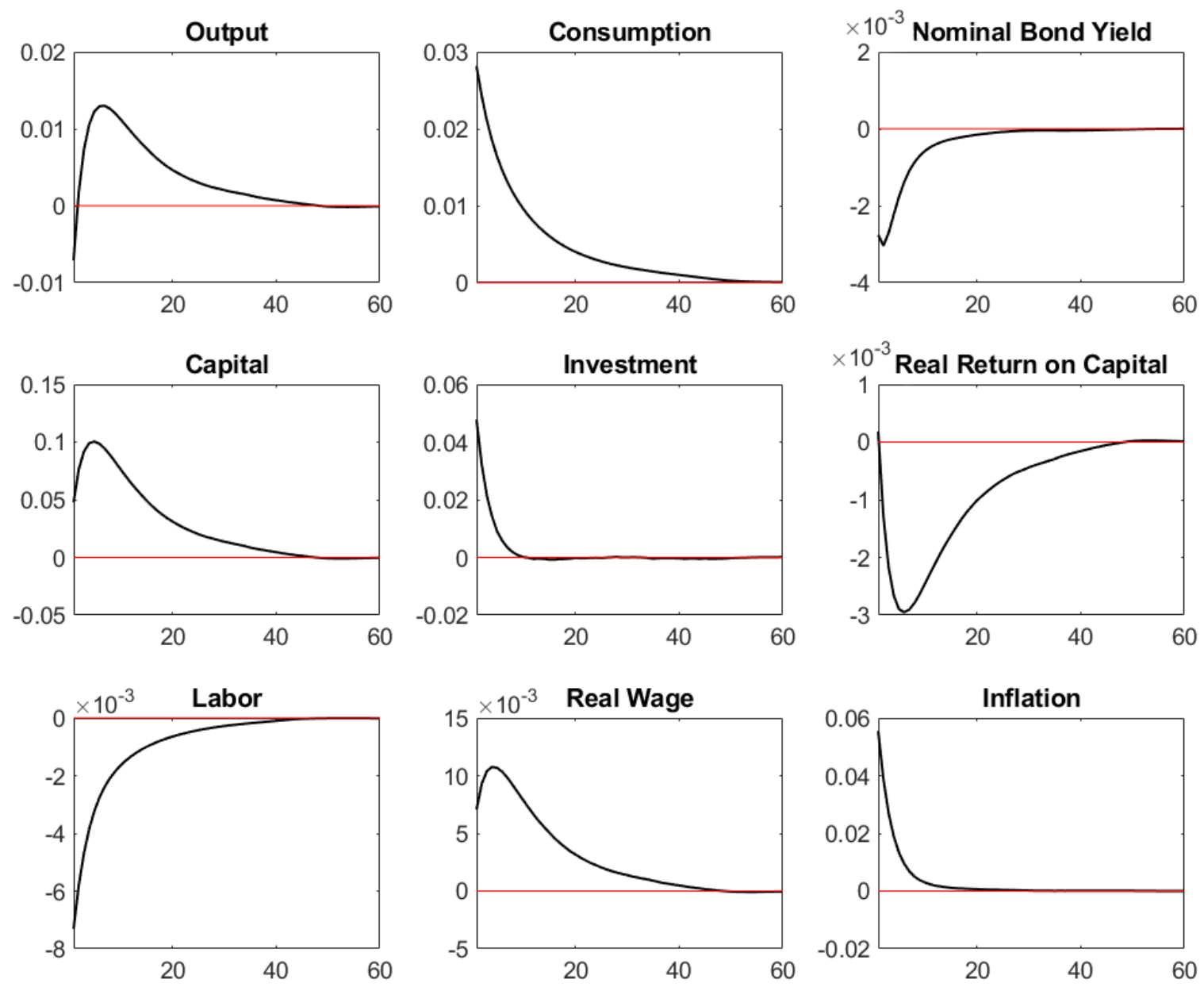